\section{Pacific Northwest}

National Laboratory

operated by Battelle for the

U.5. Dephurtment of Energy

\title{
Vadose Zone Transport Field Study: Stahus Report
}

\author{
G. W. Gee
}

A. L. Ward

November 2001

Prepared for the U.S. D epartment of Energy under Contract DE-AC06-76RL01830 


\title{
DISCLAIMER
}

This report was prepared as an account of work sponsored by an agency of the United States Government. Neither the United States Government nor any agency thereof, nor Battelle Memorial Institute, nor any of their employees, makes any warranty, expressed or implied, or assumes any legal liability or responsibility for the accuracy, completeness, or usefulness of any information, apparatus, product, or process disclosed, or represents that its use would not infringe privately owned rights. Reference herein to any specific commercial product, process, or service by trade name, trademark, manufacturer, or otherwise does not necessarily constitute or imply its endorsement, recommendation, or favoring by the United States Government or any agency thereof, or Battelle Memorial Institute. The views and opinions of authors expressed herein do not necessarily state or reflect those of the United States Government or any agency thereof.

\author{
PACIFIC NORTHWEST NATIONAL LABORATORY \\ operated by \\ BATTELLE MEMORIAL INSTITUTE \\ for the \\ UNITED STATES DEPARTMENT OF ENERGY \\ under Contract DE-AC06-76RL1830
}

Printed in the United States of America

Available to DOE and DOE contractors from the

Office of Scientific and Technical Information, P.O. Box 62, Oak Ridge, TN 37831; prices available from (865) 576-8401.

\begin{abstract}
Available to the public from the National Technical Information Service, U.S. Department of Commerce, 5285 Port Royal Rd., Springfield, VA 22161
\end{abstract}




\title{
Vadose Zone Transport Field Study: Status Report
}

\author{
G. W. Gee
}

A. L. Ward

November 2001

Prepared for the U.S. Department of Energy under Contract DE-AC06-76RL01830

Pacific Northwest National Laboratory

Richland, Washington 99352 


\section{Summary}

Studies were initiated at the Hanford Site to evaluate the process controlling the transport of fluids in the vadose zone and to develop a reliable database for testing vadose-zone transport models. These models are needed to evaluate contaminant migration through the vadose zone to underlying groundwater at Hanford. A study site that had previously been extensively characterized using geophysical monitoring techniques was selected in the $200 \mathrm{E}$ Area. Techniques used previously included neutron probe for water content, spectral gamma logging for radionuclide tracers, and gamma scattering for wet bulk density. Building on the characterization efforts of the past 20 years, the site was instrumented to facilitate the comparison of nine vadose-zone characterization methods: advanced tensiometers, neutron probe, electrical resistance tomography (ERT), high-resolution resistivity (HRR), electromagnetic induction imaging (EMI), cross-borehole radar (XBR), and cross-borehole seismic (XBS). Soil coring was used to obtain soil samples for analyzing ionic and isotopic tracers.

Laboratory-scale experiments with hypersaline fluids in Hanford sediments suggest that fluid properties may influence transport behavior, to the extent of finger formation, through an interaction between fluid and hydraulic properties. Yet, the importance of these mechanisms to field-scale transport is largely unknown, thereby limiting the accuracy of contaminant-transport predictions. To assess the importance of these interactions in field-scale solute transport, tank leaks were simulated by performing a series of injections with dilute fluids in late spring and early summer of FY 2000 and with hypersaline fluids (36 wt $\%$ sodium thiosulfate) during the spring of 2001. In both tests, a suite of isotopic and ionic tracers was included in the injected fluids. The test in FY 2000 consisted of injecting to ground a series of five $3875 \mathrm{~L}$ (1000 gal) pulses of water and tracers, weekly, for five weeks. The FY 2001 test, which was designed partly to evaluate the effects of fluid properties and transport processes, involved the injection of 19,000 L (5000 gal) of hypersaline fluid over the course of 5 weeks. This was followed by 11,400 L (3000 gal) of solute-free water applied in a 2-week period. In FY 2000, infiltration and redistribution were monitored using the nine characterization methods over the course of the injections and for 2 months after the last injection. In FY 2001, all methods except EMI were used to monitor the infiltration and redistribution of the 30,000 L (7925 gal) plume over the course of 3 months.

Thus far, field-measured distributions of soil water content have been analyzed using threedimensional spatial-moment analysis. Results clearly show that the subsurface distributions of both the dilute and hypersaline fluids are controlled by an interaction between small-scale horizontal stratification and fluid properties. The centers of mass for the two plumes were similar in the lateral and transverse directions, but were significantly different in the longitudinal plane. The cumulative travel depth of the center of mass for both the dilute and hypersaline water plumes showed a nonlinear increase with time and injected volume, indicative of the highly nonlinear transport process. After 20,000 L (5283 gal), the hypersaline plume had traveled 2.6 times deeper than the dilute plume. Most of the difference occurred during the initial stages of the experiment with the vertical center of mass of the hypersaline plume being twice as deep as that of the dilute plume. Over time, the hypersaline plume also remained more compact when compared to the dilute plume. The test site shows evidence of macroscopic anisotropy, comparing the ratio of fluxes in the principal directions for the dilute plume. Mean velocities were $\bar{v}_{x}=0.0067$

$\mathrm{m}(0.022 \mathrm{ft}) \mathrm{d}^{-1} ; \bar{v}_{y}=0.0062 \mathrm{~m}(0.02 \mathrm{ft}) \mathrm{d}^{-1} ;$ and $\bar{v}_{z}=0.0052 \mathrm{~m}(0.017 \mathrm{ft}) \mathrm{d}^{-1}$. The average $\mathrm{v}_{\mathrm{x}} / \mathrm{v}_{\mathrm{y}}$ ratio was 1.079 while the average $\mathrm{v}_{\mathrm{x}} / \mathrm{v}_{\mathrm{z}}$ ratio was 0.128 . 
Ionic tracer distributions were analyzed using one-dimensional spatial moments. Distributions of resident concentration profiles were generally asymmetric with a large mass occurring at 5 to $7 \mathrm{~m}$ (16 to $23 \mathrm{ft}$ ), and a smaller mass at 10 to $12 \mathrm{~m}$ (33 to $39 \mathrm{ft}$ ) with a preferred flow path to the southeast. At the test site, there are two relatively fine-textured layers, one at about a 6-m (20-ft) depth and one at about the $12-\mathrm{m}$ (39-ft) depth. The locations of multiple peaks were coincident with the general location of finertextured lenses derived from lithologic logs. The fine sandy sediments in these layers controlled the migration of the water in both tests and caused a substantial increase in transverse solute advection, while confining the moisture plume to a depth of $13 \mathrm{~m}$ (43 ft) in the FY 2000 test. During the FY 2001 tests, elevated water content and tracer concentrations were observed at depths of $16 \mathrm{~m}(52.5 \mathrm{ft})$ at two monitoring locations in the southeast quadrant of the monitoring site, suggesting that the plume had penetrated below the lower (12-m [39-ft] deep) confining layer. The exact cause of the observed preferential transport has not been determined at this point, but it could be due to fingering induced by the fluid properties, or simply to rapid flow along an improperly grouted sampling point or access tube. The location of the peak tracer concentrations was almost identical for $\mathrm{F}^{-}, \mathrm{Cl}^{-}, \mathrm{Br}^{-}, \mathrm{NO}_{3}^{-}, \mathrm{S}_{2} \mathrm{O}_{3}^{-}$, and $\mathrm{PO}_{4}^{2-}$ but was somewhat larger for $\mathrm{SO}_{4}^{2-}$ in the FY 2001 tests. The distribution of $\mathrm{SO}_{4}^{2-}$ also appeared very sensitive to textural changes. The location of centers of mass for the different tracers was somewhat different and increased from about $5.7 \mathrm{~m}(18.7 \mathrm{ft})$ to $8.4 \mathrm{~m}(27.6 \mathrm{ft})$ in the order $\mathrm{PO}_{4}^{2-}<\mathrm{Br}^{-}<\mathrm{F}^{-}$ $<\mathrm{S}_{2} \mathrm{O}_{3}^{-}<\mathrm{NO}_{3}^{-}<\mathrm{Cl}^{-}<\mathrm{SO}_{4}^{2-}$. The deeper penetration of $\mathrm{Cl}^{-}$relative to $\mathrm{NO}_{3}^{-}$and $\mathrm{S}_{2} \mathrm{O}_{3}^{-}$may be indicative of preferential transport due to anion exclusion, a mechanism that would be of great significance to the transport of ${ }^{99} \mathrm{Tc}$.

These observations emphasize the need to consider local-scale textural discontinuities in conceptual models of field-scale transport at the Hanford Site because they appear to cause lateral spreading of vadose-zone plumes. Lateral spreading of contaminant plumes has been observed in the vadose zone at Hanford tank farms and other waste sites. Preliminary modeling of the distribution of the FY 2000 test was performed using Pacific Northwest National Laboratory's (PNNL's) Subsurface Transport Over Multiple Phases (STOMP) simulator. The site was modeled as a heterogeneous system conditioned on initial water-content distributions and parameterized with constitutive properties of over 20,000 soil types. To date, these simulations have come closest to reproducing field observations of any of the simulations of experiments performed at this site. Although the general features of the predicted water-content distributions are similar to those observed in the field, the current conceptual and numerical model does not yet adequately describe the extensive lateral spreading observed in the field. At present, there is no model that incorporates the interactions between fluid and hydraulic properties to predict the plume distributions observed in laboratory and field studies. In addition to the incomplete conceptual model, model parameterization for field-scale simulations continues to be a major limitation. Work is ongoing to evaluate the processes that can cause accelerated transport of hypersaline plumes and to develop techniques to facilitate upscaling and parameterization of field-scale models.

Work in FY 2001 has led to the development of a parameter scaling method that can be coupled with inverse-flow modeling to estimate constitutive parameters for heterogeneous soils at the field-scale. The method is based on first assigning unique scaling factors to similar soil textures in the field after which field-scale reference hydraulic parameter values are then estimated through inverse modeling of the field experiments. The parameters for individual layers are subsequently obtained through inverse scaling of the fitted reference values using the a priori relationships between the reference parameter values and the 
specific value for each layer. STOMP was combined with the universal inverse modeling code, UCODE, to estimate the unsaturated hydraulic parameters. Three cases of heterogeneity, i.e., homogeneous soil, layered soil, and heterogeneous soil, were used to test the new technique. Predictive modeling of drainage from a well-characterized lysimeter site at Hanford that has both laboratory and field-measured soil hydraulic properties resulted in an overestimation of soil water content, $\theta$, and an underestimation of pressure heads, $\psi$. However, using field-scale parameter values derived from inverse-flow modeling with the new scaling technique resulted in significantly better model fits for both $\theta$ and $\psi$. The simulation of drainage from a layered soil at a well-instrumented field site near the 300 Area at Hanford also resulted in an overestimation of $\theta$ and $\psi$ when the local-scale parameter values were used. Again, using field-scale parameter estimates, obtained from the inverse scaling method, resulted in smaller prediction errors with regression coefficients of 0.956 to 0.997 between the observed and predicted values of $\theta$ and $\psi$, respectively. Application of this technique to the estimation of hydraulic parameters from the Vadose Zone Transport Field Study experiments has commenced with a two-dimensional simulation. The prediction of water-content distributions using lab-measured parameter values resulted in very poor model fits $\left(r^{2}=0.28\right)$. However, using inverse scaling improved the goodness of fit with $r^{2}$ increasing to 0.74 . Parameters derived from these studies will be compared with those derived from core measurements with the goal of developing an upscaling methodology. Such techniques are critical to the development of long-term, field-scale transport predictions. This type of inverse analysis will be an ongoing effort in FY 2002 and FY 2003.

The advanced characterization methods (ERT, HRR, and XBR) for the vadose zone all have significant promise as diagnostic tools for defining the depth and extent of vadose-zone plumes at Hanford, particularly where monitoring wells can be adapted for use by these instruments. XBR requires PVC casing, but HRR and ERT can be adapted for use with steel-cased wells, the typical infrastructure that currently exists at the Hanford tank farms. HRR appears to be particularly useful in being capable of diagnosing the lateral extent of the plume. Evaluation of the characterization methods will continue during future field experiments. 


\section{Glossary}

ARA Applied Research Associates

AT

Advanced Tensiometry

CEMI

Crosshole Electromagnetic Imaging

CPT Cone Penetrometer Technology

$\mathrm{DC}$

direct current

DOE

U.S. Department of Energy

EM

electromagnetic

EMI Electromagnetic Resolution Imaging

EMSP Environmental Management Science Program

ERT Electrical Resistance Tomography

GPR Ground-Penetrating Radar

HGI HydroGEOPHYSICS Incorporated

HNGS hostile-environment natural gamma ray sonde

HRR High Resolution Resistivity

ILAW Immobilized Low Activity Waste

LBNL Lawrence Berkeley National Laboratory

LDS litho-density sonde

ORP Office of River Protection (U.S. Department of Energy)

PNNL Pacific Northwest National Laboratory

PUREX plutonium uranium extraction

REDOX reduction oxidation

RLS radionuclide logging system

STOMP Subsurface Transport Over Multiple Phases

VZTFS Vadose-Zone Transport Field Study

WIDS Waste Information Data System

XBR Cross-Borehole Radar

XBS Cross-Borehole Seismic 


\section{Acknowledgments}

Contributions to this report came from a number of U.S. Department of Energy national laboratories and contractors, and we acknowledge their inputs and excellent support. Specifically, we thank W. L. Bratton and W. C. Dickerson of ARA, Inc, Richland, Washington, who provided material for the Cone Penetrometer Technology section; J. B Sisson of Idaho National Engineering and Environmental Laboratory, Idaho Falls, Idaho, who provided the Advanced Tensiometer data and analysis; W. Daily and A. L. Ramirez who provided the Electrical Resistance Tomography data and analysis; J. B. Fink, of HGI, Tucson, Arizona, who provided the High Resolution Resistivity results; G. M. Hoversten, of Lawrence Berkeley National Laboratory, Berkeley, California, who provided the Electromagnetic Resolution Imaging analysis, E. Majer and K. Williams and J. E. Peterson, of Lawrence Berkeley National Laboratory, who provided analysis for Cross-Borehole Radar and Cross-Borehole Seismic; M. E. Conrad and D. J. DePaolo, also of Lawrence Berkeley National Laboratory, who provided the Isotopic Tracer analysis. Individual credits for this work are identified in the Appendices. We also acknowledge the technical support provided in the laboratory and field by Todd Caldwell, Ray Clayton, George Last, Eric McGarrah, Alexandre Mitroshkov, Toni Owens, Jason Ritter, and Karen Waters-Husted. We thank Mark Rockhold for his involvement in our preliminary modeling activities and Fred Zhang, who has developed the inverse scaling method and implemented it for Hanford Site conditions. In addition, we thank Mark White of Pacific Northwest National Laboratory for his help in implementing the modifications to Subsurface Transport Over Multiple Phases (STOMP) and to Eileen Poeter of the Colorado School of Mines for fixing a couple bugs discovered in the application of UCODE to the unsaturated flow problem. The contribution of these individuals proved invaluable to the completion of this report. 


\section{Contents}

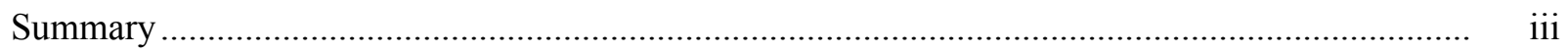

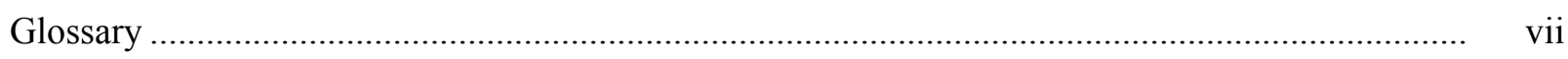

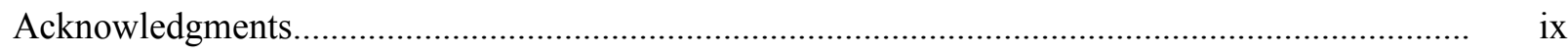

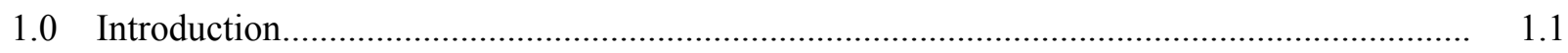

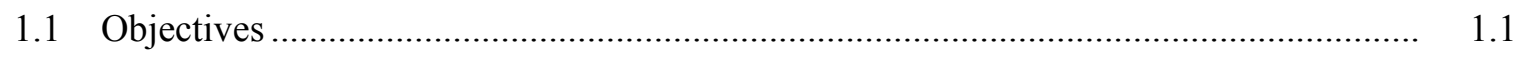

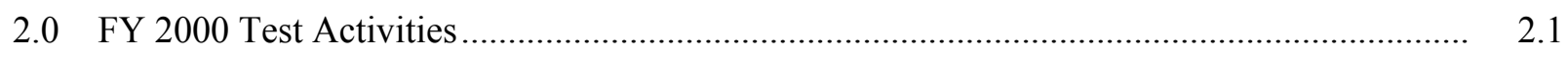

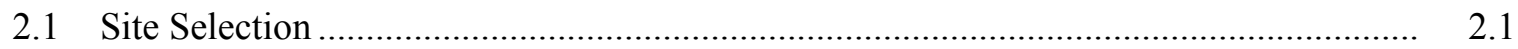

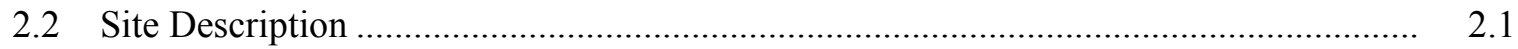

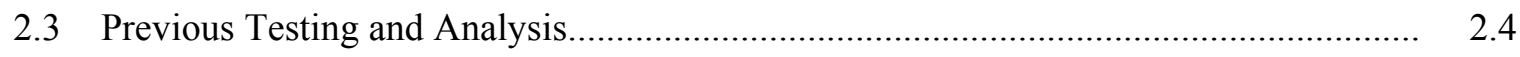

2.4 Selection of Subsurface Monitoring Methods ….................................................... 2.4

2.4.1 Neutron Moisture Logging ........................................................................ 2.5

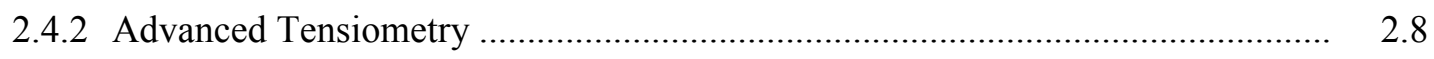

2.4.3 Electrical Resistance Tomography ............................................................ 2.8

2.4.4 High-Resolution Resistivity .................................................................. 2.9

2.4.5 Electromagnetic Imaging ................................................................... 2.10

2.4.6 Cross-Borehole Radar ….......................................................................... $\quad 2.10$

2.4.7 Cross-Borehole Seismic ........................................................................... 2.11

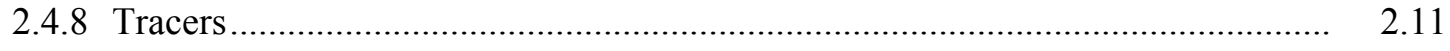

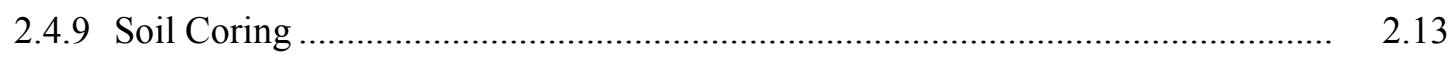

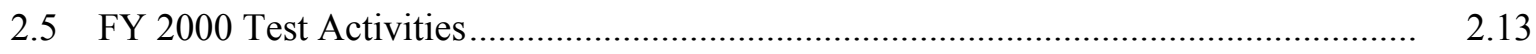

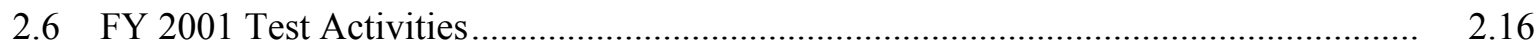

2.6.1 Pre-Test Laboratory Experiments ............................................................ 2.18

2.6.2 Fluid Injections.................................................................................... 2.19

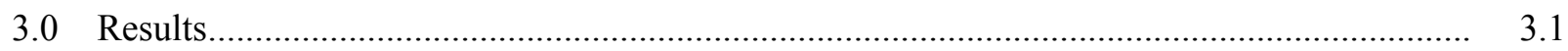

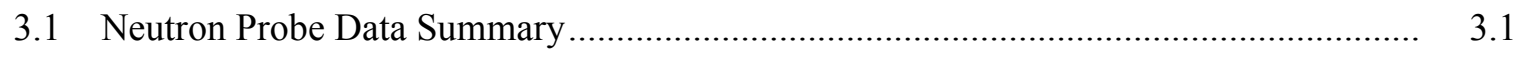

3.2 Tensiometry Data Summary ….................................................................... 3.2

3.3 Electrical Resistance Tomography Data Summary ................................................. 3.4

3.4 High Resolution Resistivity Data Summary ................................................................ 3.5

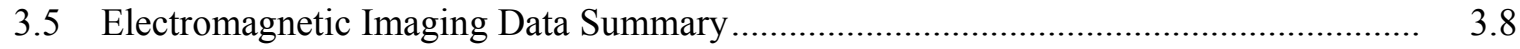

3.6 Cross-Borehole Radar Data Summary ................................................................ $\quad 3.10$

3.7 Cross-Borehole Seismic Data Summary............................................................... 3.12 
3.8 Tracer Data Summary ...................................................................................... $\quad 3.14$

3.8.1 Isotope Tracer Data Summary ........................................................................... $\quad 3.14$

3.8.2 Nonreactive Tracer Data Summary ............................................................... 3.16

3.9 Coring Data Summary ………………………………………………………... 3.16

4.0 Data Analysis ......................................................................................................

4.1 Previous Data Analysis and Modeling..................................................................... 4.1

4.2 Modeling of FY 2000 VZTFS Field Experiment …………………………………..... 4.2

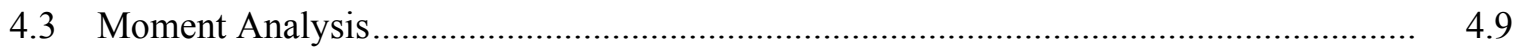

4.4 Inverse Techniques …………………………………………………………. 4.15

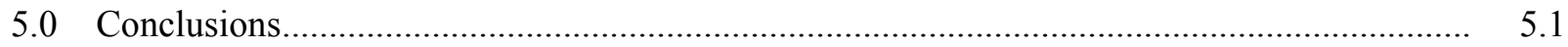

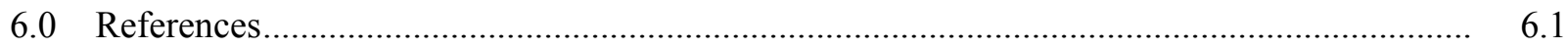

\section{Figures}

2.1. Aerial Photograph from July 13, 1996, Showing the Location of the Test Site ..................... 2.2

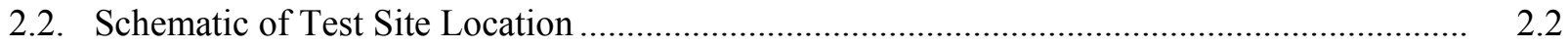

2.3. Photograph of the Vadose Zone Transport Field Study Test Site on May 31,2000, During Instrumentation and Sampling.

2.4. Plan View of FY 2000 Test Site Showing Locations of Access Tubes, Vertical Electrode

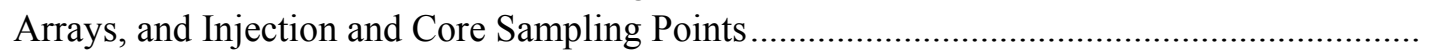

2.5. Injection Test Site and Location of Wireline Core Samples............................................ 2.22

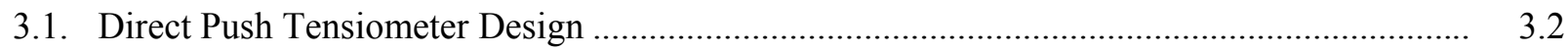

3.2. Drive Cone Tensiometer Responses During FY 2000 Injections at Locations Near Injection (A3) and Further Away (H6) from Injection Point (see Figure 2.4)....................... 3.3

3.3. Comparison of Tomographs Representing the FY00 and FY01 Spills ............................... 3.6

3.4. McOHM-21 with Transmitter Scanner ....................................................................... 3.7

3.5. Measurements Between Steel Casings (1), an Electrode in the Injection Well and Steel Casings (2), Fabricated Electrodes Placed at the Bottoms of all Casings (3), Fabricated Bottom-Hole Electrodes and Steel Casings (4), and Injection-Well Electrode and Bottom-Hole Electrodes (5) 
3.6. Cut-Way View of Test Site Showing Well Layout

3.7. Results of Radar Tomography After Approximately 500 Gallons of Water Injection (LHS, 2000) and Sodium Thiosulfate (RHS, 2001) Between Wells X1 and X2.....

3.8. Relative Peak Concentrations of Deuterium and Bromide

3.9. Schematic of Split Spoon Sampling Procedure and Typical Liner Designation

4.1. Initial Water Content Distributions Along E-W and N-S Measurement Transects ....

4.2. Simulated Water Content Distributions on June 2, 2000; 1 Day After First Injection.

4.3. Simulated Water Content Distributions on June 16, 2000; 1 Day After Third Injection..........

4.4. Simulated Water Content Distributions on June 23, 2000; 1 Day After Fourth Injection

4.5. Simulated Water Content Distributions on June 29, 2000; 1 Day After Fifth Injection.

4.6. Simulated Water Content Distributions on July 11, 2000, Final Neutron Probe Measurement.

4.7. Spatial Distribution of Change in Soil Water Content (Dq) from the Pre-injection Condition Along the D-H Transect after Injection of (a) $4000 \mathrm{~L}$ (1057 gal) of Dilute Tracer Solution (FY 2000), and (b) 4216 L (1114) of Sodium Thiosulfate Solution (FY 2001)

4.8. Spatial Distribution of Change in Soil Water Content (Dq) From the Pre-injection Condition Along the D-H Transect after Injection of (a) 12,000 L (3170 gal) of Dilute Tracer Solution During the FY 2000 Field Experiment, and (b) 11,400 L (3012 gal) of Sodium Thiosulfate Solution During the FY 2001 Field Experiment.....

4.9. Spatial Distribution of Change in Soil Water Content (Dq) From the Pre-injection Condition Along the D-H Transect after Injection of (a) 20,000 L (5283 gal) of Dilute tracer solution, and (b) 19,402 L (5125 gal) of Sodium Thiosulfate Solution.....

4.10. Spatial Distribution of Change in Soil Water Content (Dq) From the Pre-Injection Condition Along the D-H Transect After Injection of (a) 9 Days Post Injection in FY 2000 and (b) 8 Days Post Injection in FY 2001

4.11. Depth of Penetration of the Dilute and Hypersaline Plumes as a Function of Injected Volume.

4.12. Cumulative Distance Traveled by the Centers of Mass of the Dilute and Hypersaline Plumes

4.13. Comparison of the Predicted and Observed Soil Water Contents at the H-Section of the Injection Experiment Described in Sisson and Lu (1984) 


\section{Tables}

2.1. Characterization and Monitoring Technologies Selected for FY 2000 and

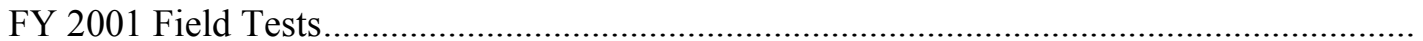

2.2. List of FY 2000 Test Activities for the VZTFS project at the 299-E24-111 Experimental Test Well (Sisson and Lu) Site, 200 E Area, Hanford Site, Washington ........... 2.14

2.3. Selected Properties of $\mathrm{Na}_{2} \mathrm{~S}_{2} \mathrm{O}_{3} \cdot 5 \mathrm{H}_{2} \mathrm{O}$ (after Weast 1986)

2.4. Schedule for FY 2001 Experiment

4.1. Calculated Three-Dimensional Spatial Moments for Distribution of Water Content Changes in FY 2000

4.2. Calculated Three-Dimensional Spatial Moments for Distribution of Water Content Changes in FY 2001 


\subsection{Introduction}

The scope of the Vadose Zone Transport Field Studies (VZTFS) is to conduct a series of tests at the U.S. Department of Energy's (DOE's) Hanford Site to evaluate how contaminant plumes move in the vadose zone. Planned experiments include two flow and transport tests in the near surface at an uncontaminated site to simulate a tank leak, followed by two flow and transport tests in coarse sediments typical of the deeper Hanford formation. The goal is to identify dominant transport processes, quantify parameters in the Hanford subsurface, and generate databases for testing three-dimensional numerical models of vadose-zone flow and transport. These studies address current data gaps related to mobile contaminants by making in situ measurements of surrogate variables using a variety of monitoring technologies. The resulting information is intended to reduce uncertainty in conceptual models of vadose-zone flow and transport and to improve transport predictions at tank farms and other waste disposal sites. During FY 2000 and FY 2001, the first two of four planned field tests were completed at an uncontaminated site. Two more field tests are planned in subsequent years (FY 2002 and FY 2003). This report provides details from the FY 2000 and FY 2001 field tests. Additional detail related to the planning of these two tests and to published reports on the Advanced Characterization Workshop that led to the selection of the geophysical methods deployed at the site may be found on the Pacific Northwest National Laboratory (PNNL) Vadose Zone web page, http://vadose.pnl.gov, and in Ward and Gee (2000, 2001).

\subsection{Objectives}

The objectives of the VZTFS are to conduct controlled transport experiments at well-instrumented field sites at Hanford to:

- identify mechanisms controlling transport processes in soils typical of the hydrogeologic conditions of Hanford's waste disposal sites

- reduce uncertainty in conceptual models

- develop a detailed database of hydraulic and transport parameters for testing and calibrating threedimensional numerical models

- identify and evaluate advanced, cost-effective characterization methods with the potential to function within the existing infrastructure and to assess changing conditions in the vadose zone, particularly as surrogates of currently undetectable high-risk contaminants. 


\subsection{FY 2000 Test Activities}

The emphasis of the studies conducted under the VZTFS project is to perform tests that delineate the dominant transport processes occurring in the Hanford vadose zone. The FY 2000 test was designed to address the focused flow of water and dilute tracers induced by both manmade and natural features, such as buried tanks or sloping or vertical (i.e., clastic dike) sedimentary layers. The field tests that have been conducted and those planned are designed on a sufficiently large scale that the data can be used to verify transport predictions.

To date, testing was approached in two phases:

1. Characterization of background site conditions.

2. Process characterization that occurs during and after the actual transport tests; this includes assessing the physical and chemical properties that may affect vadose-zone transport processes.

\subsection{Site Selection}

A test site was selected at Hanford at the 299-E24-111 Experimental Test Well (Sisson and Lu) Site located in the 200 East Area and where an extensive amount of characterization was previously completed (Sisson and Lu 1984; Fayer et al. 1993, 1995). Ward and Gee (2000) provide details of the site-selection process. Figure 2.1 shows an aerial photograph of the site while the schematic in Figure 2.2 shows the test site location relative to the location of the proposed immobilized low-activity waste (ILAW) disposal facility of the DOE Office of River Protection (ORP). More details pertaining to the site can be found in Ward and Gee $(2000,2001)$.

\subsection{Site Description}

Figure 2.3 shows the site during instrument installation on May 31, 2000. The picture was taken from the east side of the test site looking across the bare soil of the 216-A-38 crib past the Sisson and Lu test site to the adjacent shrub-steppe vegetation, visible in the background. The drilling rig used to place advanced tensiometers and to provide core samples is shown at the left of the picture. The pink pin flags on the ground in the central part of the picture demarcate locations where surface electrodes were placed for geophysical logging measurements.

Figure 2.4 shows a plan view of the well configuration at the test site, including the location of new instrumentation and boreholes installed during the collection of soil cores. The injection well used in the FY 2000 test is located adjacent to H2, and there are a total of 32 observation wells constructed by welding together sections of 15.24-cm (6-in.) diameter schedule 40 steel casing. Ward and Gee (2000) provided the details of the well placements and array configurations. 


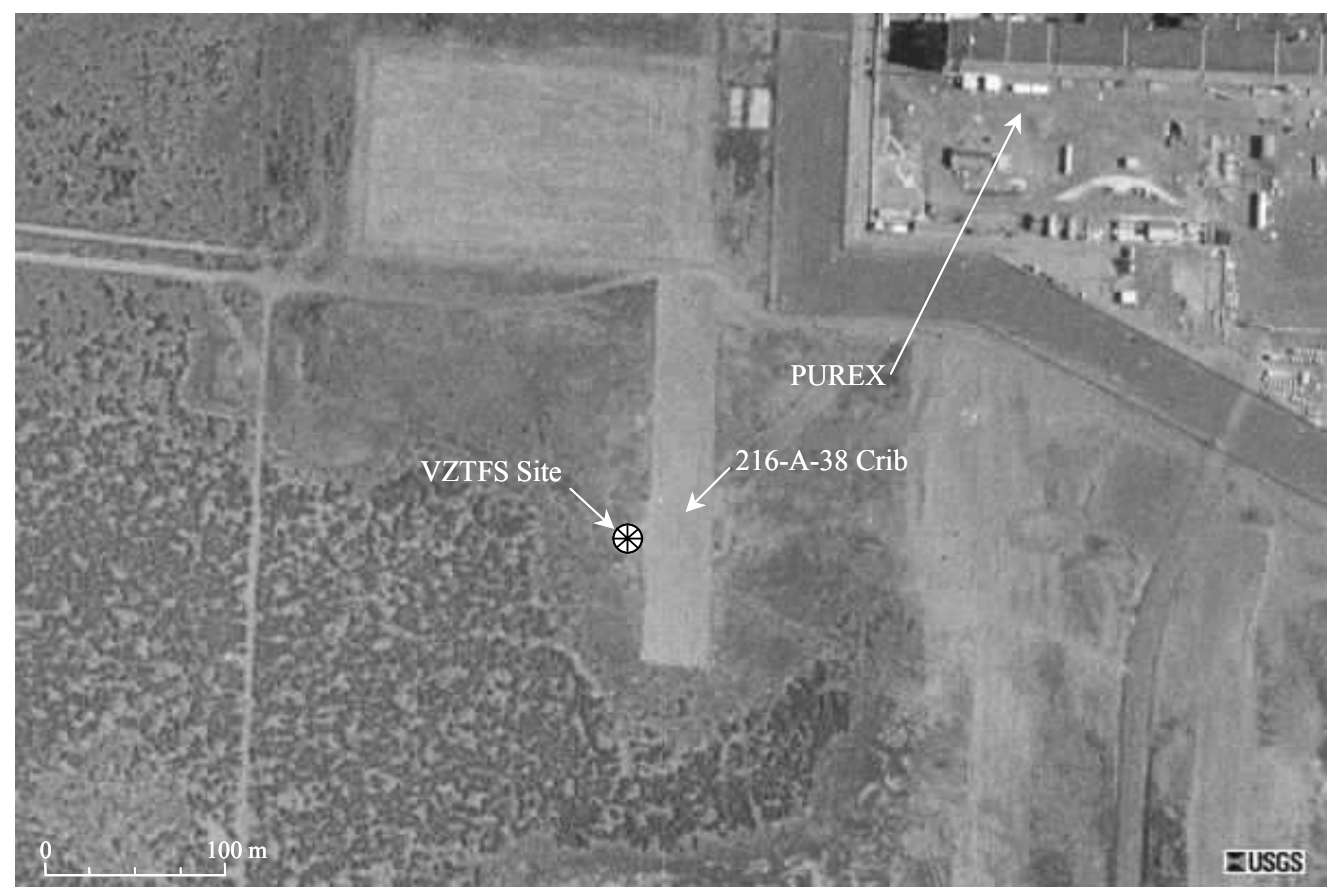

Figure 2.1. Aerial Photograph from July 13, 1996, Showing the Location of the Test Site. The injection site is adjacent to the 216-E24-111 crib and southwest of the Plutonium Extraction (PUREX) Plant. (Image courtesy of the U.S. Geological Survey at http://terraserver.microsoft.com/)

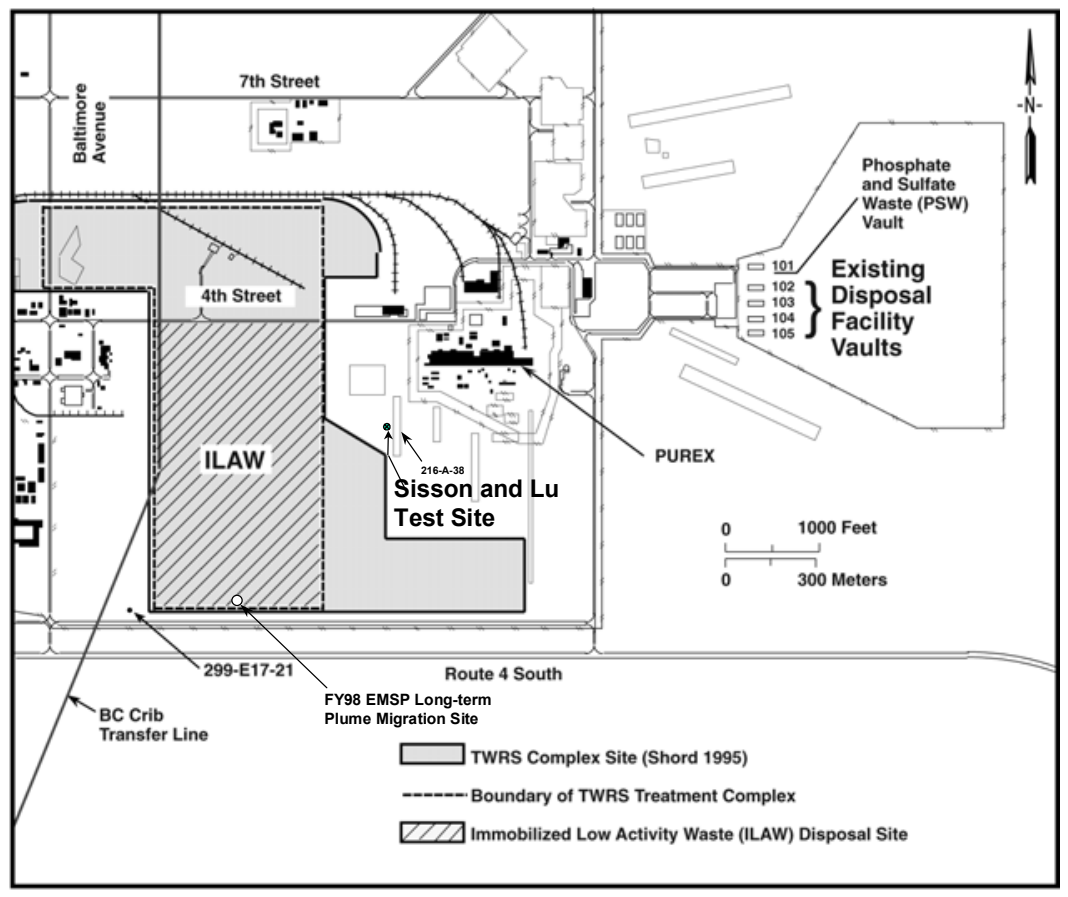

Figure 2.2. Schematic of Test Site Location. Sisson and Lu (1984) used the site to conduct the first controlled vadose zone transport study at Hanford and is now designated as 299-E24-111, Experimental Test Well Site, in the Hanford Waste Information Data System (WIDS). 


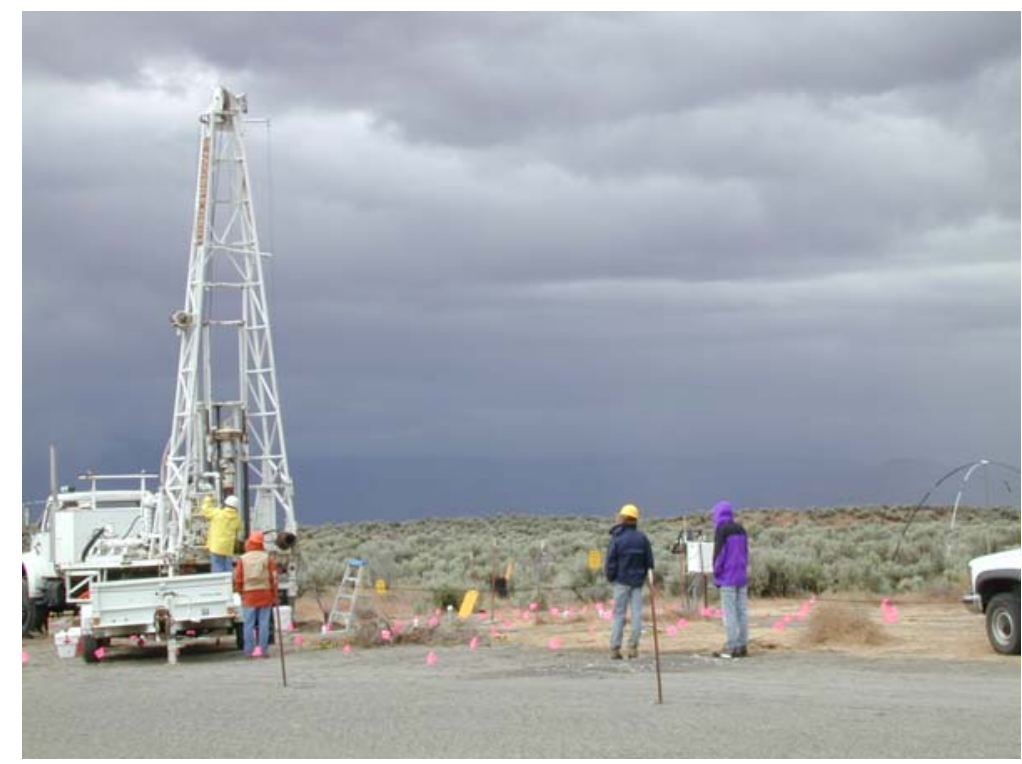

Figure 2.3. Photograph of the Vadose Zone Transport Field Study Test Site on May 31,2000, During Instrumentation and Sampling

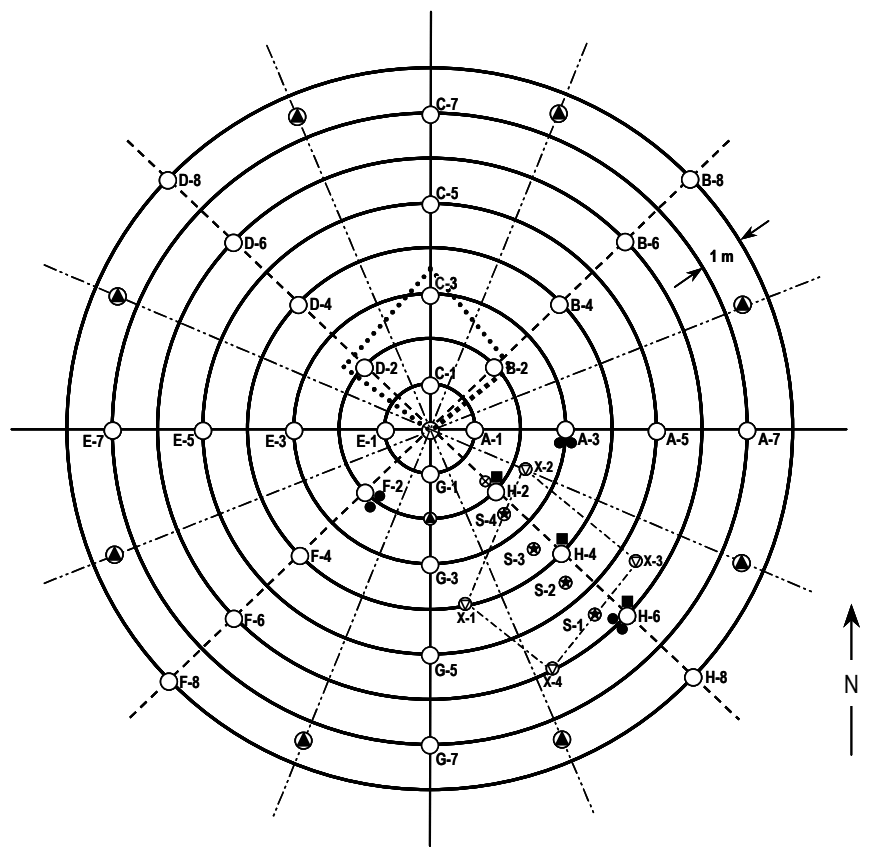

a Adv.Tensiometer Nest (Augered) $\otimes$ New Injection Point

- Adv. Tensiometer Nest (CPT) $\quad \because \because$ Subsurface Radiation Zone

$\bullet$ Cross-Borehole Access

(2) Split-spoon Cores

- ERT Array

O Steel-cased Well

Figure 2.4. Plan View of FY 2000 Test Site Showing Locations of Access Tubes, Vertical Electrode Arrays, and Injection and Core Sampling Points 


\subsection{Previous Testing and Analysis}

The original infrastructure is described in Sisson and $\mathrm{Lu}(1984)$ and in Ward and Gee $(2000,2001)$. The original arrangement consisted of 32 steel-cased wells (15.24 cm [6 in.] ID and $18.29 \mathrm{~m}$ [60 ft] deep) placed in concentric circles around a central injection well. The injection well was $4.6 \mathrm{~m}(15 \mathrm{ft})$ deep. After the initial (1980) testing, it was grouted and has not been used since. All other wells have been fully operational since installation.

In the 1980s, the first tank leak was simulated at the Sisson and Lu site by introducing water and tracers (nitrate, chloride, barium, rubidium, and calcium), including the short-lived radionuclides ${ }^{134} \mathrm{Cs}$ and ${ }^{85} \mathrm{Sr}$, into the central injection well. Eleven injections, ranging from $3200 \mathrm{~L}$ (845 gal) to $5500 \mathrm{~L}$ (1453 gal) and totaling 42,000 L (11,095 gal), were made from September 22, 1980, to February 2, 1981 (Fayer et al. 1993). The subsurface was monitored by lowering sensors to the desired depths in the observation wells and recording sensor output. The sensors included neutron probe (for water content), gamma-gamma (for formation density), and Geiger-Muller and spectral gamma (for tracer radioactivity).

In 1994, additional monitoring of the site was completed using a compensated neutron tool CNT-G (neutron-neutron logging for water content), litho-density sonde (LDS) (pulsed neutron logging for water content), and hostile-environment natural gamma ray sonde (HNGS) and radionuclide logging system (RLS) (gamma logging for radionuclides). Schlumberger-Wireline Services deployed these geophysical tools after calibrating the two water-content probes (Engleman et al. 1995b). A description of the logging equipment and the results of these additional tests can be found in Fayer et al. (1995).

The dry-soil-density data collected during the geophysical logging were subsequently used by Rockhold et al. (1999) to estimate spatial distributions of porosities and subsequently to estimate saturated water contents of subsurface sediments at this site. Inspection of the gamma-log data for bulk density (Fayer et al. 1995) suggests that the values may be lower than the actual field densities. Only wet-density data are available, and these values appear to be low by as much as $20 \%$, particularly at depths below $7 \mathrm{~m}(23 \mathrm{ft})$. Wet densities reported for depths from 12 to $15 \mathrm{~m} \mathrm{(39}$ to $49 \mathrm{ft})$ in Well E-1 were less than $1.3 \mathrm{~g} \mathrm{~cm}^{-3}$, and the reported water contents were slightly above $6 \mathrm{vol} \%$. The computed bulk density for this zone would be less than $1.25 \mathrm{~g} \mathrm{~cm}^{-3}$, which is unusually low for Hanford Sediments. Most Hanford sediments have normal bulk densities in the range from 1.5 to $1.7 \mathrm{~g} \mathrm{~cm}^{-3}$. The average bulk density for the entire profile of Well E-1, as estimated from the LDS density probe, is $1.4 \mathrm{~g} \mathrm{~cm}^{-3}$, or about 15\% lower than typical Hanford sediments (Engleman et al. 1995a). Fayer et al. (1995) noted that the LDS gamma-gamma sensor had not been calibrated for site conditions. Further deployment with the LDS sensor will likely require calibration under site-specific conditions.

\subsection{Selection of Subsurface Monitoring Methods}

As described in the Detailed Test Plan for the FY 2000 test (Ward and Gee 2000), an Advanced Characterization Workshop was convened at Hanford in February 2000 to identify technologies with potential for application at Hanford. Proceedings of the workshop are available online on the Vadose Zone Transport Study web page at http://vadose.pnl.gov/. Of the more than 20 technologies presented, techniques were sought that could reduce the uncertainty in plume delineation when used alone or in 
conjunction with others. With this objective in mind, a short list of candidate technologies was identified based on the following criteria:

- the capability to identify key geologic features controlling water movement with a vertical resolution of $0.1 \mathrm{~m}(0.033 \mathrm{ft})$ or better and a horizontal resolution of $1 \mathrm{~m}(3.28 \mathrm{ft})$ or better

- the capability to locate wetting fronts and a change in water content of $0.01 \mathrm{~m}^{3} \mathrm{~m}^{-3}$ or better with a repeatability of at least $0.01 \mathrm{~m}^{3} \mathrm{~m}^{-3}$

- the capability to determine the shape and extent of non-gamma-emitting contaminant plumes or their surrogates

- the capability to function and produce useful results in environments that are culturally noisy.

Nine technologies were selected for the FY 2000 test. These included neutron moisture logging, advanced tensiometry (AT)/suction lysimetry, electrical resistance tomography (ERT), Cross-Borehole Radar (XBR), crosshole seismic tomography, crosshole electromagnetic induction (CEMI), and highresolution resistivity (HRR). Additional methods included tracers (including isotopes) and coring. The details of each of the nine methods selected and the collaborators who helped deploy the selected methods are listed in the VZTFS test plan (Ward and Gee 2000, 2001) and are described briefly in the following paragraphs. Table 2.1 shows the nine characterization technologies that were chosen for FY 2001.

\subsubsection{Neutron Moisture Logging}

Neutron probes were used to monitor water content at the Sisson and Lu injection site in the past (Sisson and Lu 1984; Fayer et al. 1993, 1995). These probes are used routinely to monitor field water contents at the Hanford Site (e.g., Ward and Gee 1997; Fayer et al. 1999, DOE 1999).

Conventional nuclear moisture logging devices use a technique called neutron moderation. The probe used in this technique, commonly referred to as a neutron probe, contains a source of neutrons (the neutral particle inside the nucleus of an atom), usually $50 \mathrm{mCi}$ of americium- 241 and beryllium, and a neutron detector. The neutrons given off by the source (called "fast" neutrons) collide with the hydrogen atoms in any water present. Since the fast neutrons and the hydrogen atoms have the same mass, the fast neutrons are slowed down by this process, much like a billiard ball hitting a stationary ball of the same size and each moving away with equal speeds (one slowing down and the other speeding up). If the neutrons collide with other much more massive elements, they retain the same speed, much like a billiard ball colliding with a large fixed object. The detector is set up to measure these resulting slow neutrons; therefore, the amount of slow neutrons detected is directly related to the amount of hydrogen present. The main source of hydrogen in most sites is bound up in the water molecules; therefore, this type of sensor is very effective for measuring soil moisture. Higher counts reflect higher water contents. 
Table 2.1. Characterization and Monitoring Technologies Selected for FY 2000 and FY 2001 Field Tests

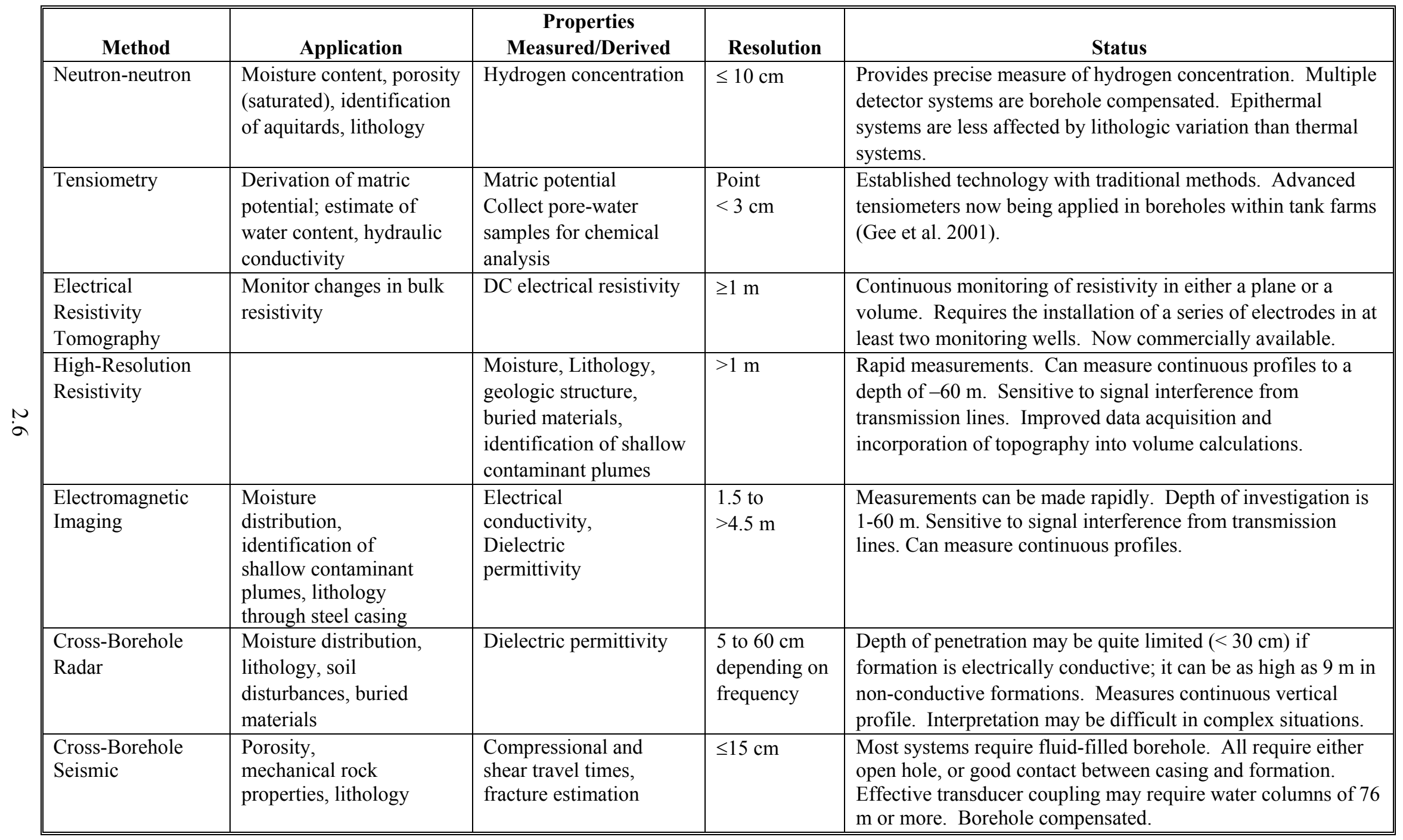


Table 2.1 (Contd)

\begin{tabular}{||l|l|l|l|l|}
\hline \multicolumn{1}{|c|}{ Method } & \multicolumn{1}{c|}{ Application } & \multicolumn{1}{c|}{$\begin{array}{c}\text { Properties } \\
\text { Measured/Derived }\end{array}$} & \multicolumn{1}{c|}{ Resolution } & \multicolumn{1}{c|}{ Status } \\
\hline Tracers & Chemistry, tracer analysis & Tracer location & $\begin{array}{l}1-5 \mathrm{~cm} \\
(\text { Core } \\
\text { Sample })\end{array}$ & $\begin{array}{l}\text { Point measurements of chemistry and tracer-for moment } \\
\text { analysis, etc. }\end{array}$ \\
\hline Soil Coring & $\begin{array}{l}\text { Physical properties, } 1: 1 \\
\text { extract for chemistry }\end{array}$ & $\begin{array}{l}\text { Water content, bulk } \\
\text { density, chemical } \\
\text { analysis }\end{array}$ & $\begin{array}{l}1-5 \mathrm{~cm} \\
(\text { Core } \\
\text { Sample })\end{array}$ & $\begin{array}{l}\text { Point measurement of soil properties, including water content, } \\
\text { texture, and chemistry. }\end{array}$ \\
\hline
\end{tabular}


The use of the neutron probe requires cased access tubes. The probe is either lowered into vertical access tubes or towed through horizontal access tubes, for example, those installed below hazardous waste sites, to measure soil moisture. The neutron probe, which is slightly under 5-cm (1.9-in.) OD, was used to monitor through the existing $15-\mathrm{cm}$ (5.9 in.) ID steel casings. This was done without a need for centering devices because the probe used for the experiments has been adequately calibrated (Tyler 1988; Fayer et al. 1995). One of the neutron probes used by Fayer et al. (1995) was used for the FY 2001 test. Two additional probes were also available for use and were cross calibrated with one of the probes calibrated by Fayer et al. (1995).

\subsubsection{Advanced Tensiometry}

Tensiometers are water-filled porous cups placed in contact with soils to measure the matric potential (Cassel and Klute 1986). The water pressure inside the porous cup is subsequently monitored with a pressure gauge or electronic transducer and related directly to the matric potential of the soil water. The matric potential is a key state variable for describing water flow in unsaturated soils. To date, only limited measurements have been made of this variable in Hanford soils or sediments (Fayer et al. 1999).

Various configurations of tensiometers have been used over the years to measure the matric potentials in the near surface (generally, the top $3 \mathrm{~m}$ [9.8 $\mathrm{ft}$ ] of the soil profile), but recent advances have been made in tensiometer design so that tensiometers can be placed at almost any depth (Hubble and Sisson 1996, 1998). The new tensiometer is known as the advanced tensiometer. Two configurations of the advanced tensiometer were tested during the FY 2000 experiment. The first was a standard nest configuration where tensiometers were placed together in a hole by using a split-spoon auger device. The tensiometers, connected to the surface via a 2.54-cm (1-in.) diameter PVC pipe to accommodate both pressure transducer wiring and water refilling, were placed at selected depths, and the hole was subsequently backfilled. The second was a less intrusive method, where individual tensiometers were placed at a depth of interest by pressing them into the ground using a cone penetrometer. Both methods have been deployed successfully at the Hanford site. A description of the advanced tensiometers and examples of real-time data that have been collected during previous testing can be found at the VZTFS web page at http://vadose.pnl.gov.

In the FY 2000 test, some of the tensiometers failed due to rupture of the porous cups, and in some cases, the desired depths could not be achieved. However, 10 units were found to be operable. These units were monitored in FY 2000, and the monitoring continued through FY 2001 testing. Because the water-content monitoring was spatially removed from the tensiometers (i.e., the horizontal separation distance is often a meter or more), it was not possible to obtain in situ water-retention characteristics. In addition, the range over which the tensiometers operated was confined to the drainage tensions, which for the most part were less than $200 \mathrm{~cm}$ (78.7 in.) pressure. In spite of these limitations, the tensiometer readings were valuable in assessing the drainage state of the profile.

\subsubsection{Electrical Resistance Tomography}

ERT has been demonstrated to be a useful characterization tool, providing details of the stratigraphy between wells (e.g., Newmark et al. 1994), subsurface processes such as fluid infiltration (Daily et al. 1992), and steam injection and ohmic heating (Ramirez et al. 1993, 1996) by mapping the spatial and temporal changes in soil resistivity resulting from changes in liquid saturation and temperature. Since 
tank wastes at Hanford were generally rich in high-ionic-strength electrolytes, resistivity could be an ideal surrogate for locating difficult-to-detect contaminants. In general, ERT has been conducted using a crossborehole geometry, using multiple electrically isolated electrodes placed in vertical arrays. This geometry has the potential to produce relatively high-quality, high-resolution images when the aspect ratio of vertical to horizontal spacing is equal to or greater than 1.5:1.0. Typical electrode installations involve multiple electrodes strung on nonconductive casing (e.g., plastic or fiberglass) in conventionally installed boreholes, or as instrumentation strings installed using cone penetrometers. Both designs have been effective in shallow to moderate depths (most recently over $395 \mathrm{~m}$ [1296 ft]), but deeper installations require significant and more costly modifications.

The method of ERT data collection and processing has been described in detail (Ramirez et al. 1995). LaBrecque et al. (1996) described the forward and inverse modeling codes used to analyze the ERT data. The forward solution is implemented using the finite difference technique with Newman boundary conditions at the ground-air interface and Dirichlet boundary conditions along the other faces of the cube. The inverse solution employs an objective function, which aims to minimize data misfit and model roughness. The minimization of the objective function is done iteratively.

The capability to obtain ERT images using existing conventional steel casings would increase the applicability of the technique and make it particularly useful for deployment at the Hanford Site at facilities such as the tank farms. Recent simulations of ERT with vertical casings as electrodes show that there is a distinct signature indicative of the changing resistivity across the field, which is well above the noise level in the simulations. However, vertical resolution may be limited (Newmark et al. 1994).

\subsubsection{High-Resolution Resistivity}

Electrical surveys undertaken by a direct current (DC) resistivity device involve placement of electrodes in the ground. There are various geometries for the electrode layout, but most have all four electrodes in line. The Wenner and Slumberger arrangements are the most popular. The two outer electrodes are the current source and sink; self-contained batteries drive current. The two inner potential electrodes sense the electrical potential at the surface while current is flowing between the outer electrodes. The potential measured varies with electrode spacing in a predictable way, and also changes as the strata and contained fluids vary laterally and vertically. High-resolution resistivity (HRR) is an evolutionary development in DC electrical resistivity differing from conventional, industry-standard approaches by modification of the field data acquisition procedures (Fink 1980, 1994) and subsequent data processing. ${ }^{\text {(a) }}$ Determining the volume under investigation gives a physical basis for the manner in which the data are presented. HRR has proven itself in extremely rugged terrain by incorporating the topography into the volume calculations. HRR is particularly useful in mapping the distribution and time-dependent changes of moisture in the subsurface. HRR is optimally based on the pole-pole electrode geometry but may be derived from any array of electrical sensors including steel well casings.

Two modes of operation are common: a) depth sounding and b) profiling. In the depth-sounding mode, all four electrodes are placed in the ground initially with very short spacing between adjacent electrodes. A reading is taken, and then the array is reset with an incremental increase in spacing. Another reading is taken, and the array is, in turn, progressively expanded in this manner until the maximum depth to be investigated is reached. The current and potential sense progressively deeper layers as the array is expanded. In the profiling mode, a constant electrode spacing is selected that senses the

(a) This is a subcontractor report that can be accessed at http://vadose.pnl.gov/vadose rpts.stm. 
subsurface geology to the depth of interest, and this constant array is "leap-frogged" along a profile line to measure lateral variations that have geologic meaning.

HRR was applied to the Hanford vadose-zone at the VZTFS test site to demonstrate whether HRR could quantitatively monitor the movement of the injected solution. A two-dimensional electrode array was installed on the surface of the injection site for surface-only measurements. The specific number of electrodes installed and the array dimensions are described in the contractor report found at http://vadose.pnl.gov. In addition, the 32 steel casings were used as electrodes by connecting them to the tops of the casings and installing electrodes in the bottoms of the wells. An electrode was also placed in the bottom of the PVC injection well. Potential measurements were made using various combinations of the surface and downhole electrodes. The results are presented in the contractor report in color-contoured plan maps of potential distribution as a function of depth, two-dimensional profiles showing key changes in time and distance, and in a three-dimensional format showing wet-volume changes as a function of time. A summary of the HRR results is found in Section 3.

\subsubsection{Electromagnetic Imaging}

Electromagnetic imaging (EMI) uses the principle of induction to measure the electrical conductivity of the subsurface between two boreholes. The technique can provide high-resolution images of the subsurface between existing wells up to $1000 \mathrm{~m}$ (3280 ft) apart. The crosshole electromagnetic imaging (CEMI) system consists of a transmitter tool deployed in one well and a receiver tool deployed in a second well. The transmitter uses a vertical axis coil wrapped with 100 to 300 turns of wire tuned to emit a single low-frequency sinusoidal signal that induces currents to flow in the surrounding soil. The optimum operating frequency depends on borehole separation and background resistivity, but generally the frequency ranges between 40 to $100 \mathrm{kHz}$. A frequency that is too low limits the resolution, while one too high limits the range of the measurement. At the receiver borehole, a custom-designed coil detects the total magnetic field, consisting of the magnetic field from the induced currents as well as the primary magnetic field generated by the transmitter. The receiver section consists of a magnetic field sensor and a commercial lock-in amplifier located at the surface. The lock-in amplifier operates like a radio by measuring only those signals that are coherent with the transmitted signal while rejecting incoherent background noise. By positioning both the transmitter and receiver tools at various levels above, below, and within the zone of interest, images of the resistivity distribution between the wells can be generated. The EM data are interpreted by inverse modeling to produce a tomogram.

The field study included both surface-based EMI and CEMI. The surface-based EMI consisted of two orthogonal lines approximately $20 \mathrm{~m}(65 \mathrm{ft})$ long across the expected leak zone. The operation frequency was between 100 to $20,000 \mathrm{~Hz}$. The surface-to-borehole measurements made use of at least two and surface transmitter locations transmitting into all four PVC wells and at least 12 steel-cased wells. The operation frequency was from 100 to $20,000 \mathrm{~Hz}$. The PVC wells allowed the highest frequencies to be collected while the steel-cased wells admitted at most, $1000 \mathrm{~Hz}$. The surface lines were done first (May 23, 2000) with the surface-to-borehole data acquired on May 24 and May 25, 2000. No EMI testing was done in FY 2001.

\subsubsection{Cross-Borehole Radar}

Cross-Borehole radar measurements provide information about the porous medium rock between two boreholes. Radar is analogous to the seismic reflection technique, except that radar (microwaves) is used 
rather than acoustic waves. The primary information obtained is the variation of dielectric properties of the subsurface. Due to the large contrast in the dielectric constant between water $(\varepsilon=80)$ and most earth materials ( $\varepsilon=3$ to 5 ), volumetric water contents can be easily inferred from radar data (Hubbard et al. 1997). Also inferred is the lithology and distribution of different soil types. Media with strong discontinuities (e.g., fracture zones) delay pulse arrival times and attenuate the transmitted radar pulse. The late arrivals and reduced pulse amplitudes are measured and analyzed using tomographic processing. Even later arrivals from reflectors are also analyzed. The velocity and amplitude of the data are recorded as a function of time resulting in a series of data in the time domain. However, the data are often reduced to the frequency domain to infer attributes of the data indicative of various subsurface properties. Normally, numerous rays are measured, and the data are usually collected in a tomographic mode; the data are then inverted to provide a tomogram of either velocity or attenuation properties. The data can also be collected in a more rapid fashion in just a limited cross-well configuration. The data can also be processed to give reflection images in stratigraphic sequences. The schedules used for monitoring with cross-borehole radar are shown in Tables 2.2 and 2.4.

\subsubsection{Cross-Borehole Seismic}

Crosshole seismic tomography (CST) involves measuring the travel time of seismic energy transmitted between two or more boreholes to derive information on the dynamic elastic properties of the intervening porous medium (Majer et al. 1997). Such data can then infer lithology, bed geometry and continuity, fracture and fault properties, porosity, and in some cases, the fluid distribution. The CST uses a transmitter in one hole and either single or multiple receivers in an adjacent hole or holes. Energy is transmitted at multiple positions in the transmitter well and received in the receiver well(s) with sensors. In practice, a three-component wall-locking geophone and a directional downhole seismic source are initially lowered to the bottom of two boreholes. The two probes are then moved together in intervals of $30-60 \mathrm{~cm}$ so that a near horizontal ray path is maintained between them. Average shear (S) and compressional $(\mathrm{P})$ wave velocity values are obtained by calculating wave travel times between the source and receiver boreholes. Accuracy of the data require that the boreholes be installed as vertically as possible and be cased with steel or PVC. The technique requires that the boreholes be sealed at the bottom so they can be filled with water. At the test site, steel-cased boreholes (15-cm i.d.) are already in place, but their verticality is unknown. The bottoms of these wells are also unsealed. Inflatable packers that can be removed after the test are used to seal the boreholes. A deviation survey was run to determine the verticality of the boreholes. Measurements were made at the end of the flow and transport experiments under the schedules shown in Tables 2.2 and 2.4.

\subsubsection{Tracers}

Large uncertainties in the flow regimes in the vadose zone can lead to several plausible but conceptually different models of important hydrogeological properties at the test site. Thus, uncertainty in the spatial variability of the constitutive properties cannot be attributed to parameter uncertainty alone. A significant contribution to the uncertainty could be due to variation in physical characteristics as represented by different conceptual models of inferred hydrogeologic features. In addition to the infiltration tests, a series of tracers was injected to help accomplish one of the objectives of the VZTFS, namely, to obtain data to support the reduction of uncertainty in vadose-zone conceptual models and to facilitate the testing and calibration of flow and transport models. In formulating flow models for the vadose zone, there can be much uncertainty in the spatial representation of constitutive properties. The 
most common approach to identifying these properties is based on the inversion of matric potential $\psi$, water content, $\theta$, or a combination of $\psi$ and $\theta$ measurements. Another approach to dealing with the data limitations during inverse modeling is to introduce a second state variable and perform a joint inversion. Because the subsurface distribution of passive tracers (those that have minimal effect on viscosity and density) is highly sensitive to spatial variations in hydraulic properties, a variety of efforts have been made at the field scale to relate the arrival times of these tracers to permeability (Harvey and Gorelick 1995).

For the FY 2000 experiment, the objectives of the tracer-testing component were to help define flow paths and ultimately constrain permeability estimates in the development of a more accurate conceptual model of the site and to identify the mechanisms controlling contaminant transport in Hanford sediments. To meet these objectives, both reactive and conservative tracers were used in FY 2000 and FY 2001 as described below. These tracers were selected based on their capability to meet certain criteria. Tracers were required to have low background concentration and to be stable while posing few problems for managing residuals or regulatory concern over their use.

\subsubsection{Isotopic Tracers}

Isotopic tracers were used to simulate transport of contaminants in the vadose zone under conditions that reflected leaks of both low and high ionic strength fluids. The isotopic tracers were injected in FY 2000 during the third of a series of six injections as described in Section 2.5. The tracers were chosen to represent specific contaminants of concern at Hanford. They included $2 \mathrm{~kg}$ of $\mathrm{D}_{2} \mathrm{O}, 25 \mathrm{mg}{ }^{87} \mathrm{Sr}, 1$ $\mathrm{mg}^{145} \mathrm{Nd}, 1 \mathrm{mg}^{179} \mathrm{Hf}$ and $3 \mathrm{mg}^{207} \mathrm{~Pb}$. With the exception of $\left(\mathrm{D}_{2} \mathrm{O}\right)$ which was assumed to move with the water, all of the isotopic tracers were considered to be chemically reactive and had some degree of sorption in Hanford sediments. As specified above these tracers met the requirements of having very low background concentrations and were stable in the Hanford sediments.

\subsubsection{Nonreactive Tracers}

In addition to the isotopic tracers, approximately $6 \mathrm{~kg}$ of $\mathrm{KBr}$ (concentration of $\sim 1000 \mathrm{ppm}$ ) was added to the solution containing the isotopic tracers to provide a non-reactive chemical tracer to track the advance of the water during and after the injection. The isotopic tracers and $\mathrm{KBr}$ were added only during the third injection and only during the FY2000 testing. However, these tracers were sampled and analyzed throughout both of the two years of testing (FY2000 and FY 2001).

A combination of sodium salts was chosen to mimic the high levels of sodium present in tank effluents for the FY 2001 test. The non-reactive tracer selected for use in FY 2001 was a $0.5 \%$ wt of sodium chloride, $\mathrm{NaCl}$, which was combined with a $36 \%$ (by wt) sodium thiosulfate solution. The thiosulfate provided the increase in density, viscosity, and surface tension needed to mimic tank waste at much lower concentrations than would be required with $\mathrm{NaCl}$. However, thiosulfate is not easily detected with conventional analytical methods, so adding chloride simplified tracking the solute migration by analyzing water samples and soil extracts for the chloride ion. Tracer distributions were determined from core samples and from pore-water samples, using standard ion chromatographic methods.

The core for analyzing chloride was prepared using leaching methods described in the sampling and analysis plan (Ward and Gee 2000, Appendix B). PNNL subsequently analyzed pore-water extracts and 
solution samples to determine tracer depth and time breakthrough curves. Tracer distributions were analyzed to locate the center of mass (time or depth) and the variance about the mean. In Section 4.0, tracer distributions were fit to various models to quantify the transport velocity and the degree of transverse and longitudinal dispersion. Pore water and soil core data were used to resolve mass balance.

\subsubsection{Soil Coring}

Drilling of the boreholes to provide access for the geophysical instrumentation provided an opportunity to collect samples for geochemical characterization. One of the boreholes was installed before starting the experiment. Background concentrations of selected tracers, isotopic profiles, and major anions were determined from this core. In addition, water content and bulk-resistivity profiles were collected by cone penetrometer before ERT arrays were installed and during the installation of the advanced tensiometers and installation of the PVC access tubes for cross-borehole radar. Cross-borehole radar and ERT profiles were also collected before the fluid injections began. Cores were taken by both auger drilling (see Figure 2.3) and by waveline drilling (Last and Caldwell 2001; Last et al. 2001.)

Subsamples of the split spoon core were analyzed to determine soil physical and hydrologic properties. Parameters measured included gravimetric soil water content, matric potential, bulk resistivity, particle-size distributions, water retention, and the saturated and unsaturated hydraulic conductivity. Background measures of resistivity were made by ERT.

Periodically during the course of the experiment, water content, matric potential, resistivity, and tracer concentrations were monitored. Tracers were sampled using a combination of soil cores (split spoon and wireline samples). Chemical analyses were made on 1:1 extracts of pore waters. Following the tracer injection, pore-water samples were collected from the suite of cores taken over the 2-year period. The resulting time and depth history of tracer movement were used to characterize transport properties using spatial and time moment analyses. After these tests are fully analyzed, it is anticipated that multidimensional reactive transport models will be deployed in future years to evaluate the transport.

\subsection{FY 2000 Test Activities}

In late April 2000, the field site was approved for use, and installation of equipment (e.g., electrodes for electrical resistance tomography, cross-borehole ports, and advanced tensiometers) began in early May 2000. Electrode, port, and tensiometer placements were completed by May 20 in time for scheduled baseline measurements by all of the geophysical methods before starting water injections. A schedule was set so that baseline sampling and subsequent data collection from each method could be obtained in the most efficient manner and so that there was minimal interference between methods. For example, XBR and ERT measurement schedules were compatible and these measurements could be made simultaneously with the neutron probe. In contrast, the HRR and electromagnetic imaging (EMI) measurements could not be taken at the same time, so a rather strict schedule was set to ensure collection of the best possible data. Table 2.2 shows the detail of the schedule followed during the FY 2000 test.

After baseline data from all methods were obtained, a series of five injections occurred. Injections began on June 1 when $4000 \mathrm{~L}$ (1057 gal) of water was metered into the 5-m (16-ft) deep injection well over a 6-hour period. Subsequent injections occurred weekly for a period of 5 weeks. Neutron logging of 32 steel-cased wells (surrounding the injection well) occurred before the initial injection and followed each of the five injections within a day, with the exception of the injection that occurred on June 26, 2000. 
Table 2.2. List of FY 2000 Test Activities for the VZTFS project at the 299-E24-111 Experimental Test Well (Sisson and Lu) Site, 200 E Area, Hanford Site, Washington

\begin{tabular}{|c|c|c|c|c|c|c|c|c|c|c|}
\hline \begin{tabular}{|l|} 
Date \\
2000
\end{tabular} & \begin{tabular}{|l|} 
Action \\
Item \\
\end{tabular} & $\begin{array}{l}\text { Method } 1 \\
\text { Neutron }\end{array}$ & $\begin{array}{l}\text { Method } 2 \\
\text { AT Tens. }\end{array}$ & $\begin{array}{c}\text { Method } 3 \\
\text { ERT } \\
\end{array}$ & \begin{tabular}{|c|} 
Method 4 \\
HRR \\
\end{tabular} & $\begin{array}{c}\text { Method } 5 \\
\text { EMI } \\
\end{array}$ & $\begin{array}{l}\text { Method } 6 \\
\text { XB Radar } \\
\end{array}$ & $\begin{array}{c}\text { Method } 7 \\
\text { XB Seismic } \\
\end{array}$ & $\begin{array}{c}\text { Method } 8 \\
\text { Isotopes }\end{array}$ & $\begin{array}{c}\text { Method } 9 \\
\text { Coring } \\
\end{array}$ \\
\hline 05-May & Pre-Leak & & & & & & & & & \\
\hline 06-Мау & & $\begin{array}{l}\text { Cross- } \\
\text { Calibrate }\end{array}$ & & & & & & & & \\
\hline 09-May & & & & $\begin{array}{l}\text { CPT Install } \\
\text { (3 day) }\end{array}$ & & & & & & \\
\hline 12-May & & & $\begin{array}{l}\text { CPT Install } \\
(2 \text { day }) \\
\end{array}$ & & & & & & & \\
\hline 15-May & & & & & & & $\begin{array}{l}\text { CPT Install } \\
\text { (2 day) }\end{array}$ & & & \\
\hline 19-May & & & & & & & & & & Install/Inject \\
\hline 20-May & & & $\begin{array}{l}\text { Install Nest } \\
\text { (2 day) }\end{array}$ & & & $\begin{array}{l}\text { Set up/Read } \\
\text { (3 day) }\end{array}$ & & & & \\
\hline 23-May & & & $\begin{array}{l}\text { Read- } \\
\text { continuously }\end{array}$ & $\begin{array}{l}\text { Setup/Read } \\
\text { (3 day) }\end{array}$ & & & & & & \\
\hline 25-May & & & & & & & Set/Read & & & \\
\hline 26-May & & & & & Set/Read & & Read & & & \\
\hline 30-May & & & & & Read & & & & Sample & Core (S-1) \\
\hline 31-May & & & & & Read & & & & Samples & Core (S-1) \\
\hline 01-Jun & $1^{\text {st }}$ Leak & & & Read & & & & & & \\
\hline 02-Jun & & Read 32 & & Read & & & & & & \\
\hline 05-Jun & & & & & & Read (2 day) & & & & \\
\hline 08-Jun & $2^{\text {nd }}$ Leak & Read 8 & & & & & & & & \\
\hline 09-Jun & & Read 24 & & & & & & & & \\
\hline 12-Jun & & & & & & & & & & \\
\hline 13-Jun & & & & & & & Read & & & \\
\hline 14-Jun & & & & Read & & & Read & & & \\
\hline 15-Jun & $3^{\text {rd }}$ Leak & Read 8 & & Read & & & & & & \\
\hline 16-Jun & & Read 24 & & Read & & & & & & \\
\hline 19 Jun & & & & & $\begin{array}{l}\text { Read } \\
\text { (6 day) }\end{array}$ & & & & & \\
\hline
\end{tabular}


Table 2.2 (Contd)

\begin{tabular}{|c|c|c|c|c|c|c|c|c|c|c|}
\hline \begin{tabular}{|l|} 
Date \\
2000 \\
\end{tabular} & \begin{tabular}{|l} 
Action \\
Item \\
\end{tabular} & $\begin{array}{l}\text { Method } 1 \\
\text { Neutron } \\
\end{array}$ & $\begin{array}{l}\text { Method } 2 \\
\text { AT Tens. }\end{array}$ & $\begin{array}{c}\text { Method } 3 \\
\text { ERT } \\
\end{array}$ & \begin{tabular}{|c|} 
Method 4 \\
HRR \\
\end{tabular} & $\begin{array}{c}\text { Method } 5 \\
\text { EMI }\end{array}$ & $\begin{array}{c}\text { Method } 6 \\
\text { XB Radar } \\
\end{array}$ & \begin{tabular}{|c|} 
Method 7 \\
XB Seismic \\
\end{tabular} & $\begin{array}{c}\text { Method } 8 \\
\text { Isotopes }\end{array}$ & $\begin{array}{c}\text { Method } 9 \\
\text { Coring } \\
\end{array}$ \\
\hline 21-Jun & & & & & & & & & & \\
\hline 22-Jun & $4^{\text {th }}$ Leak & Read 8 & & & & & & & & \\
\hline 23-Jun & & Read 24 & & & & & & & & \\
\hline 24-Jun & & & & & & & & & & \\
\hline 28-Jun & $5^{\text {th }}$ Leak & Read 8/Fire & & & & & Read & & & \\
\hline 06-Jul & & & & & & & & & Samples & Core (S-2) \\
\hline 07-Jul & Post Leak & Read 32 & & & & & $\begin{array}{l}\text { Read } \\
\text { (2 day) }\end{array}$ & & Samples & Core (S-2) \\
\hline 10-Jul & & & & $\begin{array}{l}\text { Read } \\
\text { (2 day) }\end{array}$ & & & & & Samples & Core $(\mathrm{S}-3)$ \\
\hline 13-Jul & & & & & & \begin{tabular}{|l} 
Read \\
(2 day)
\end{tabular} & & & & \\
\hline 14-Jul & & & & & & Read & & & & \\
\hline 17-Jul & & Read 32 & & & & & & & & \\
\hline 21-Jul & & & & & & & & & Samples & CPT (WL1) \\
\hline 31-Jul & & Read 32 & & & & & & & & \\
\hline 1-Aug & & & & & & & & \begin{tabular}{|l} 
Read \\
(2 day)
\end{tabular} & & \\
\hline 11-Sep & & & & & & & & & Samples & CPT (WL2) \\
\hline 12-Sep & & & & & & & & & Samples & CPT (WL2) \\
\hline 15-Sep & & & \begin{tabular}{|l} 
CPT \\
$(2 \mathrm{ATs})$ \\
\end{tabular} & & & & & & & \\
\hline 18-Sep & Pulse & \begin{tabular}{|l} 
Read \\
(5 day)
\end{tabular} & \begin{tabular}{|l} 
Read \\
(5 day)
\end{tabular} & & & & & & & \\
\hline
\end{tabular}


On that day, a wildfire burned within about $0.5 \mathrm{~km}(0.3$ mile $)$ of the test site. After the injection, the Hanford Site was closed to traffic because of the fire, so no neutron logging occurred at the test site on July 7, 2000. Two more readings of the 32 wells were completed during July 2000. One additional 4000L (1057-gal) injection was made on September 18, 2000. This injection was made to obtain in situ hydrologic properties using a combination of pressure measurements and neutron-probe water-content measurements at the same depth. Only limited water-content measurements were made at a few selected locations, and no other geophysical measurements were made after the September injection. Details of the neutron-probe logging are provided in a companion report ${ }^{(\mathrm{a})}$ found on the VZTFS web page.

\subsection{FY 2001 Test Activities}

Both the original experiment (Sisson and Lu 1984) and the FY 2000 tests showed considerable lateral spreading of the plume in relatively uniform sandy sediments. Water movement and chemical transport through the Hanford sediments appeared to be controlled by thin layers of fine-textured soils that impeded vertical water movement and accelerated horizontal chemical transport. In Hanford sediments, these finetextured regions are often relatively thin, pinched lenses generally about $10 \mathrm{~cm}(3.9 \mathrm{in}$.) or less in thickness, and 1 to $5 \mathrm{~m}$ (3.28 to $16.4 \mathrm{ft}$ ) in length. Therefore, characterization methods designed to describe flow and transport for a chosen site may be required to map thin fine-textured soil features in three-dimensions to accurately model chemical transport. For such features to be seen, geophysical methods were selected based on their potential to measure lithological changes to within $10 \mathrm{~cm}$ (3.9 in.) vertically and $100 \mathrm{~cm}$ (39.4 in.) horizontally. Once the lithology is completely mapped, unsaturated hydraulic properties can be determined for at least a representative set of the units. In FY 2001, more emphasis was placed on the units with lower permeability since these units appeared to control water movement during the FY 2000 test.

All of the vadose-zone transport tests at Hanford prior to FY 2001 focused on relatively low concentrations of solutes and tracers. These tests were justified in that they allow determination of the physics of flow and transport and identification of the main processes without too many complications. Studies before FY 2001, however, did not address the significance of density-concentration, viscosityconcentration, or surface tension-concentration relationships and their impact on transport. It has been recognized for some time that high-level waste tank fluids are not similar in either physical or chemical character to that of pure water. Because of their unique properties (e.g., high density, viscosity, and surface tension), the leaking fluids could possibly move deeper and faster than water when subjected to the same surface and boundary conditions in a similar porous medium. Nevertheless, most transport experimental and numerical transport studies at Hanford have assumed that free convection due to density of the solute is negligible relative to the forced advection resulting from hydraulic gradients and dispersion (Ward et al. 1997).

Recent work by Ward et al. (1997) suggests that the assumption of negligible effects of fluid properties, while valid for contaminant plumes of low concentrations, is probably not correct for highconcentration saline waste disposed of at Hanford. The observed deep movement of contaminants under leaking tanks could be in part the result of the fluid properties of the leak effluent as well as other geochemical characteristics such as those documented by McKinley et al. (2001). For this reason, when tank leaks at the Hanford Site SX tank farm were simulated by Ward et al. (1997), the unique properties

(a) Ward and Caldwell 2000. 
of high (1.4) fluid density and elevated (>1) viscosity were considered. The simulations indicated that dense fluids moving through coarse gravel layers, in the presence of non-uniform water fluxes (e.g., from meteoric water shedding off buried tank surfaces), can give rise to accelerated transport due to fingering (i.e., movement of fluids in narrow channels or rivulets as compared to large-scale movement throughout the entire flow cross-section). More recent studies conducted under EMSP show that elevated surface tensions of tank waste simulants, coupled with vapor-pressure lowering and enhanced flux of water in the vapor phase, can indeed lead to the initiation and persistence of fingers in coarse textured soils. Enhanced vapor flux toward the finger can increase the resident moisture content of the finger by more than $30 \%$, with an associated increase in penetration depth.

Inorganic solutes can increase the density $\left(\rho_{\mathrm{w}}\right)$ and the dynamic viscosity $(\eta)$, and, with the exception of a few salts $\left(\mathrm{H}_{4} \mathrm{OH}, \mathrm{HNO}_{3}, \mathrm{HCl}\right)$, they will also increase the surface tension $\left(\gamma_{\mathrm{sol}}\right)$ of aqueous solutions. In general, inorganic salts increase $\gamma_{\text {sol }}$ by $1.2 \mathrm{mN} \mathrm{m}^{-1}$ per unit increase in normality (Weast 1986). However, this effect has not always been detected in field soils because soil organic matter and humic acids in the root zone can reduce $\gamma_{\text {sol }}$ to less than $72 \mathrm{mN} \mathrm{m}^{-1}$ and the surface tension of pure water $\left(\gamma_{\mathrm{w}}\right)$ at $25^{\circ} \mathrm{C}$ (Tschapek et al. 1978). In subsurface soils and soils lacking organic matter, Tschapek et al. (1978) found $\gamma_{\text {sol }}$ and $\gamma_{\mathrm{w}}$ to be almost identical, leading them to conclude that $\gamma_{\mathrm{sol}}$ is independent of salt content. While this may be true for cultivated soils in which salt concentrations are typically kept low, it may not be true for soils exposed to saline radioactive brines.

At Hanford, Reduction Oxidation (REDOX) wastes were typically hypersaline ([NaNO$\left.\left.{ }_{3}\right] \geq 10 \mathrm{~N}\right)$, caustic ( $\mathrm{pH} \geq 14)$, dense $\left(\rho_{\mathrm{L}} \geq 1.4 \mathrm{~g} \mathrm{~cm}^{-3}\right)$, viscous $(\eta \geq 1.2 \mathrm{cP})$, and elevated in surface tension $\left(\gamma_{\mathrm{LV}} \geq 85 \mathrm{mN} \mathrm{m}^{-1}\right)$. Such changes in fluid properties have the potential to influence capillary-flow phenomena, soil-water retention characteristics, and, ultimately, infiltration and transport processes in the vadose zone. However, the effect of concentrated aqueous electrolytic solutions, or hypersaline fluids, on capillary flow phenomena and wettability in unsaturated porous media is still mostly unknown. Much of what is known about the effects of fluid properties on transport is based on studies performed in saturated media. In general, these studies suggest that a viscous fluid displacing a less viscous fluid (favorable viscosity ratio) tends to suppress the effect of heterogeneities and results in a more uniform displacement (Krupp and Elrick 1968). Others have observed the development of displacing fluid fingers when the displacing fluid is less viscous than the resident fluid. Such fingers are accelerated through the medium, bypassing the liquid originally present. Conversely, an unfavorable density ratio (denser fluid displacing a less dense fluid) usually causes gravity fingering, while a favorable density ratio tends to suppress dispersive mixing to produce a more uniform displacement.

The fingering of waste-leak fluids in Hanford sediments has not been observed directly in the field, but is the subject of an ongoing Environmental Management Science Program (EMSP) study currently underway (Ward et al. 1997). This study of the rapid migration of radionuclides (from high-level waste tanks) is focused on understanding the effect of fluid properties on transport in unsaturated porous media using a series of laboratory experiments and field studies. Preliminary results with $5 \mathrm{M} \mathrm{NaNO}_{3}$ plumes suggest that fluid properties can alter the shape of the wetting front through a combination of effects due to elevated surface tension, density, and enhanced vapor flux in response to the osmotic gradient. The elevated surface tension also appears to have an effect similar to soil-particle hydrophobicity, leading to an increase in initial wetting angle and preferential flow. The EMSP project has demonstrated through laboratory and field experiments that under certain conditions, the exclusion of these mechanisms could result in inaccurate predictions of water and solute movement in the vadose zone. While density-driven 
transport may be an important phenomenon, it is not known at what depth it might be attenuated due to dilution or heterogeneities. Although there is some speculation that enhanced water-vapor flux due to elevated osmotic gradients may be active at a scale of tens of meters, the impact of such a mechanism is also unknown. Thus, knowledge of the effect of surface tension, density, and viscosity difference on the movement and displacement of liquids in porous media at the field-scale is basic to understanding these more complex problems. The results of this EMSP project strongly influenced the design of the FY 2001 field experiment for the VZTFS to allow the impacts of density, surface tension, and wetting angle on plume shape and distribution to be investigated.

\subsubsection{Pre-Test Laboratory Experiments}

Sodium thiosulfate $\left(\mathrm{Na}_{2} \mathrm{~S}_{2} \mathrm{O}_{3} \cdot 5 \mathrm{H}_{2} \mathrm{O}\right)$, when prepared as a concentrated solution (at $40 \%$ atomic weight), has a specific gravity of nearly 1.4 (Table 2.3 ). When such a dense solution is applied to unsaturated Hanford sediments, the solution moves at rates different from that of water. Preliminary tests were conducted in the laboratory to evaluate the movement of saturated sodium thiosulfate in Hanford sediments. To assist with the design of the field experiment, several laboratory experiments were performed with sodium thiosulfate in Hanford sediments.

Table 2.3. Selected Properties of $\mathrm{Na}_{2} \mathrm{~S}_{2} \mathrm{O}_{3} \cdot 5 \mathrm{H}_{2} \mathrm{O}$ (after Weast 1986)

\begin{tabular}{|c|c|c|c|c||}
\hline wt\% (atomic) & Specific Gravity & $\begin{array}{c}\text { Concentration } \\
(\mathbf{g} / \mathbf{L})\end{array}$ & $\begin{array}{c}\text { Relative } \\
\text { Viscosity }\end{array}$ & $\begin{array}{c}\text { Conductivity } \\
\text { (mmho/cm) }\end{array}$ \\
\hline 0.50 & 1.0041 & 5.0 & 1.010 & 5.7 \\
\hline 4.00 & 1.0333 & 41.3 & 1.088 & 35.6 \\
\hline 8.00 & 1.0673 & 85.2 & 1.197 & 40.2 \\
\hline 16.00 & 1.1385 & 181.8 & 1.534 & 108 \\
\hline 26.00 & 1.2350 & 320.5 & 2.351 & 135 \\
\hline 40.00 & 1.3852 & 553.1 & 5.747 & 118 \\
\hline
\end{tabular}

In a test cell $(28 \mathrm{~cm}$ [11 in.] wide x $23 \mathrm{~cm}$ [9 in.] high x $2 \mathrm{~cm}$ [0.8 in.] thick), $50 \mathrm{~mL}(0.05 \mathrm{qt})$ of a $40 \%$ solution of $\mathrm{Na}_{2} \mathrm{~S}_{2} \mathrm{O}_{3} \cdot 5 \mathrm{H}_{2} \mathrm{O}$, equivalent to $1 \mathrm{~cm}(0.4 \mathrm{in}$.) of fluid height, was applied to a $6-\mathrm{cm}$ (2.4-in.) thick layer of dry Hanford sand and placed over a graded $\left(\mathrm{d}_{50}=1.5 \mathrm{~mm}\right.$ [0.06 in.]) quartz sand layer that was $7 \mathrm{~cm}$ ( $2.8 \mathrm{in}$.) thick. The $\mathrm{Na}_{2} \mathrm{~S}_{2} \mathrm{O}_{3} \cdot 5 \mathrm{H}_{2} \mathrm{O}$ solution was wicked through the Hanford sand and within a few minutes fingered through the quartz sand into an underlying silt layer. After several days, the plume had spread little (e.g., plume diameter was less than $7 \mathrm{~cm}[2.8 \mathrm{in}$.$] ), suggesting that in fine (silt)$ materials, the dense fluid diffuses very slowly. In contrast, when we repeated the same experiment with tap water, $1 \mathrm{~cm}$ (0.4 in.) of tap water wicked into the 6-cm (2.4-in.) layer of dry Hanford sand without penetrating the underlying coarse sand and silt layers. The difference in movement is attributed to differences in solution properties (e.g., density, surface tension, and wetting angle) between saturated sodium thiosulfate and tap water.

Additional laboratory testing demonstrated the difference between the penetration of saturated sodium thiosulfate and water into fine-textured (silt) materials. When a 2-cm (0.8-in.) (100-mL [0.1 qt]) increment of tap water was applied to a 6-cm (2.4-in.) thick Hanford layer of dry sand, the water wicked into the Hanford sand initially, but then fingered through the coarse sand and into an underlying silt layer. Over several weeks, the water diffused out into the silt layer, creating a diffuse halo of water with a 
diameter exceeding $18 \mathrm{~cm}$ (7.1 in.). In contrast, when a similar volume of thiosulfate solution was applied, the fluid fingered into the silt and diffused outward, but left a sharp wetting front even several weeks after the injection.

To further evaluate the effect of fluid properties, a series of experiments using a modified Washburn method (Washburn 1921) was also conducted. Capillary-imbibition experiments were conducted with methanol, assumed to be a perfectly wetting fluid with a contact angle $(\alpha)$ of zero, deionized water, and a $40 \%$ solution of $\mathrm{Na}_{2} \mathrm{~S}_{2} \mathrm{O}_{3} \cdot 5 \mathrm{H}_{2} \mathrm{O}$ in Hanford sand. Results from these tests show a dramatic difference in the wetting properties of the three liquids, which translates into a higher advancing contact angle for concentrated electrolytes.

These bench-scale tests illustrated that saturated sodium thiosulfate behaves quite differently than water when injected into the Hanford formation sediments. The tests suggest that for the field-scale tests, there was a relatively high probability that the thiosulfate would move more rapidly through coarse sand layers, but it may be retarded in the fine sands or silts. These laboratory observations were confirmed by field observations as discussed later in Sections 3.0 and 4.0 of this report.

\subsubsection{Fluid Injections}

The fluid injections and monitoring activities for FY 2001 are listed in Table 2.3. The injections totaled 18,925 L (5000 gal) of saline solution followed by 11,355 L (3000 gal) of Columbian River water. The injections were started on March 30, 2001. The saline fluid was applied at a rate of $5 \mathrm{~L}$ per min (1.4 gpm) such that there was a total of 1892 L (500 gal) applied each day, 2 days each week, for 5 weeks. One week after the saline fluid injections were completed, Columbia River water was applied in three increments of $3785 \mathrm{~L}$ (1000 gal) each over a 2-week period. The water was applied to simulate the effects of a water-line leak and its impact on a subsurface contaminant plume at a tank farm. Table 2.3 shows the sequence of applications and the monitoring schedule related to the applications.

Selected properties of the injected sodium thiosulfate pentahydrate $\left(\mathrm{Na}_{2} \mathrm{~S}_{2} \mathrm{O}_{3} \cdot 5 \mathrm{H}_{2} \mathrm{O}\right)$ solution at various concentrations are listed in Table 2.4. The tabulated data suggest that concentrated sodium thiosulfate has similar characteristics to leaked tank waste since the thiosulfate solution has high density, electrical conductivity, and viscosity, values that are similar to tank-waste solutions.

As indicated in the schedule (Table 2.3), the FY 2001 test included the following:

- Ten injections of 1892-L (500-gal) increments over a 5-week period of a saturated sodium thiosulfate.

- Tracer applications of sodium chloride $(0.5 \%)$ during the first 10 injections.

- Three injections of $3785 \mathrm{~L}$ (1000 gal) each of river water after brine injection.

- Geophysical logging of water content; water potential, resistivity; dielectric properties.

- Monitoring for soil-solution concentrations using soil cores and pore-water samples.

Geophysical logging included monitoring with a neutron probe, ERT, HRR, XBR, and seismic methods for plume and lithologic delineation. EMI was not tested in FY 2001. In FY 2001, core samples were taken to depths of $18 \mathrm{~m}(60 \mathrm{ft})$, at ten locations. This was in addition to the six locations that were 
sampled in FY 2000. Figure 2.5 shows the locations of all of the wireline samples that were taken over the course of the 2-yr testing (FY 2000 and FY 2001).

Figure 2.5 can be compared to Figure 2.4 and illustrates the additional 13 wireline samples that were taken in addition to the three auger drillings taken in FY 2000. For additional detail, see Last et al. (2001). The additional cores were taken from the added holes shown in the figure, showing what additional sampling was done in FY 2001. The data were analyzed to evaluate the capability of the sensor arrays to adequately monitor the migration of the wetting fronts from the leaks and to track the spread of the tracer plume as a function of the site geology and hydrologic characteristics. This analysis is described in Sections 3.0 and 4.0 of this report. 
Table 2.4. Schedule for FY 2001 Experiment

\begin{tabular}{|c|c|c|c|c|c|c|c|c|c|}
\hline $\begin{array}{l}\text { Date } \\
2001\end{array}$ & $\begin{array}{l}\text { Action } \\
\text { Item }\end{array}$ & \begin{tabular}{|l} 
Method 1 \\
Neutron
\end{tabular} & \begin{tabular}{|l|} 
Method 2 \\
AT Tens. \\
\end{tabular} & $\begin{array}{c}\text { Method 3 } \\
\text { ERT }\end{array}$ & \begin{tabular}{|c|} 
Method 4 \\
HRR
\end{tabular} & \begin{tabular}{|l|} 
Method 6 \\
XB Radar \\
\end{tabular} & \begin{tabular}{|c|} 
Method 7 \\
Seismic \\
\end{tabular} & \begin{tabular}{|c|} 
Method 8 \\
Isotopes
\end{tabular} & $\begin{array}{c}\text { Method } 9 \\
\text { Coring } \\
\end{array}$ \\
\hline Mar 12 & Walkdown & & & & & & & & \\
\hline Mar 21 & $\begin{array}{l}\text { Pre-Job } \\
\text { Safety } \\
\text { Meeting }\end{array}$ & & & & & & & & \\
\hline Mar 22 & \begin{tabular}{|l|} 
Start \\
Pre-Inject \\
Monitor \\
\end{tabular} & $\begin{array}{l}\text { Read } 20 \\
\text { (cross- } \\
\text { calibrate) }\end{array}$ & & $\begin{array}{l}\text { CPT } \\
\text { Install } \\
(1 \text { day }) \\
\end{array}$ & & & & & \\
\hline Mar 23 & & Read 12 & & $\begin{array}{l}\text { Read } \\
\text { (3 days) }\end{array}$ & & & & Samples & $\begin{array}{l}\text { CPT-wire } \\
\text { (2 holes) }\end{array}$ \\
\hline Mar 26 & & & Read-cont. & & & $\begin{array}{l}\text { Read } \\
(2 \text { days })\end{array}$ & & & \\
\hline Mar 27 & & & & & $\begin{array}{l}\text { Read } \\
\text { (2 days) }\end{array}$ & & & & \\
\hline Mar 29 & $\begin{array}{l}\text { Start Inject - } \\
\text { Shutdown }\end{array}$ & & & & & & & & \\
\hline Mar 30 & $\begin{array}{l}1^{\text {st }} \text { Leak } \\
(1321 \mathrm{~L})\end{array}$ & $\begin{array}{l}\text { Read } 32 \\
(2 \text { days }) \\
\end{array}$ & & $\begin{array}{l}\text { (2 days) } \\
\text { set } / \text { read }\end{array}$ & $\begin{array}{l}\text { (3 days) } \\
\text { set/read }\end{array}$ & $\begin{array}{l}\text { (2 days) } \\
\text { set /read }\end{array}$ & & & \\
\hline Apr 3 & $\begin{array}{l}2^{\text {nd }} \text { Leak } \\
(1321 \mathrm{~L})\end{array}$ & \begin{tabular}{|l}
$\begin{array}{l}\text { Read } \\
\text { (select) }\end{array}$ \\
\end{tabular} & & & & & & & \\
\hline Apr 4 & $\begin{array}{l}3^{\text {rd }} \text { Leak } \\
(1321 \mathrm{~L})\end{array}$ & \begin{tabular}{|l}
$\begin{array}{l}\text { Read } \\
\text { (select) }\end{array}$ \\
\end{tabular} & & & & & & & \\
\hline Apr 5 & $\begin{array}{l}4^{\text {th }} \text { Leak } \\
(1321 \mathrm{~L})\end{array}$ & $\begin{array}{l}\text { Read } 32 \\
(2 \text { days })\end{array}$ & & & & & & & \\
\hline Apr 11 & $\begin{array}{l}5^{\text {th }} \text { Leak } \\
(1321 \mathrm{~L})\end{array}$ & $\begin{array}{l}\text { Read } \\
\text { (select) }\end{array}$ & & & & & & & \\
\hline Apr 12 & $\begin{array}{l}6^{\text {th }} \text { Leak } \\
(1321 \mathrm{Ll})\end{array}$ & $\begin{array}{l}\text { Read } 32 \\
(2 \text { days }) \\
\end{array}$ & & $\begin{array}{l}\begin{array}{l}\text { Read } \\
\text { (3days) }\end{array} \\
\end{array}$ & & & & & \\
\hline Apr 16 & & & & & & & & Samples & $\begin{array}{l}\text { CPT-wire } \\
(2 \text { holes })\end{array}$ \\
\hline Apr 18 & $\begin{array}{l}7^{\text {th }} \text { Leak } \\
(1321 \mathrm{~L})\end{array}$ & $\begin{array}{l}\text { Read } \\
\text { (select) }\end{array}$ & & & & & & & \\
\hline Apr 19 & $\begin{array}{l}8^{\text {th }} \text { Leak } \\
(1321 \mathrm{~L})\end{array}$ & $\begin{array}{l}\text { Read } 32 \\
(2 \text { days }) \\
\end{array}$ & & & & $\begin{array}{l}\text { Read } \\
\text { (2 days) }\end{array}$ & & & \\
\hline Apr 25 & $\begin{array}{l}9^{\text {th }} \text { Leak } \\
(1321 \text { L) }\end{array}$ & \begin{tabular}{|l}
$\begin{array}{l}\text { Read } \\
\text { (select) }\end{array}$ \\
\end{tabular} & & & & & & & \\
\hline Apr 26 & $\begin{array}{l}10^{\text {th }} \text { Leak } \\
(1321 \mathrm{~L})\end{array}$ & $\begin{array}{l}\text { Read } 32 \\
(2 \text { days }) \\
\end{array}$ & & & $\begin{array}{l}\text { Read } \\
(3 \text { days })\end{array}$ & & & Samples & \begin{tabular}{|l} 
CPT-wire \\
$(2$ holes $)$
\end{tabular} \\
\hline May 2 & $\begin{array}{l}1^{\text {st }} \text { Chase } \\
(3785 \text { L) }\end{array}$ & $\begin{array}{l}\text { Read } \\
\text { Select }\end{array}$ & & & & & & & \\
\hline May 3 & $\begin{array}{l}2^{\text {nd }} \text { Chase } \\
(3785 \mathrm{~L})\end{array}$ & $\begin{array}{l}\text { Read 32 } \\
(2 \text { days }) \\
\end{array}$ & & & & & & & \\
\hline May 9 & $\begin{array}{l}3^{\text {rd }} \text { Chase } \\
(3785 \text { L) }\end{array}$ & $\begin{array}{l}\text { Read } 32 \\
(2 \text { days })\end{array}$ & & & & & & & \\
\hline May 16 & Post Leak & $\begin{array}{l}\text { Read } 32 \\
(2 \text { days })\end{array}$ & & $\begin{array}{l}\text { Read } \\
2 \text { days }\end{array}$ & & $\begin{array}{l}\text { Read } \\
2 \text { days }\end{array}$ & $\begin{array}{l}\text { Read } \\
2 \text { days }\end{array}$ & & \\
\hline
\end{tabular}




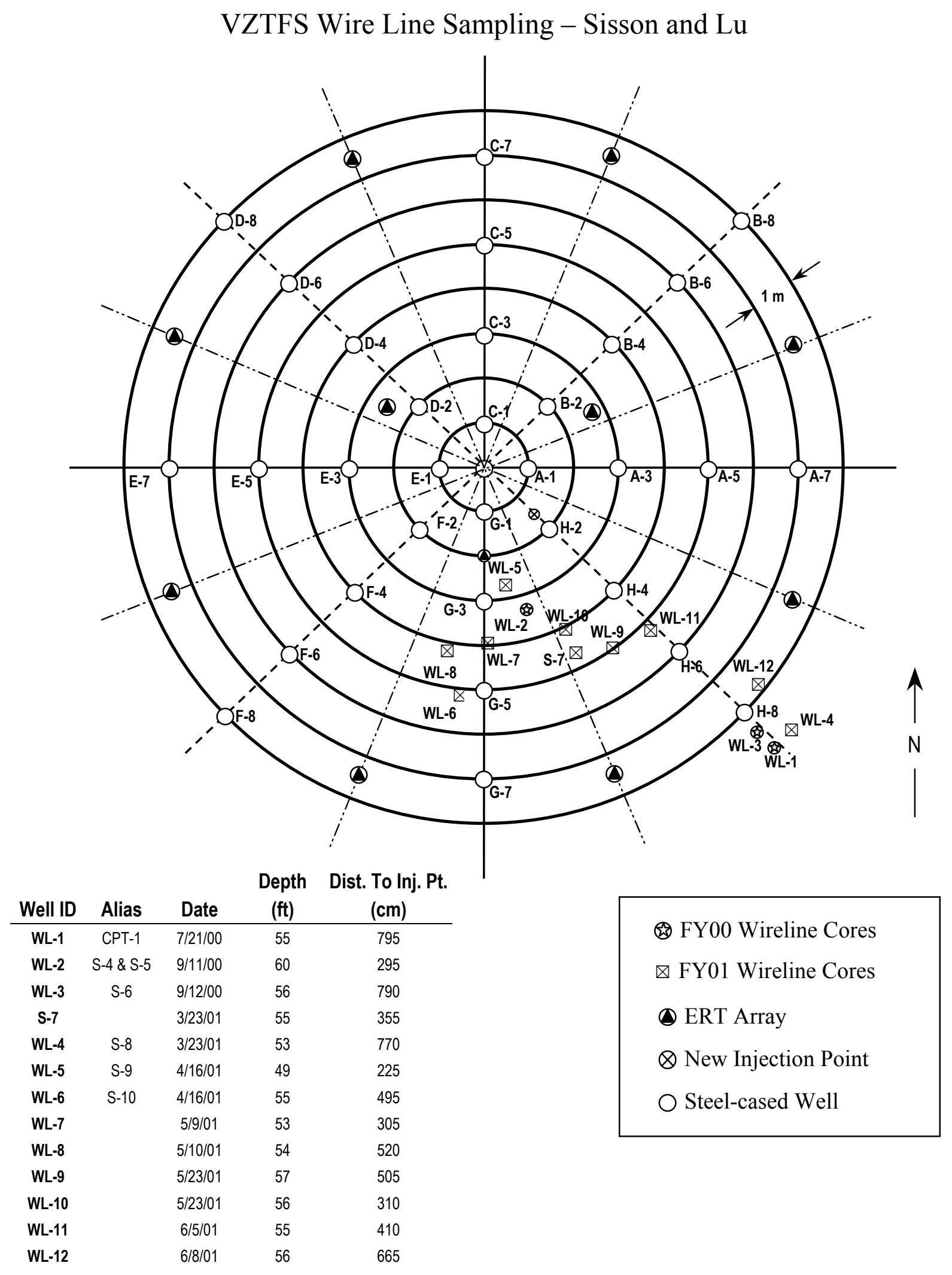

Figure 2.5. Schematic Injection Test Site and Location of Wireline Core Samples 


\subsection{Results}

This section describes the results of the following tests for FY 2000 and FY 2001: neutron probe, tensiometry, electrical resistance tomography, electromagnetic imaging, high-resolution resistivity, crosshole radar, cross-hole seismic, isotope tracer, nonreactive tracer, and coring. Additional details for each of the field-measurement methods are included in the reports identified through web links at the end of each section.

\subsection{Neutron Probe Data Summary}

As documented in this report, part of the focus of the VZTFS has been to monitor the infiltration and redistribution of subsurface injections of 1) water and dilute tracers and 2) a hypersaline fluid (36\% sodium thiosulfate) containing a suite of ionic tracers and develop an accurate database of flow-andtransport measurements. Temporal and spatial distributions of volumetric water-content distributions, $\theta(\mathrm{x}, \mathrm{y}, \mathrm{z}, \mathrm{t})$, were measured by neutron probe in 32 wells $(18 \mathrm{~m}$ [59 ft]deep) arranged in a concentric pattern extending to $16 \mathrm{~m}(52.5 \mathrm{ft})$ in diameter. This section provides a brief status of the interpretation of flow and transport observations made during FY 2001, compares the wetting front and tracer distributions with those observed, and advances some theories to explain the field observations.

A comparison of lithologic logs and neutron-probe data shows a continuous layer of higher moisture content, indicative of a fine-textured layer, between 5.5 and $7.0 \mathrm{~m}$ (18 and $23 \mathrm{ft})$ and sloping upwards in an easterly direction. A similar layer is also observed between 10.5 and $11.5 \mathrm{~m}(34.4$ and $37.7 \mathrm{ft})$. Because these fine-textured regions are underlain by coarser soils, they could very well act as regions of preferential lateral flow until the water-entry pressure of the coarser soils is exceeded. At this point, data analysis has been mostly qualitative. Nevertheless, patterns of subsurface water content and tracer distributions show a clear dependence on textural stratification, which suggests that conceptual and numerical models need to include the fine-textured lenses to adequately predict the lateral migration of water and contaminants.

The method of spatial moments was used to analyze the location of the wetting front during the infiltration of low salt-and hypersaline injections. Differences in the location of the fronts were apparent with the magnitude being dependent on fluid properties. Fine-textured layers at 6 and $11 \mathrm{~m}(20$ and $36 \mathrm{ft})$ increased lateral flow and confined longitudinal penetration to the 12-m (39-ft) depth in FY 2000.

Infiltration and redistribution show similar behavior in FY 2001, except at one location where water was detected at $16 \mathrm{~m}(52.5 \mathrm{ft})$ in the southeast quadrant of the monitoring site. It is uncertain whether the observed preferential flow to $16 \mathrm{~m}(52.5 \mathrm{ft})$ is due to fingering caused by fluid properties, or whether it is due to bypass along an unsealed hole as a result of coring. While there was considerable coring in the area of the observed deep penetration there is indirect evidence from the CPT wireline drilling that the salt penetrations occurred at some distance from the existing boreholes. Details of the neutron probe data

are provided in Section 4.0 of this report and also in the contractor report on neutron probe analysis found on the web at http://vadose.pnl.gov. 


\subsection{Tensiometry Data Summary}

During the FY 2000 and FY 2001 VZTFS field tests, the advanced tensiometer (AT) units were used to monitor soil water pressure at the test site. The tensiometers were installed at depths ranging from 4.5 $\mathrm{m}(15 \mathrm{ft})$ to $12 \mathrm{~m}(40 \mathrm{ft})$ below land surface and at distances up to $8 \mathrm{~m}(26 \mathrm{ft})$ from the point of injection. As indicated in section 2, The tensiometers were placed in stacked profiles near existing steel-cased wells (F2, A3, H2, H4, and H6). The basic features of the tensiometers units deployed in augur holes near wells H2, H4 and H6 can be found in Hubbell and Sisson (1998) and in Gee et al. (2001). Tensiometers deployed by direct push using cone penetrometer technology (CPT) are shown in Figure 3.1.

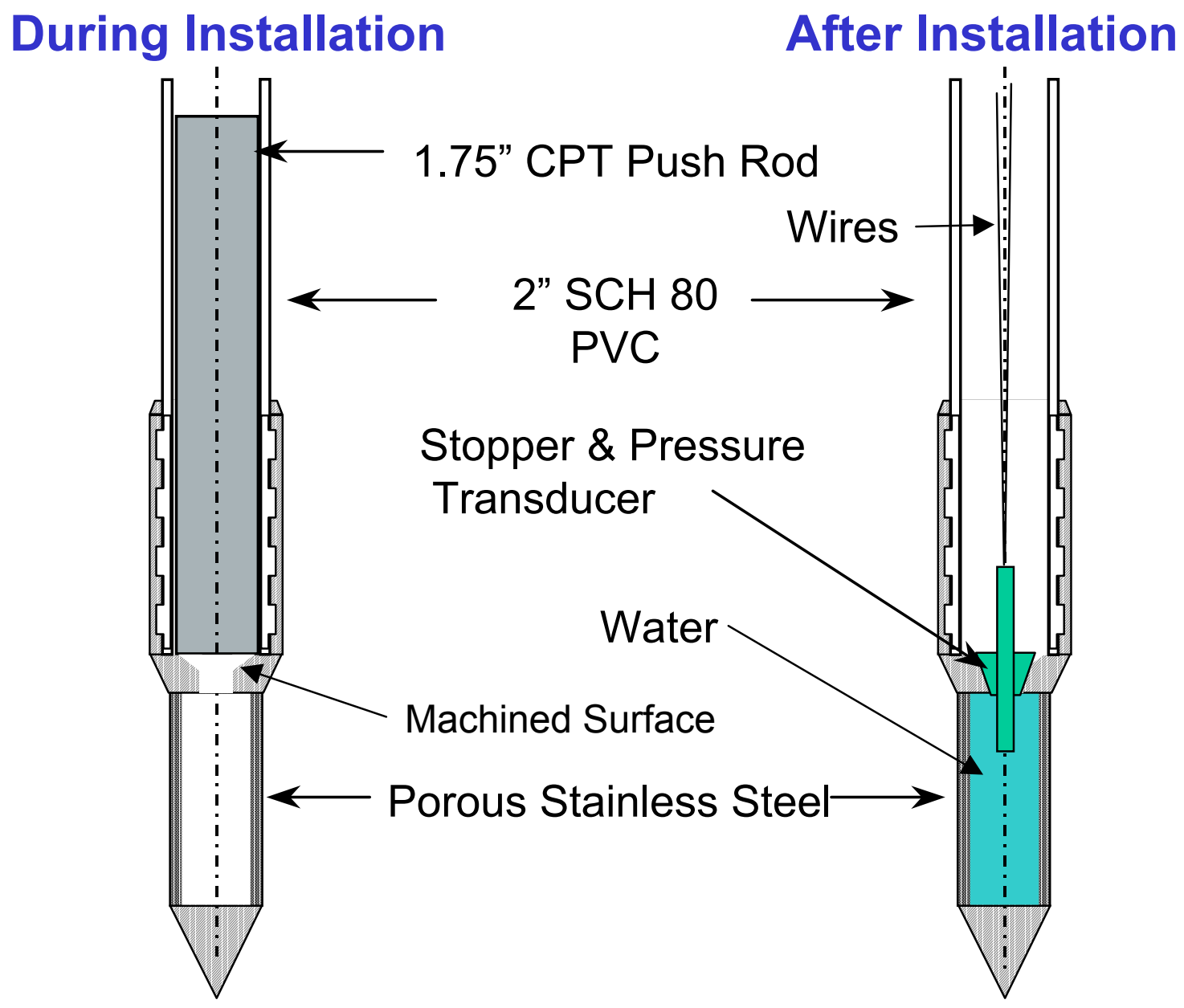

Figure 3.1. Direct Push Tensiometer Design. Cone Penetrometer Technology (CPT) was used to place these units at depth in the sediments at the VZTFS test site.

The pressure values obtained from the tensiometers were used to determine direction and flow of water during the course of the testing. The data in general show that the pressures stayed within the expected range of soil water pressures typical of draining sands. 
The AT proved capable of monitoring soil water-pressure transients throughout the series of injection tests at the VZTFS. Figure 3.2 shows representative data sets of pressures with time during the injection phase of the testing during FY 2000.

\section{Drive cone tensiometers near $\mathrm{A} 3$ and $\mathrm{H} 6$}

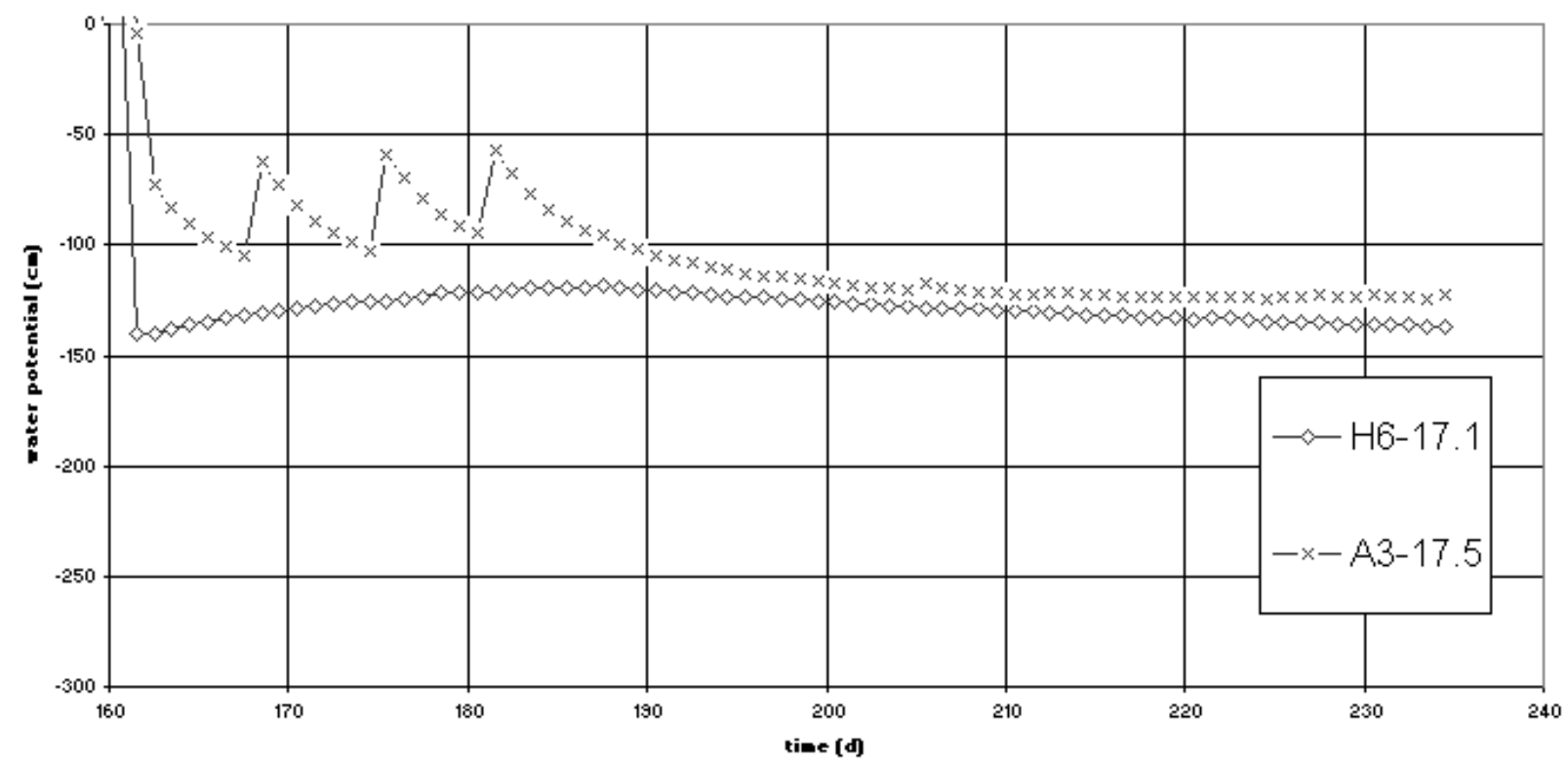

Figure 3.2. Drive Cone Tensiometer Responses During FY 2000 Injections at Locations Near Injection (A3) and Further Away (H6) from Injection Point (see Figure 2.4).

The tensiometer installed within a few feet of the point where water was injected indicated rapid and large changes in soil water pressure as the injections were carried out (see Figure 3.2). While not all tensiometers responded to the injections, the general pattern of response was for the ATs at larger distances from the point of injection to respond more gradually and not to indicate as large a pressure response as those tensiometers situated close to the point of injection.

Soil water pressures continued to be monitored following the FY 2000 injections and through the FY 2001 injections. The soil water pressures found during and following the FY 2001 injections of the $30 \%$ sodium thiosulfate solution responded differently than the nearly pure-water injections of the previous year. The water pressures observed near the point of injections appeared to be about $50 \mathrm{~cm}$ (20 in.) greater when the sodium thiosulfate was injected than when river water was injected. Otherwise, the pressure responses were similar to those seen in FY 2000.

The deployment of ATs at the VSTFS site has provided soil-water-pressure data during highly transient wetting events. While water was being injected into the subsurface, sharp wetting fronts were indicated by an almost vertical rise in pressures. In contrast, following the injections, the water pressures would slowly decay toward their pre-injection values over time periods of several months. The rapid 
wetting and slow drying behavior was expected as a result of the nonlinearity in the Richard's Equation used to model water movement in the vadose zone.

Attempts to establish the relationship between soil water content and pressure based on data collected during the FY 2000 and FY 2001 field tests were unsuccessful because water contents, as measured by the neutron probes, were physically separated from the tensiometers. The distance between the neutronprobe monitoring zones of the tensiometers was several feet or more at all locations. As a result of this separation, the dynamics between the water content and pressure measurements could not be directly compared. For future tests, the physical separation between the water-content sensor and the waterpressure sensor will be shortened to eliminate this problem. A more detailed discussion of the AT results can be found in the contractor report for advanced tensiometers at the web address, http://vadose.pnl.gov.

\subsection{Electrical Resistance Tomography Data Summary}

ERT was used successfully in the VZTFS to produce high-resolution images of the developing plumes. Measurements were made using the steel casings as long electrodes and also using electrodes placed in cone penetrometer (pushed) boreholes. From this work, we can draw conclusions about both the attributes of ERT and about the physical response of the subsurface during the experiment.

Based on initial observations it appears that ERT tomographs and the neutron data show good agreement. The location and general size of the ERT and neutron plumes agree. In FY 2000, a massbalance calculation based on neutron and the ERT data yielded volume estimates (32,180 L [8500 gal]) that are in reasonable agreement with volume released (30,280 L [8000 gal]).

The water transport during the FY 2000 field experiment was largely as expected. A bulbous anomaly formed below the release point, and this anomaly moved to the southeast. Some of the tracer may have been lost to the image block to the southeast, but most was retained inside the image block. Almost all of the tracer volume remained above the 12-m (39.4-ft) depth. The resistivity change tomographs compare reasonably well with neutron differences that show the plume contained above the 12-m (39.4-ft) layer. The initial pore water had a higher electrical conductivity (ionic concentration) than the tracer water in Releases 1 and 2. During the $\mathrm{KBr}$ release, the original pore fluid was largely replaced by the tracer fluid directly below the injection point, but this effect decays rapidly away from the injection point.

During the FY 2001 field experiment, the results from the ERT testing suggested that the sodium thiosulfate solution moved deeper and faster than observed in the FY2000 test for similar amount lowionic strength fluid. When the saline solution was injected, there was less lateral spreading of the plume when compared to plumes of relatively fresh water. Plumes of relatively fresh water did not display evidence of fingering but showed considerable lateral spreading. The tomographs suggest that the highly concentrated brine penetrated the fine-grained layers located at 6- and 12-m (19.7- and 39.4-ft) depths. The relatively fresh water plumes did not penetrate the 12-m (39.4 ft) silt layer (compare observations by the neutron probe in Sections 3.1 and 4.3).

The resistivity change tomographs compare reasonably well with neutron differences that show that most of the brine plume was contained above the 12-m (39.4-ft) layer (Section 3.1). The location and general size of the ERT and neutron results are similar. However, the tomographs suggest that not all of the brine stopped at the 12-m (39.4-ft) depth. A strong, well-developed finger penetrates below the 12-m 
(39.4-ft) layer in the vicinity of boreholes H4 and H6. Neutron surveys taken after all the spills were concluded also indicate a region of increased saturation in this area.

Some of the tomographs suggest that the anomaly associated with the plume gets weaker in the vicinity of the 6- and 12-m (19.7- and 39.4-ft) layers. A possible explanation for this observation is that perched water on top of these fine-grained layers diluted the saline solution, thereby reducing the electrical resistivity changes observed in the tomographs. However, there are other mechanisms that could account for this observation.

Comparing the top two images in Figure 3.3, it is clear that there are significant differences in plume migration when fluids of different ionic strengths are used. The plume's vertical extent is longer for the high ionic strength fluid while the low ionic strength fluid shows more lateral extent. The time required to reach the bottom of the volume shown is shorter for the high ionic strength fluid. Also, discrete, localized, vertical flow paths (fingers) can be observed for the high ionic strength fluid but not for the low ionic strength fluid.

Resistivity changes created by the fresh water injected after the sodium thiosulfate injections suggest that the fresh water formed fingers that follow pathways around the saline plume without penetrating the sodium thiosulfate plume itself. The full report of the ERT analysis for FY 2000 and FY 2001 can be found in the contractor report section of http://vadose.pnl.gov

\subsection{High Resolution Resistivity Data Summary}

During FY 2000 and FY 2001 tests, High Resolution Resistivity (HRR) was used to monitor subsurface plumes and determine their extent and lateral spreading in a situation where electrical methods are tested to the extreme because of unusual site conditions. The Sisson and Lu site is a good example of unusual conditions because of the presence of 32 steel well casings in close proximity ( $2 \mathrm{~m}$ [6.56 ft] apart along eight radials from a central point), each one approximately $18 \mathrm{~m}(60 \mathrm{ft})$ long. The injections (simulated leaks) were located near the middle of the "forest" of vertical conductors. HRR was implemented using non-invasive surface sensors and the existing infrastructure. No additional drilling or special site preparations were required to deploy HRR technology.

As with last year's study, the instrument used for the electrical measurements was an OYO Corp. McOHM-21 (see Figure 3.4). The McOHM-21 is a DC-powered electrical resistivity instrument. Battelle owns the McOHM-21, and use of the instrument and peripherals was kindly authorized by Mr. Mark Sweeney.

HRR proved capable of quantitative volumetric imaging of the water injection in FY 2000 using two completely separate modes of deployment:

- using a two-dimensional array of non-invasive surface sensors for three-dimensional imaging

- using the existing 32-steel-well casing infrastructure as a sensor array for dynamic monitoring and three-dimensional imaging. 
Both deployments resulted in three-dimensional images of the injection suitable for volume calculations. Resultant volume calculations based on HRR measurements were within a few percent of the neutron-probe volume calculations.

\section{Comparison of resistivity changes due to low and high ionic strength fluids}

70 ohm-m fluid displacing 30 ohm-m fluid.

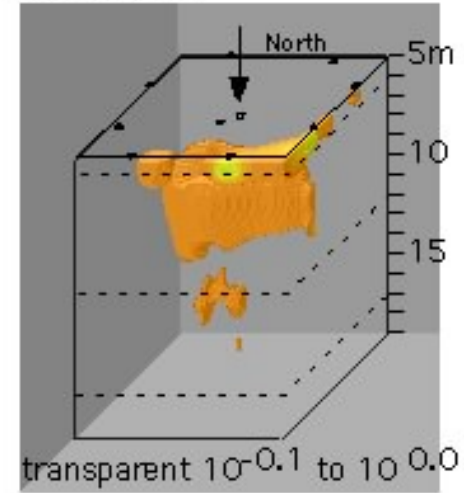

7900 liters fresh riverwater, brine $6 / 14 / 00$
0.3 ohm-m fluid displacing 30 ohm-m fluid.

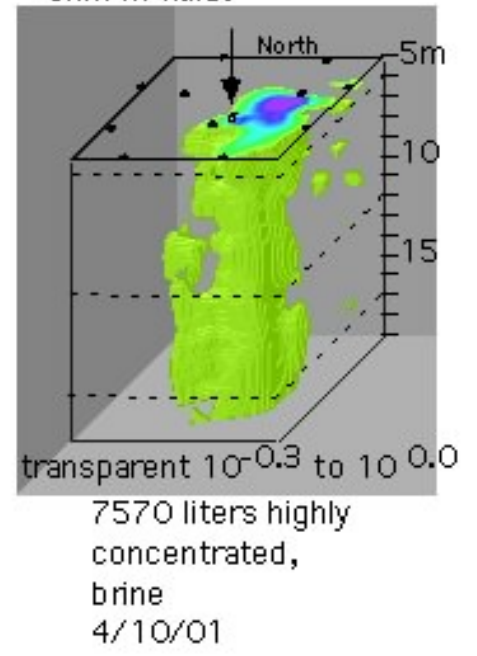

0.3 ohm-m fluid displacing $0.3 \mathrm{ohm}-\mathrm{m}$ fluid.

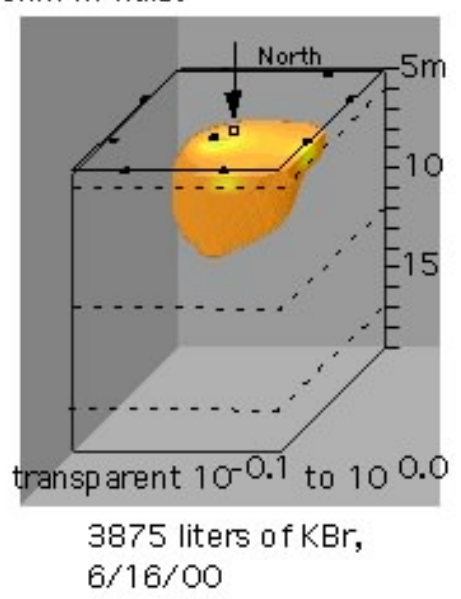

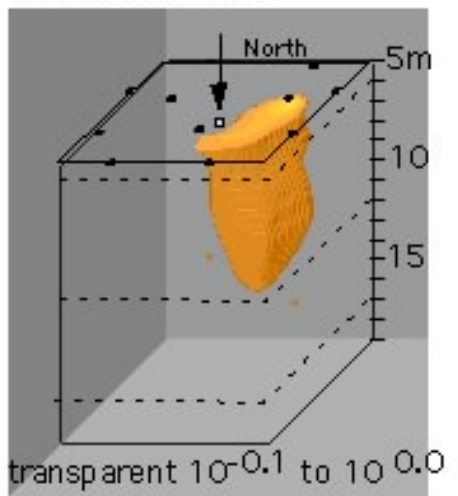

3875 liters of sodium thiosulfate, $4 / 13 / 01$

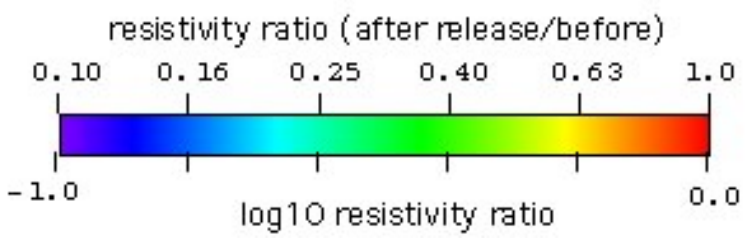

Figure 3.3. Comparison of Tomographs Representing the FY00 and FY01 Spills. The FY00 spills released low ionic strength fluids and the FY01 spills released high ionic strength fluids. 


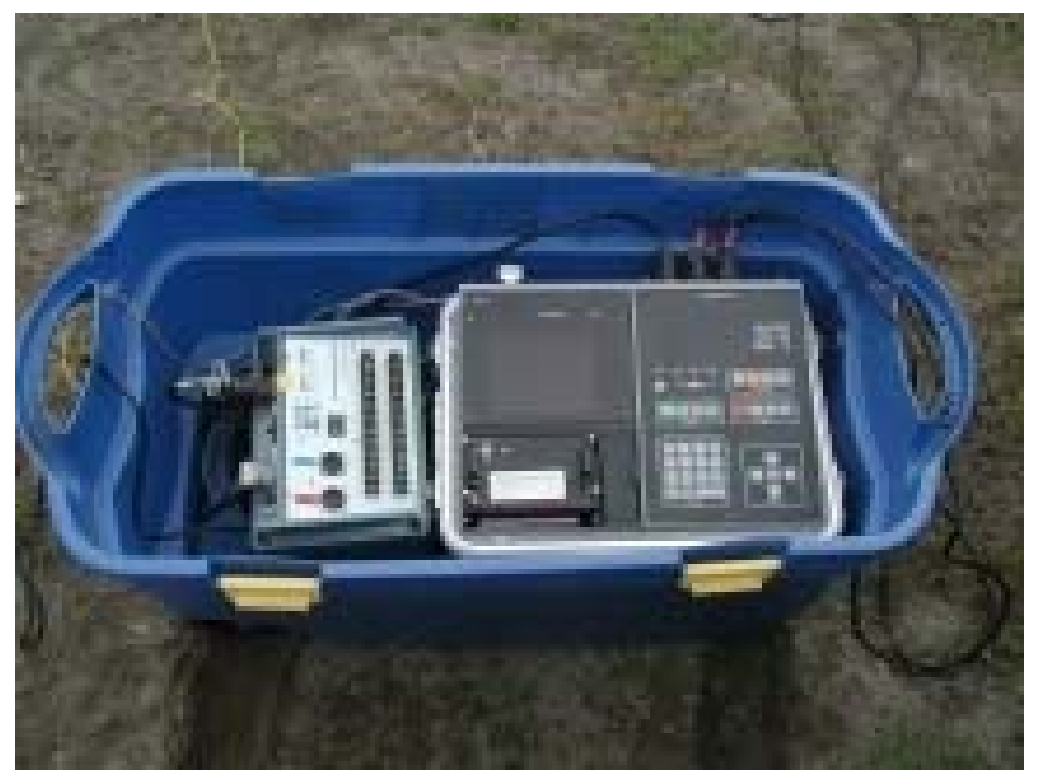

Figure 3.4. McOHM-21 with Transmitter Scanner

Knowledge gained during the FY 2000 field experiment resulted in modifications of the procedures for the FY 2001 study. These modifications allowed improved dynamic monitoring and imaging during the sodium thiosulfate injection.

The FY 2001 test with HRR based nearly all measurements on the existing 32 steel casings. Electrodes were placed at the bottoms of the 32 casings and were physically isolated from the casing walls. In addition, an electrode was placed at the bottom of the PVC injection well in the same manner as was done in the FY 2000 test. The various combinations of electrical grounding for the casings are shown in Figure 3.5. Surface sensors are not shown. The incorporation of the injection-well electrode substantially enhanced the system sensitivity. It has become clear that direct contact with the injected fluids has significant advantages over the more complex and difficult external volume measurements.

Five configurations of electrical measurements were tested (see Figure 3.5).

The following observations can be made:

1. Measurements using steel casings exclusively as sensors provided:

a. positive indication of the existence of the leak, i.e., leak detection

b. coarse quantitative volumetric information about the injection

c. accurate location of the leak source

d. qualitative travel times for the injected solution

e. good lateral resolution of the spread of the solution

f. poor vertical resolution of the spread of the solution. 
2. Measurements using direct electrical contact with the injected solution provided:
a. highly accurate timing of the onset of the leak
b. minimum volume detection limit of one liter
c. qualitative indication of reactivated leaks, as shown by interrupted injections
d. accurate, quantitative travel times for the injected solution
e. quantitative volumetric estimates of the injection
f. precise location of the leak source
g. simple mathematical relationships between injected volume and data.

3. Refinement of data processing algorithms and techniques should reduce calculation time to nearly real-time results.

4. The technology can be implemented non-invasively, although pre-existing invasive structures such as steel well casings can be incorporated and will enhance the results.

5. Deployment of the system is straightforward, requiring only simple electrical connections to appropriately grounded metallic structures.

6. Deployment can be made relatively inexpensively and can be adapted to virtually any onsite conditions.

7. Monitoring may be controlled remotely or made autonomous.

8. Results may be telemetered in real-time to a centralized location.

9. The technology can be deployed using existing infrastructure, although site-specific modifications would enhance the performance

Although HRR shows excellent horizontal resolution (because of the density of the Sisson and Lu well casings), it suffers from the "smearing out" of the vertical resolution along the casings. ERT has much better vertical resolution because the sensors are distributed vertically, but ERT requires expensive, invasive, multiple array installations. Over the years, HRR has been implemented using most commercially available resistivity systems. Two consistent shortcomings of most systems are the lack of adequate channels and autonomous operation. In recent years, a few new systems have been developed that approach a suitable number of channels and that allow autonomous operation. However, the remaining weakness of these newer systems is the inability to measure reliably and repeatedly at low resistance (milli-ohm) levels. An appropriate, purpose-built system should be developed for future deployment, particularly for dynamic monitoring situations.

\subsection{Electromagnetic Imaging Data Summary}

Two electromagnetic techniques were tested as part of the VZTFS during FY 2000 to determine their capability to map fluid flow in the vadose zone. One technique was a purely surface method in which a surface transmitter generated electromagnetic (EM) fields, and the electromagnetic impedance was measured on survey lines over the test site. The second method employed the same surface transmitter but measured the vertical component of the magnetic field in boreholes around the leak site. 


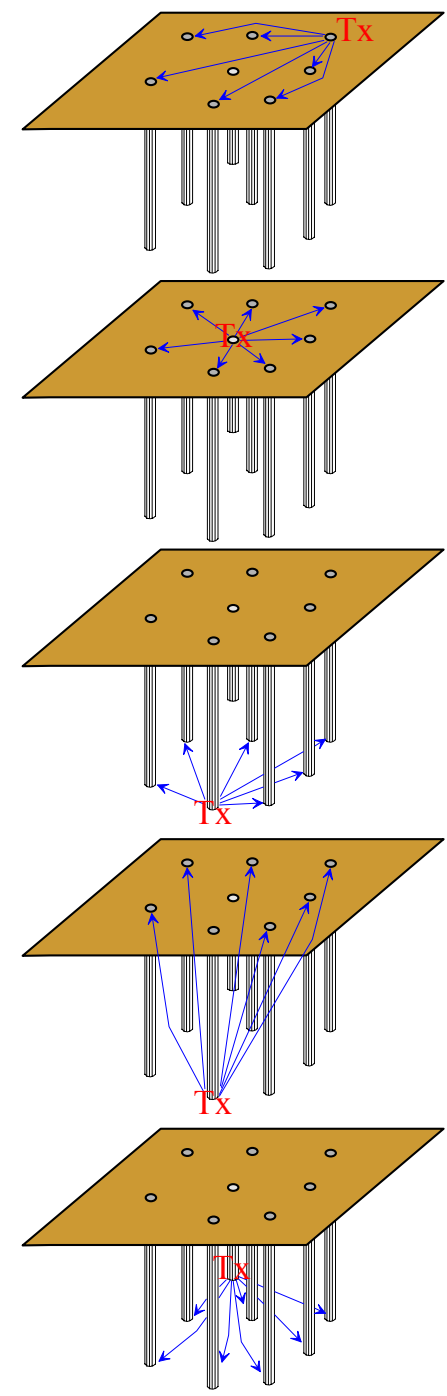

1. Measurements between steel casings. This configuration consisted of electrically energizing an individual steel casing and measuring the resultant potentials on all other steel casings.

2. Measurements between an electrode in the injection well and steel casings. This configuration consisted of electrically energizing the electrode placed at the bottom of the injection well and measuring the resultant potentials on all 32 steel casings.

3. Measurements between fabricated electrodes placed at the bottoms of all casings. This configuration consisted of electrically energizing individual electrodes placed at the bottom of each steel casing and measuring the resultant potentials at all other bottom-hole electrodes.

4. Measurements between the fabricated bottom-hole electrodes and steel casings. This configuration consisted of electrically energizing individual bottom-hole electrodes and measuring the resultant potentials at all the steel casings, other than the one containing the energized electrode.

5. Measurements between the injection-well electrode and bottom-hole electrodes. This configuration consisted of electrically energizing the injection-well electrode and measuring the resultant potentials at all 32 bottom-hole electrodes.

Figure 3.5. Measurements Between Steel Casings (1), an Electrode in the Injection Well and Steel Casings (2), Fabricated Electrodes Placed at the Bottoms of all Casings (3), Fabricated Bottom-Hole Electrodes and Steel Casings (4), and Injection-Well Electrode and BottomHole Electrodes (5)

The surface technique employed a commercial system from EMI, called the "IMAGEM" system, to profile one transect across the site. The transects were measured May 23, 2000, June 5, 2000, and July 13, 2000, using frequencies between $1 \mathrm{KHz}$ and $66 \mathrm{KHz}$. The data quality was generally good.

Between May 23, 2000, and June 5, 2000, there was a general decrease in near surface resistivity and an increase at depth. The increase at depth is puzzling and presently unexplained. However, it is consistent with DC resistivity data collected by the HRR method. Between May 23, 2000, and July 13, 2000, the main difference is a decrease in resistivity centered around Well X3 (Figure 2.4). The depth of the resistivity decrease is greater than observed in the water-content logs but has approximately the correct spatial configuration. 
The surface impedance IMAGEM survey operated at too low a frequency to give detailed images of the upper $15 \mathrm{~m}$ (49 ft). The results suggest that a higher frequency system would be a good tool for nearsurface imaging. The general behavior of the changes in resistivity is consistent with the movement of water downward and outward from the release point over time. In addition, it seems to be consistent with observations made in the surface DC resistivity array. The presence of increased resistivity at depth as a function of time is unexplained.

The second technique tested was surface-to-borehole EM. Observed data quality in the surface-toborehole EM experiment was lower than expected. In retrospect, a more detailed noise analysis should have been done and adjustments made to the data acquisition. The three-dimensional inversions of the data show a conductive plume that occurs at the base of the zone identified as having increased water content based on neutron probes. The plume direction is consistent with the expected transport direction. Ambiguity remains in the interpretation of early time conductivity. Without knowledge of the in situ pore fluid electrical properties at the time of the leaks, it is impossible to forecast whether the bulk conductivity of the ground would increase or decrease during the initial fresh-water injections.

Borehole measurements were also made through steel-cased holes. These measurements showed changes over time as the leak progressed. However, the separation between transmitter and receivers was too small to generate enough electromagnetic induction to be able to resolve the location of conductivity changes that caused the observed data changes. The high background resistivity at Hanford makes it impossible to get sufficient EM induction at typical well separations found at tank storage sites. Therefore, EM imaging through steel cased boreholes is unlikely to be feasible unless the tanks have already leaked sufficiently to cause a significant decrease in the resistivity of the zone between observation wells. Details of the FY 2000 tests with EMI can be found on the contractor report section of http://vadose.pnl.gov.

\subsection{Cross-Borehole Radar Data Summary}

The ground penetrating radar (GPR) measurements for the VZTFS consisted of repeated crossborehole tomographic data sets being collected between the six possible well pairs at the Sisson-Lu site. These include monitoring between the following pairs of wells: X1-X2, X2-X3, X3-X4, X1-X2, X1-X3, and X2-X4 (see Figure 2.5). In FY 2000, a total of four data sets was collected: one prior to injection as a background data set, two during the injections, and one after the injections. In FY 2001, a total of four data-collection visits were also made to the site. These include March 26 to 28, 2001, which constituted the baseline data set, followed by the monitoring of the initial release of $1900 \mathrm{~L}$ (502 gal) of sodium thiosulfate on March 30. The next data set was acquired on April 28 and 29, 2001, after 19,000 L (5019 gal) of sodium thiosulfate had been injected (injection stopped on April 26). The last data set was collected on May 18, 2001, after 3785 L (1000 gal) of a mixture of tank sludge and river water and 7570 L (2000 gal) of Columbia River water had been injected (injection stopped on May 9, 2001). All of the radar data were collected using the Sensors \& Software, Inc. PulseEKKO 100 GPR system using the 200-MHz center frequency antennas. The step size for data collection between all well pairs was $0.125 \mathrm{~m}$ $(0.41 \mathrm{ft})$ in 2000 and $0.25 \mathrm{~m}(0.82 \mathrm{ft})$ in 2001 .

Figure 3.6 shows a cut-away view of the test site and well layout with a conceptual diagram of how flow took place during the last experiments. In the previous experiments, an injection well was placed in the center of the well field and was surrounded by 32 observation wells. The wells were constructed from 
three 20 -ft sections and one 5 -ft section of 6-in.-diameter Schedule 40 steel casing. The sections were welded together to form watertight joints reinforced with four steel straps welded symmetrically around the casing. During installation, the 5-ft section of casing was driven into the soil, and then the 20 - $\mathrm{ft}$ section was welded on and the driving was continued until the top of the casing was beyond the reach of the drive hammer. Soils with the casing (drill cuttings) were removed by advancing $20 \mathrm{ft}$ with a rotary by using air as a drilling fluid. Cuttings were blown out of the casing and collected near the point of drilling. Samples were collected of these cuttings and stored in containers, and selected samples were later analyzed for hydraulic properties (Rockhold et al. 1999). In the present case, the X wells were PVC cased (2-in. I.D.) and emplaced with cone penetrometer technology. The crosswell methods were used to monitor the simulated leak injections of both the 2000 and 2001 injections. In 2000, the injections were in 4000-L increments of Columbia River water over a 6-week period. In 2001, the injections were five increments of approximately 4000-L of sodium thiosulfate over a 5-week period, followed by three 4000-L injections of Columbia River water. In 2000, the crosswell data were combined with the neutron logging results in the steel-cased wells. The measurement focus was to determine the state variables controlling water movement (i.e., water content, physical heterogeneities, and, if possible, water potential, chemical concentrations, and temperature). It was also desired to determine if the density of the fluid would change the flow behavior.

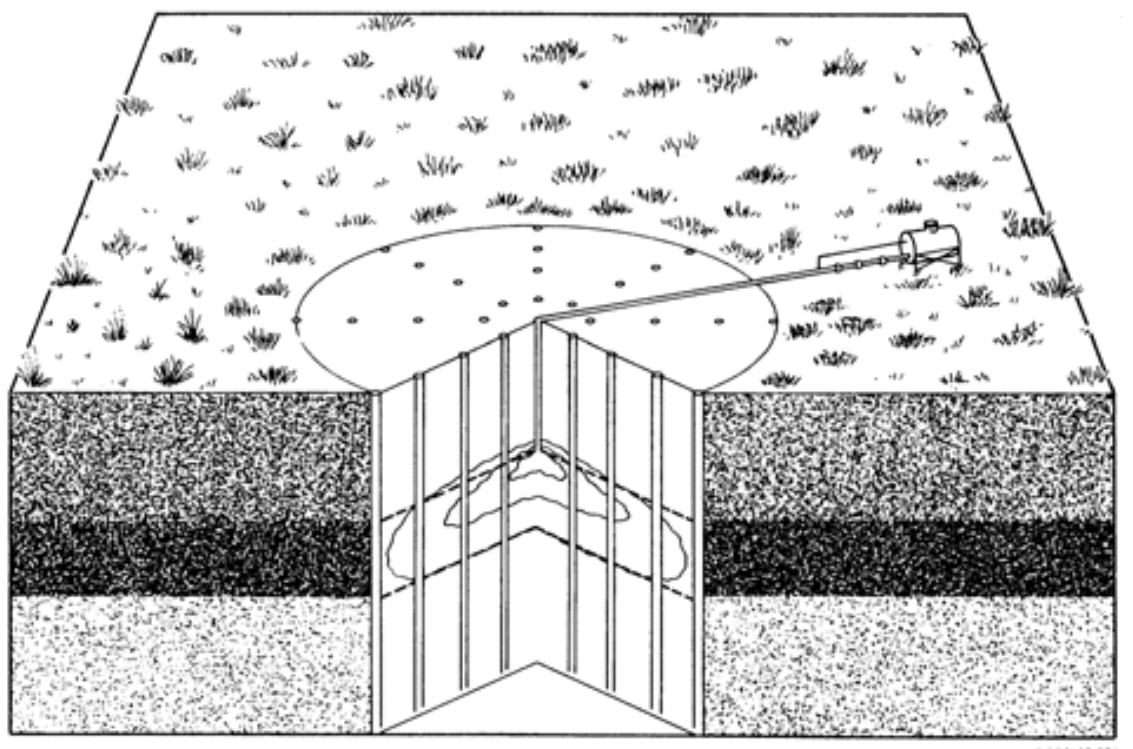

Figure 3.6. Cut-Way View of Test Site Showing Well Layout

When the experiments were designed, it was not known how well this method could penetrate or resolve moisture content and structure. The radar penetrated up to $5 \mathrm{~m}(16.4 \mathrm{ft})$ or even $10 \mathrm{~m} \mathrm{(32.8 \textrm {ft } )}$ between boreholes at $200 \mathrm{MHz}$ and even further (up to 20 or $30 \mathrm{~m}$ [65.6 or $98.4 \mathrm{ft}]$ ), giving high resolution. Because the radar is primarily sensitive to moisture content, taken in a time lapse, it can show the moisture content changes to a high resolution. The radar delineated geological layers 0.25 to $3.5 \mathrm{~m}$ (0.82 to $11.5 \mathrm{ft})$ thick with $0.25-\mathrm{m}(0.82-\mathrm{ft})$ resolution:

- delineated moisture movement and content with $0.25 \mathrm{~m}(0.82 \mathrm{ft})$ resolution

- compared favorably with neutron probe measurements

- penetrated up to $30 \mathrm{~m}(98.4 \mathrm{ft})$. 
Radar results indicate that the transport of the water injection is different from that of the viscous sodium thiosulfate solution. It appears that the heavier fluids are not mixing readily with the in situ fluids, and the transport may be influenced by the density differences. Figure 3.7 shows an example of how the radar tracked the migration of water and the migration of the sodium thiosulfate. This figure shows the changes in the radar signals between wells X1 and X2 for the tests in 2000 and 2001 respectively. Note that in the 2001 case, the heavier, more viscous fluid had a different travel path than the water injected in 2000 . The injection point was approximately $1 \mathrm{~m}(3.3 \mathrm{ft})$ behind the plane of these two wells at $5 \mathrm{~m}(16.4 \mathrm{ft})$ depth, and $1.5 \mathrm{~m}(5 \mathrm{ft})$ from Well X1.

Details of the cross borehole tests can be found in the contractor reports section of http://vadose.pnl.gov.
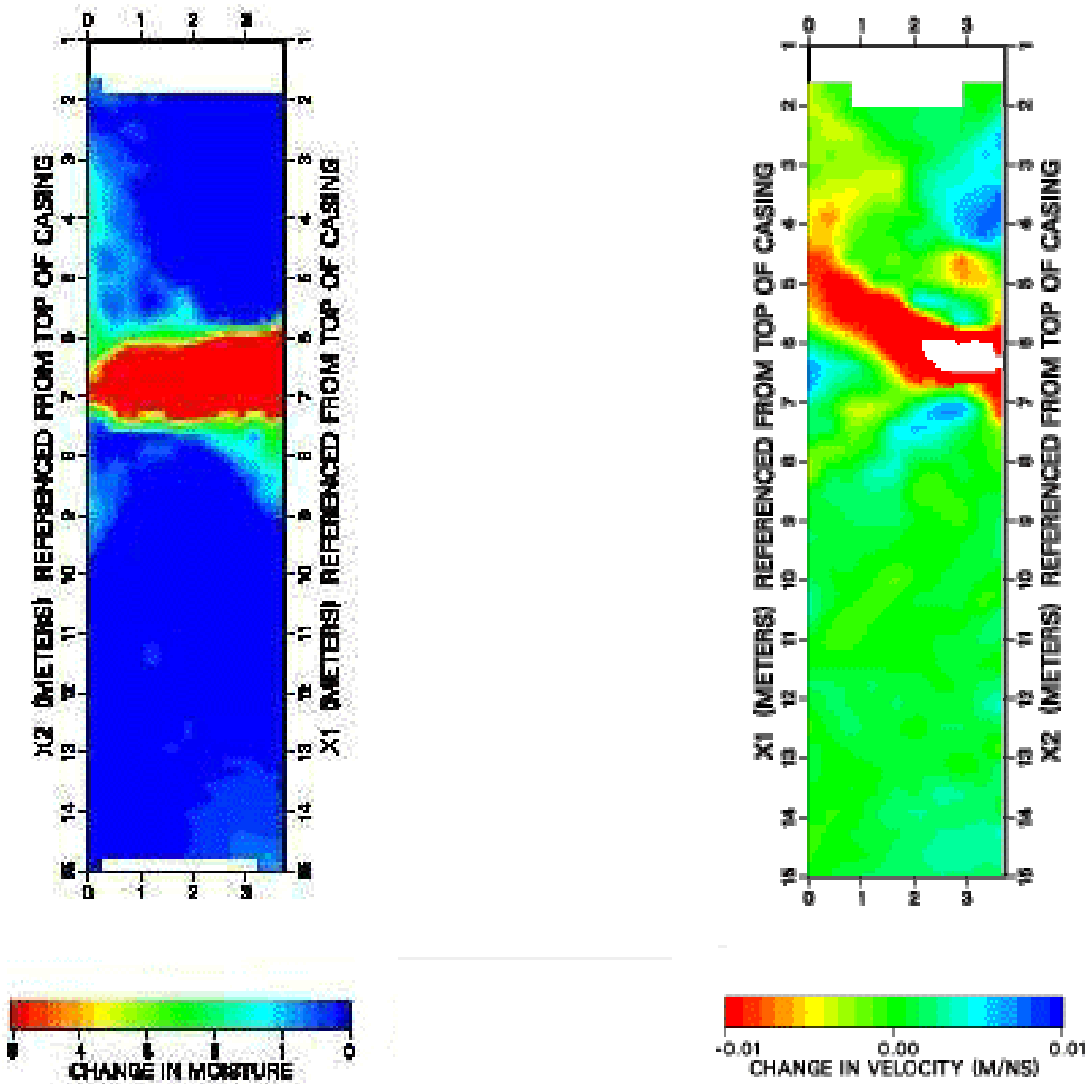

Figure 3.7. Results of Radar Tomography After Approximately 500 Gallons of Water Injection (left side, FY 2000 test) and Sodium Thiosulfate (right side, FY 2001 test) Between Wells X1 and $\mathrm{X} 2$

\subsection{Cross-Borehole Seismic Data Summary}

The cross-borehole seismic data were collected after all of the field-injection tests were completed in both FY 2000 and FY 2001. This was because the wells used for the cross-hole seismic had to be filled 
with water (this would not have to be the case in the tank farm; it just made it easier in this case) to provide good seismic coupling in the small PVC cased wells. Because we did not know if the wells would leak, it was not desirable to have water into the formation during the infiltration tests. Until this experiment, experience by Lawrence Berkeley National Laboratory (LBNL) has shown that it is very difficult to collect high-resolution seismic data (in the kilohertz range) in a vadose zone. This is because partial saturation usually greatly attenuates seismic energy. In fact, until this experiment, to our knowledge, there had been no high-frequency seismic data collected at this scale in any vadose-zone environment. In FY 2000, there were four different seismic crosswell sections obtained, three highresolution sections and one long offset section using a distant $16.24 \mathrm{~cm}$ (6-in.) steel-cased hole for a source hole. The three high-resolution sections were collected by placing a 24-element hydrophone array in Well X4, which was filled with water. A 3.8-cm (1.5-in.) diameter by 10-cm (4-in.) long piezoelectric cylindrical seismic source was then used successively in Wells X3, X2, and X1. In 2001, only the highfrequency crosswell seismic data were collected. The data were collected at $1 / 4-\mathrm{m}(0.83-\mathrm{ft})$ intervals for both source and receiver. The piezoelectric source put out energy from 1 to 10 kilohertz. The long offset section was obtained by leaving the hydrophone array in Well X4 and placing an orbital vibrator source in Well 2E-24-110, which was also filled with water, approximately $19 \mathrm{~m}(62.3 \mathrm{ft})$ away from X4. The purpose of this was to see how far seismic energy could be transmitted in the vadose zone. The orbital vibrator is a much stronger source than the piezoelectric source, but puts out lower frequencies, in the 50to 300-hertz range. Assuming that the resolution is on the order of $1 / 4$ wave length, and the velocities are on the order of $700 \mathrm{~m}(2296.6 \mathrm{ft}) / \mathrm{sec}$ (this is what we measured), then we were obtaining a possible resolution of $10 \mathrm{~cm}(3.9 \mathrm{in}$.) for the piezoelectric data and $60 \mathrm{~cm}(23.6 \mathrm{in}$.) for the orbital source (assuming 300 hertz for the orbital and 2000 hertz for the piezoelectric source).

When the field experiments were designed, it was not known how well this method (as well as radar) could penetrate the vadose zone or resolve the moisture content and structure. The seismic results indicate that at several hundred hertz, the propagation of 20 to $30 \mathrm{~m}$ (65.6 to $98.4 \mathrm{ft}$ ), giving high resolution, is possible. The seismic is primarily sensitive to porosity and can show high-resolution lithology. To date, the seismic delineated lithology at $0.25-\mathrm{m}(0.82-\mathrm{ft})$ resolution:

- penetrates over $20 \mathrm{~m}(65.6 \mathrm{ft})$, with a possibility of up to 30 or more $\mathrm{m}$ (98.4 or more $\mathrm{ft}$ )

- maps porosity and density differences of the sediments.

Overall, the seismic is mapping the porosity and density distribution. The results are consistent with the flow field mapped by the radar; there is a change in flow properties at the 10 - to $11-\mathrm{m}$ (32.8- to $36.1 \mathrm{ft}$ ) depth in the flow cell. There also appears to be breakthrough by looking at the radar data with the denser sodium thiosulfate finally penetrating the barrier, but not the river water. The radar and seismic data imply that the fluid property differences (density, viscosity, surface tension) between the river water and the sodium thiosulfate do make a difference in flow characteristics.

One of the most important results is that together the seismic and radar are complementary in their properties estimation. Detail of the cross-hole seismic study for FY 2000 and FY 2001 are found on the contractor report section of the web page, http://vadose.pnl.gov. 


\subsection{Tracer Data Summary}

\subsubsection{Isotope Tracer Data Summary}

The isotope analyses during both the FY 2000 and FY 2001 field experiments were designed to track the movement of isotopic tracers injected into the subsurface during June of 2000. In FY 2000, the cocktail of non-radioactive isotopic tracers included $2 \mathrm{~kg}$ of $\mathrm{D}_{2} \mathrm{O}, 3 \mathrm{~g}$ of $\mathrm{NaH}^{13} \mathrm{CO}_{3}, 25 \mathrm{mg}$ of ${ }^{87} \mathrm{Sr}, 1 \mathrm{mg}$ of ${ }^{145} \mathrm{Nd}, 1 \mathrm{mg}$ of ${ }^{179} \mathrm{Hf}$, and $3 \mathrm{mg}$ of ${ }^{207} \mathrm{~Pb}$ added to $4000 \mathrm{~L}$ (1057 gal) of water. This solution also contained $1000 \mathrm{ppm}$ of bromide. The tracer solution was the third of five 4000-L (1057-gal) aliquots of water injected at 1-week intervals during June of 2000. To monitor the migration of these tracers through the subsurface, a series of cores were drilled at the site.

During FY 2000, samples from two of those cores (S-2 and S-3) were analyzed. The location of these augured boreholes can be seen in Figure 2.4. These boreholes were drilled approximately $3 \mathrm{~m}$ (9.8 ft) from the injection well about 3 weeks after the tracer solution was injected into the subsurface. During September of 2000, another borehole (WL-2) was drilled approximately $3 \mathrm{~m}(9.8 \mathrm{ft}$ ) from the injection well, but samples from that core were not analyzed until FY 2001. In March of 2001 (approximately 9 months after injection of the tracers), two additional boreholes were drilled and sampled for isotopic analyses just before the FY 2001 field experiment with sodium thiosulfate. One of these boreholes (WL-3A) was drilled approximately $3.5 \mathrm{~m}$ (11.5 ft) from the injection well and the other (WL-4) was drilled approximately $8 \mathrm{~m}(26.2 \mathrm{ft}$ ) away (see Figure 2.5$)$. Samples from four additional boreholes (WL-7, WL-8, WL-9, and WL-10) drilled following the injection of sodium thiosulfate solutions were collected for isotopic analyses. The relative peak concentrations of deuterium and bromide measured for the boreholes drilled before the sodium thiosulfate solution was injected are plotted on Figure 3.8. The bromide concentration is clearly decreasing faster than the deuterium concentration.

The deuterium and bromide data from FY 2000 clearly indicated that most of the tracer solution was spreading laterally between two less-permeable layers located at approximately 7 and $12 \mathrm{~m}$ (23 and $39.4 \mathrm{ft}$ ) below the surface. Peak concentrations were approximately $60 \%$ of the initial composition of the tracer solution $\left(\mathrm{C} / \mathrm{C}_{\mathrm{o}}\right)$. This is significant, given that the tracer solution only represented $20 \%$ of the total water leaked at the site. Further, there was no evidence that the tracer solution mixed with a perched water body developed above the lower less-permeable layer. This was confirmed by oxygen isotope data and geophysical studies that indicated that essentially none of the water released during the tests had mixed with this water. Apparently, each individual aliquot of water was remaining relatively coherent and not mixing with the other water in the subsurface.

There was no evidence of the other isotopic tracers in any of these cores. None of the samples contained isotopic ratios for $\mathrm{Sr}, \mathrm{Nd}$, or $\mathrm{Pb}$ that were outside of the normal background range. The predicted shift in the ${ }^{87} \mathrm{Sr} /{ }^{86} \mathrm{Sr}$ ratio (based on the increase in deuterium and bromide) would have been from $\sim 0.715$ to $>0.79$ (depending on the concentration of $\mathrm{Sr}$ in the pore water). Clearly, these cations were significantly retarded by sorption and exchange with the sediments. 


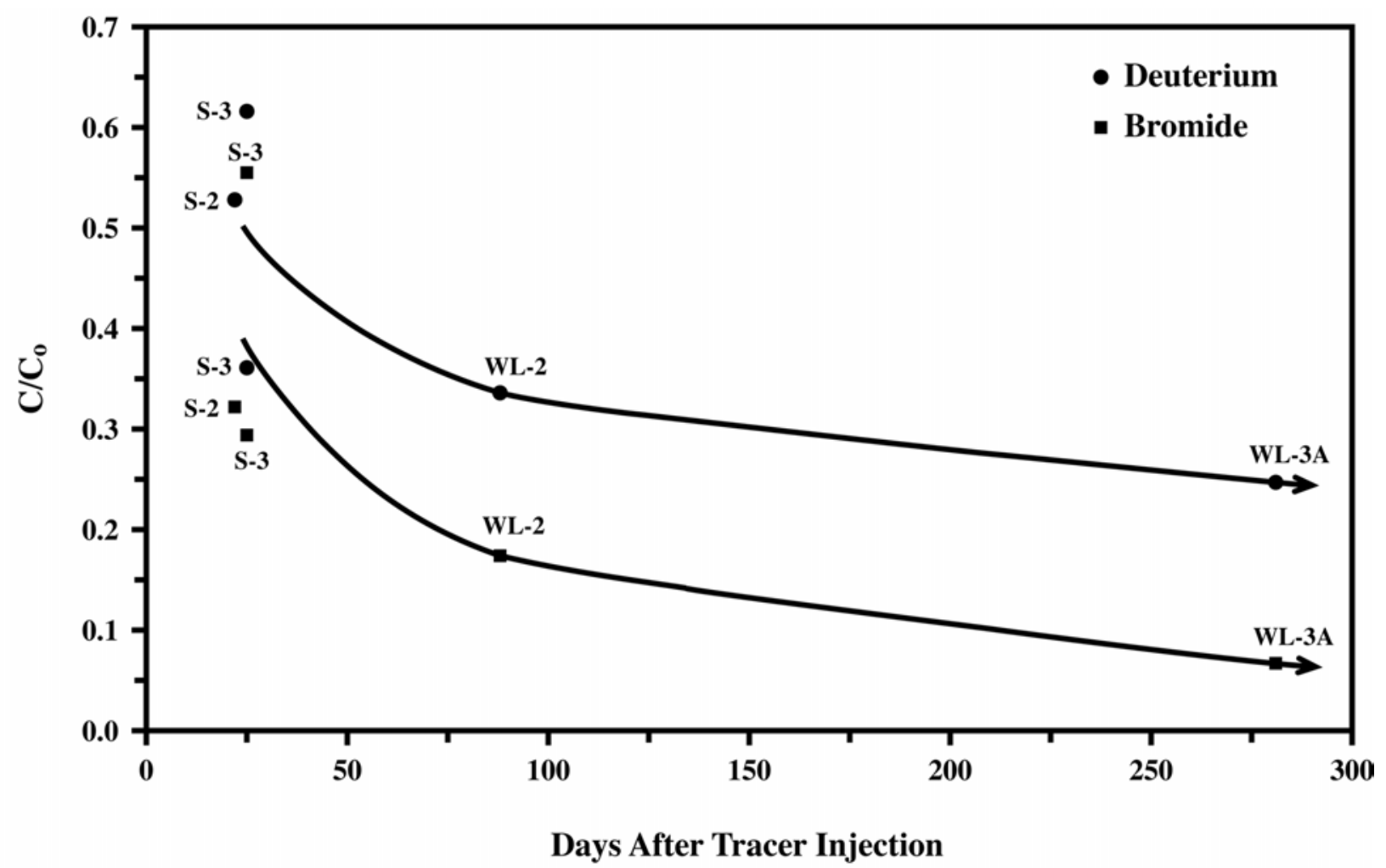

Figure 3.8. Relative Peak Concentrations of Deuterium and Bromide

The results of the isotopic analysis from cores taken in FY 2000 and FY 2002 indicate the following:

- At 3 to $4 \mathrm{~m}$ (9.8 to $13 \mathrm{ft}$ ) lateral distance from the injection well, deuterium and bromide from the tracer cocktail remained confined to a narrow portion of the unsaturated zone between two lesspermeable layers.

- The bromide concentrations in the sediments drop off more rapidly over time than the deuterium concentrations.

- Shifts in the oxygen-isotope ratio of the pore water suggest that the water injected into the subsurface interacted with a larger fraction of the sedimentary column than indicated by the tracer solution alone.

- After 9 months, there was no clear evidence of the strontium in the tracer cocktail, indicating that it is strongly retarded by interaction with the sediments.

- The deuterium signal was still detected (although significantly attenuated) at the same depth in the sediments after injection of a dense, sodium thiosulfate solution during late March through May of 2001.

These data indicate that fluids injected or disposed of into the Hanford sediments have a strong tendency to spread out laterally rather than infiltrate straight down to the water table. There is also strong evidence that the water (tracked by the deuterium) does not travel at the same rate as the dissolved constituents. The use of non-radioactive isotopic tracers as proxies for contaminants of concern at the site (e.g., deuterium for tritium, ${ }^{87} \mathrm{Sr}$ for ${ }^{90} \mathrm{Sr}$ ) clearly represents a powerful tool for understanding the movement of the contaminants in the sediments. 
Analysis of tracer distributions show that multiple peaks were coincident with the finer-textured lenses, emphasizing the need to consider local-scale textural discontinuities in conceptual models of fieldscale transport at the Hanford Site. The complete moment analyses of the water are found in Section 4.3. Details of the neutron-probe calibration, water-content distributions, and ionic tracer profiles are provided in the contractor report section of the web page http://vadose.pnl.gov.

\subsubsection{Nonreactive Tracer Data Summary}

Water extracts from soil cores were analyzed for anions, including $\mathrm{F}^{-}, \mathrm{Cl}^{-}, \mathrm{Br}^{-}, \mathrm{NO}_{3}^{-}, \mathrm{PO}_{4}^{2-}, \mathrm{SO}_{4}^{-}$, and $\mathrm{S}_{2} \mathrm{O}_{3}^{2-}$. Ionic tracer distributions were analyzed using one-dimensional spatial moments. Distributions of resident concentration profiles were generally asymmetric with a large mass occurring at 5 to $7 \mathrm{~m}$ ( 16 to $23 \mathrm{ft}$ ), and a smaller mass at 10 to $12 \mathrm{~m}$ (33 to $39 \mathrm{ft})$ with a preferred flow path to the southeast. At the test site, there are two relatively fine-textured layers, one at about a $6-\mathrm{m}(20-\mathrm{ft})$ depth and one at about the 12-m (39-ft) depth. The locations of multiple peaks were coincident with the general location of finer-textured lenses derived from lithologic logs. The fine sandy sediments in these layers appeared to control the migration of the water in both tests and caused a substantial increase in transverse

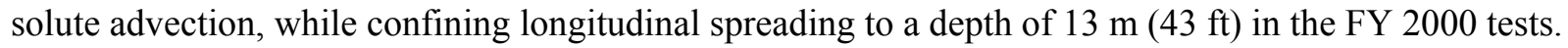
During the FY 2001 tests, elevated water content and tracer concentrations were observed at depths of $16 \mathrm{~m}(52.5 \mathrm{ft})$ at two monitoring locations in the southeast quadrant of the monitoring site, suggesting that the plume had penetrated below the lower (12-m [39.4 ft] deep) confining layer. However, there appears to be no evidence to support fingering due to fluid properties. The location of the peak tracer concentrations was almost identical for $\mathrm{F}^{-}, \mathrm{Cl}^{-}, \mathrm{Br}^{-}, \mathrm{NO}_{3}^{-}, \mathrm{S}_{2} \mathrm{O}_{3}^{-}$, and $\mathrm{PO}_{4}^{2-}$ but was somewhat larger for $\mathrm{SO}_{4}^{2-}$ in the FY 2001 tests. Distribution of $\mathrm{SO}_{4}^{2-}$ also appeared very sensitive to textural changes. The location of centers of mass differed among tracers and increased from about $5.7 \mathrm{~m}(18.7 \mathrm{ft})$ to $8.4 \mathrm{~m}$ $(27.6 \mathrm{ft})$ in the order $\mathrm{PO}_{4}^{2-}<\mathrm{Br}^{-}<\mathrm{F}^{-}<\mathrm{S}_{2} \mathrm{O}_{3}^{-}<\mathrm{NO}_{3}^{-}<\mathrm{Cl}^{-}<\mathrm{SO}_{4}^{2-}$. The deeper penetration of $\mathrm{Cl}^{-}$relative to $\mathrm{NO}_{3}^{-}$and $\mathrm{S}_{2} \mathrm{O}_{3}^{-}$may be indicative of preferential transport due to anion exclusion.

\subsection{Coring Data Summary}

Core samples were collected from a number of boreholes in FY 2000 and FY 2001 to determine selected physical, hydrologic, and geochemical properties of the test site before, during, and after a number of water and tracer injection tests. Sample materials were visually examined for moisture content, sedimentary structure, dominant grain size(s), color, gross mineralogy/lithology, and reaction to hydrochloric acid. Each sample was subjectively assigned to one of 19 sediment types. These materials were then grouped into six fairly distinct and correlative litho-stratigraphic units, generally consisting of stratified sand deposits, with variable silt content and rare pebbles. Selected core samples were submitted for laboratory analyses of water content, percent fine material, and tracer concentration.

The sampler was driven into relatively undisturbed materials in front of the augur flights using a drive hammer weighting up to $227 \mathrm{~kg}$ (500 lbs.) (Figure 3.9). Once the sampler was driven the length of the sampler, or to refusal, the sampler was withdrawn and taken to the breakdown table for disassembly and subsampling. However, at times, during difficult retrievals, the sampled materials were not retained by 
the sampler and thus were not recovered from the particular sampling interval. Once the sampler was retrieved from the borehole, the pilot bit was again lowered into the augur flights, and the borehole was advanced to the next sampling interval.

During the FY 2000 field experiment, over 130 soil samples were collected from three soil borings. The first boring was sampled just before the first injection test. The other two borings were sampled after completion of the injection tests. These soil samples were collected using a 7.6-cm (3-in.) ID split-spoon sampler, with internal 15-cm (6-in.) long Lexan ${ }^{\circledR}$ liners. The samples ranged in depth from 4 to $17 \mathrm{~m}$ (13.5 to $56.5 \mathrm{ft}$ ), and were submitted to various laboratories for hydraulic property characterization and/or geochemical/tracer analyses. Preliminary results indicate that the major concentration front of the bromide tracer reached a relative depth of $5 \mathrm{~m}(16.4 \mathrm{ft}$ ) (below the injection point) eight days after the final water injection. Four days later, the bromide tracer had migrated to a relative depth of about $7 \mathrm{~m}$ $(23 \mathrm{ft})$.

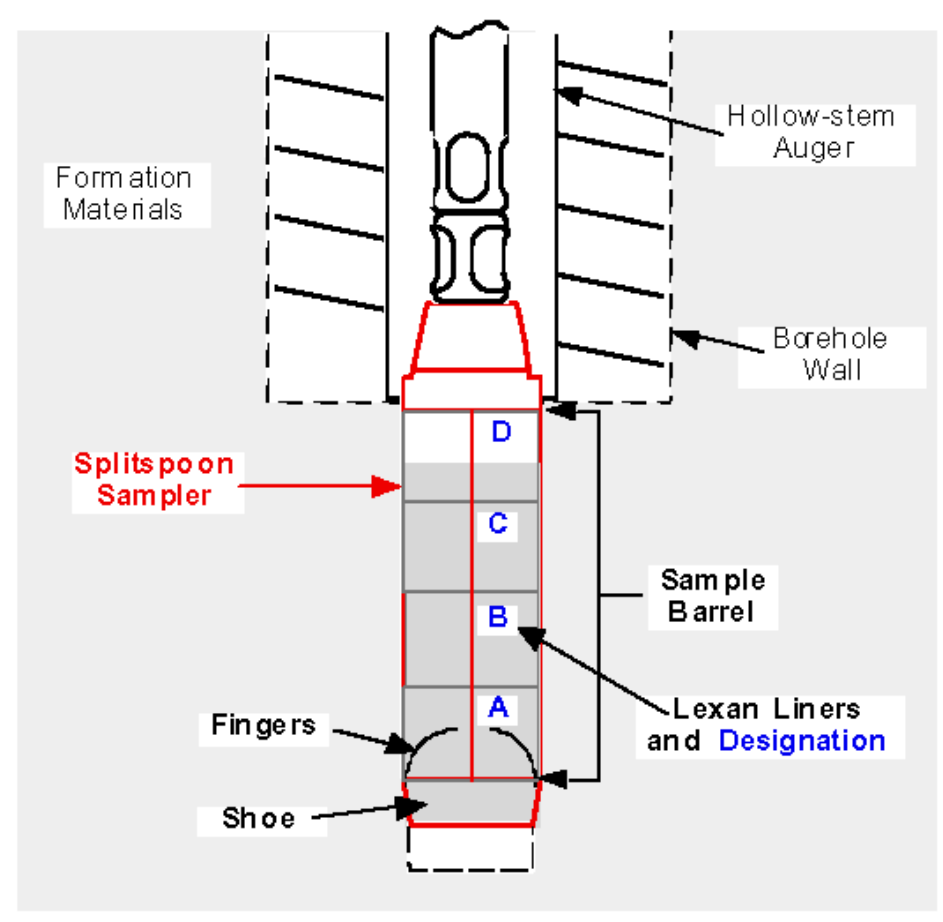

Figure 3.9. Schematic of Split Spoon Sampling Procedure and Typical Liner Designation

During the FY 2001 field experiment with the sodium thiosulfate tracer, 10 soil borings were taken before, during, and after the tracer was injected. The first two soil borings were sampled 7 days before the tracer injections began. Two more soil borings were sampled midway during the series of injections, and the remaining six soil borings were installed at three different times after the cessation of the injections. Over 300 soil samples were collected using a cone penetrometer and wireline sampling tools. The samples generally ranged in depth from 4.6 to $17.4 \mathrm{~m}$ (15 to $57 \mathrm{ft})$. Selected samples were analyzed for percent fines, moisture content, and/or tracer concentrations. Preliminary results from the core-sample analyses indicate that the major concentration front of the thiosulfate tracer reached a relative depth of at least $5.5 \mathrm{~m}$ (180.4 ft) (below the injection point) 17 days after the tracer injections began. Fifty-one days 
later, the tracer appears to have migrated to a relative depth of at least $10.2 \mathrm{~m}(33.5 \mathrm{ft})$. Lateral spreading appears to have exceeded $5.8 \mathrm{~m}(19 \mathrm{ft})$ even at the deepest points of migration.

Two reports were prepared (Last and Caldwell 2001; Last et al. 2001) that document the stratigraphic features of the site based on the core sampling efforts. These reports provide detailed descriptions of the borehole logs and show profiles of the bromide tracer concentrations found in the core samples. Analysis of the core samples is used in combination with other geophysical and geochemical results to further our understanding of contaminant transport within the vadose zone. As an example, the bromide data have been used in a subsequent analysis of moments (see Section 4.3) to describe chemical transport under Hanford test-site conditions. The core reports are published in hard copy (see above) but can also be found on the contractor report section of the web page http://vadose.pnl.gov. 


\subsection{Data Analysis}

In the following sections, we summarize previous efforts to model this site and our recent efforts to incorporate the new data from the FY 2000 and FY 2001 field tests to improve the conceptual model and to use numerical methods to evaluate the flow and transport in a systematic way.

\subsection{Previous Data Analysis and Modeling}

Previous modeling of the Sisson and Lu experiment met with mixed success (Sisson and Lu 1984; Lu and Khaleel 1993; Smoot and Lu 1994; Smoot and Williams 1996; Rockhold et al. 1999). Because the radioactive tracers were short-lived and retarded by the sediments, the collection of tracer data was confined to wells within a 2-m (6.56-ft) radius of the injection point. The focus of most of the data analysis and modeling was on the spatial and temporal distribution of water. For water-transport analysis, the entire well network was used, and the data set is quite extensive. In general, lateral spreading of the water plume has been significantly under-predicted by the past modeling efforts. Apparently, small-scale heterogeneities (either thin silt or fine sand lenses) that are difficult to identify from air rotary sediment samples and not adequately described in the numerical models act to retard the vertical transport of the water plume beyond what has been computed using typical grid spacings of $0.5 \mathrm{~m}(1.6 \mathrm{ft})$ or greater.

Small-scale layering in sands, even with modest size differences (gradation changes), has been shown to cause significant horizontal spreading at both the laboratory and field scale (Stephens and Heermann 1988; McCord et al. 1991). This small-scale layering is the primary cause of anisotropic behavior, a phenomenon that has also been shown to be dependent on moisture conditions. Research on moisturedependent anisotropy has focused mostly on stochastic methods (Yeh et al. 1985a; Mantoglou and Gelhar 1987; Polmann et al. 1991; Pruess 1996). A major limitation of the stochastic methods is inability to handle large amounts of parameter variability because of their roots in small-scale perturbation theory. Furthermore, applications at Hanford have been met with limited success, and a major knowledge gap is how to best incorporate these mechanisms into a numerical model for field-scale predictions. A scarcity of data, including lack of cores for direct physical measurements of anisotropic hydraulic properties of sediments, has hampered studies to address the effects of hydraulic variability on the lateral spreading of a plume at this site (Khaleel and Freeman 1995; Khaleel and Relyea 1995; Rockhold et al. 1999). In the previous tests, no undisturbed core samples were taken from the site for hydrologic analysis, and there were no measurements of transport properties, such as molecular diffusion coefficients or dispersivities. However, a few sediment samples obtained from cuttings during air rotary drilling were repacked and analyzed for water-retention characteristics (Fayer et al. 1993). This study has resulted a several undisturbed cores on which physical and hydraulic property measurements are being made.

More recently, unsaturated flow and transport experiments were conducted at the ILAW site east of the Sisson and Lu Site. These measurements have been used to determine flow and transport properties, including unsaturated hydraulic conductivity and dispersivity, as well as their geostatistical features to a maximum depth of $2 \mathrm{~m}(6.56 \mathrm{ft})$. Of the 45 undisturbed cores obtained from the ILAW borehole, 20 were analyzed to determine particle-size distributions, water retention, and saturated and unsaturated hydraulic conductivity (Fayer et al. 1999). Shortcomings in the subsampling strategy preclude the use of these data to estimate correlation lengths, a critical piece of information for field-scale models. The spacing 
between boreholes limits their use in estimating horizontal correlation lengths and the vertical subsampling intervals limit their use in estimating vertical correlation lengths. Nevertheless, information about the relative properties of the major textural zones provides an invaluable dataset for testing new scaling techniques under development. Yeh et al (1985b) in their derivation of the effective hydraulic conductivity showed that the effective hydraulic conductivity is linearly related to the mean value of the local scale conductivity for a given degree of variability and a correlation length. Data such as those from the ILAW boreholes allow an estimation of the scaling factors that we needed for the evaluation of a parameter scaling approach that is under development.

\subsection{Modeling of FY 2000 VZTFS Field Experiment}

The FY 2000 test was simulated using Subsurface Transport Over Multiple Phases (STOMP), a multiphase (unsaturated) flow and transport code developed at PNNL. A conditional simulation of the five injections was made using methods developed by Rockhold et al (1999). In the analysis, Rockhold ${ }^{(a)}$ performed numerical simulations of the FY 2000 injections. Simulations were conditioned on the initial water contents, as measured by neutron probe using the calibration functions described in Ward and Gee (2000), and the water retention characteristics of Hanford Site soils that are similar, but not identical, to those soils found at the VZTFS Site. The depth of the injection point was located $4.26 \mathrm{~m}$ (14 ft) below ground surface and at the center of the well array, as in the earlier experiments. Subsurface injections were represented using a single source node at the $4.26-\mathrm{m}(14-\mathrm{ft})$ depth. The five weekly injections were simulated, consisting of $4000 \mathrm{~L}$ (1057 gal) of water injected over a period of 4 to 6.75 hours.

The boundary condition for the upper surface of the modeled domain was represented using a constant flux. The lateral and bottom boundaries were treated as no-flow and unit hydraulic gradient boundaries, respectively.

The modeled domain was represented using spatially variable, anisotropic hydraulic properties. The hydraulic properties were generated using a conditional simulation and upscaling method with scale-mean parameters corresponding to Case 2 of Rockhold et al. (1999). The modeled domain represents a volume of unsaturated porous media that spans $17 \mathrm{~m}(55.77 \mathrm{ft}$ ) in both the E-W (or x-) and N-S (or y-) directions, and approximately $12 \mathrm{~m}(39.4 \mathrm{ft}$ ) in the vertical (or z-) direction. This domain was discretized using $22,050$ nodes with a non-uniform node spacing of 0.5 to $1 \mathrm{~m}$ (1.64 to $3.28 \mathrm{ft})$ in the $\mathrm{x}$ - and y-directions, and 0.1524 to $0.3048 \mathrm{~m}(0.5$ to $1 \mathrm{ft})$ in the $\mathrm{z}$-direction.

Figures 4.1 through 4.6 depict vertical slices (E-W or N-S) extracted from three-dimensional numerical simulation results of the VZTFS injection. In these figures, the vertical axis represents depth below ground surface. The horizontal axis represents the distance (E-W or N-S) from the original injection well used in an earlier experiment at this site (Sisson and $\mathrm{Lu} \mathrm{1984).} \mathrm{Results} \mathrm{indicate} \mathrm{that} \mathrm{the} \mathrm{model} \mathrm{captured}$ the general flow depths and directions of the plume but did not completely describe the extent of the lateral spreading of the plume. This discrepancy could be due to a variety of factors. First, initial water contents from the test site were used in the conditional simulation while the parameters used were from a different location. Secondly, while it is recognized that anisotropy in hydraulic properties and their dependence on moisture conditions may play an important role in vadose-zone flow, there has

(a) Currently at Oregon State University, on educational leave-of-absence from PNNL. 


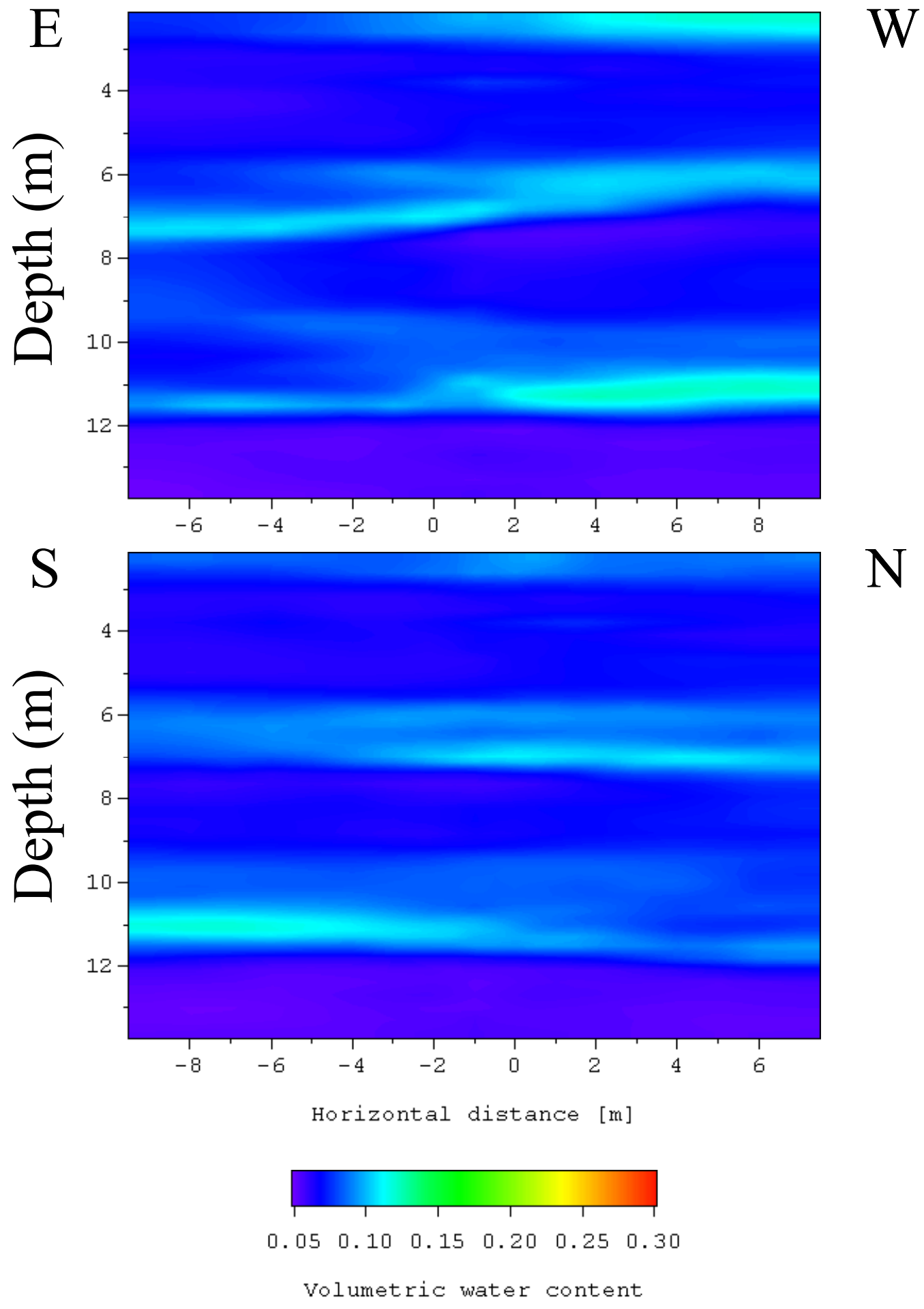

Figure 4.1. Initial Water Content Distributions Along E-W and N-S Measurement Transects 

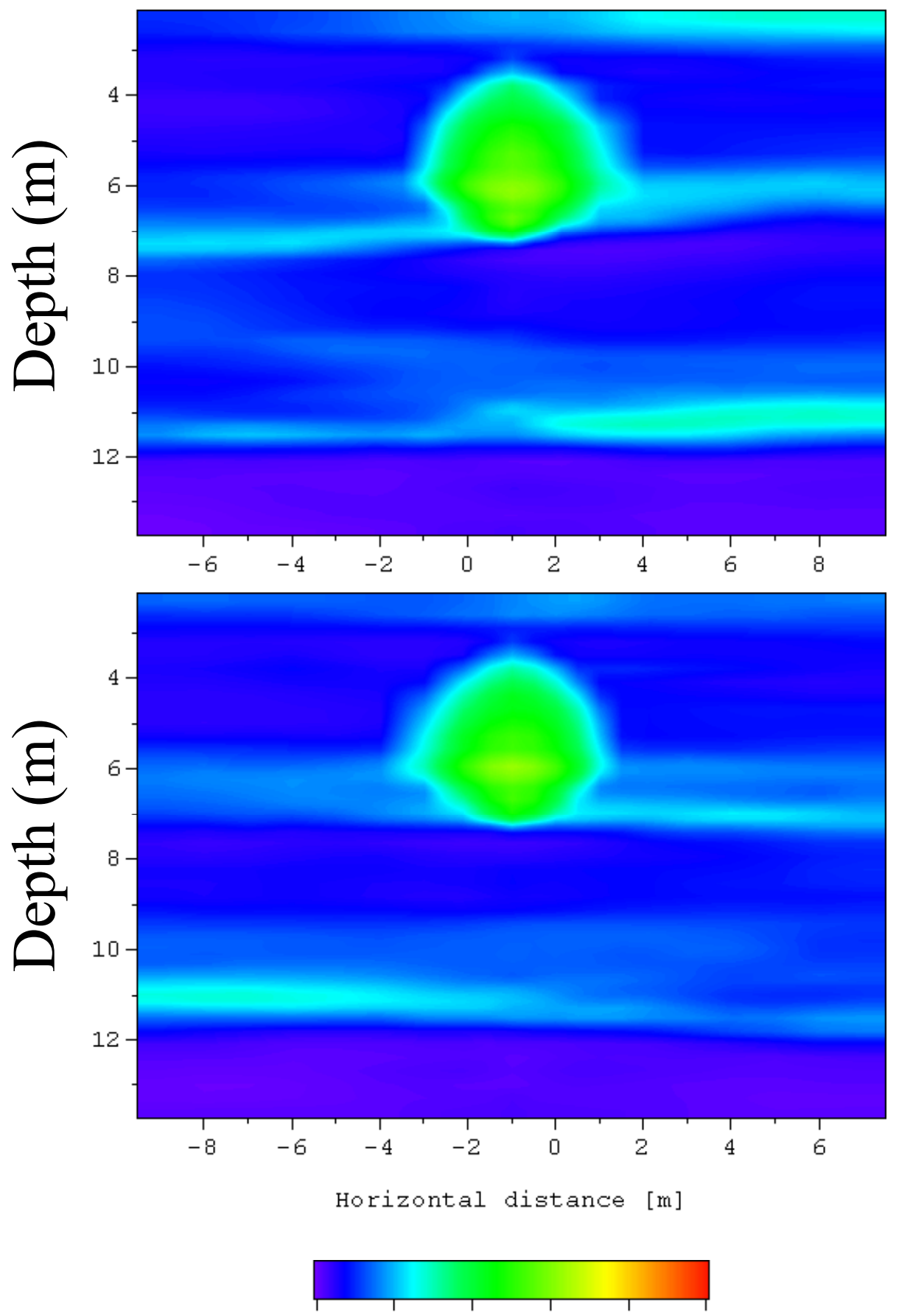

$0.05 \quad 0.10 \quad 0.15 \quad 0.20 \quad 0.25 \quad 0.30$

Volumetric water content

Figure 4.2. Simulated Water Content Distributions on June 2, 2000; 1 Day After First Injection 

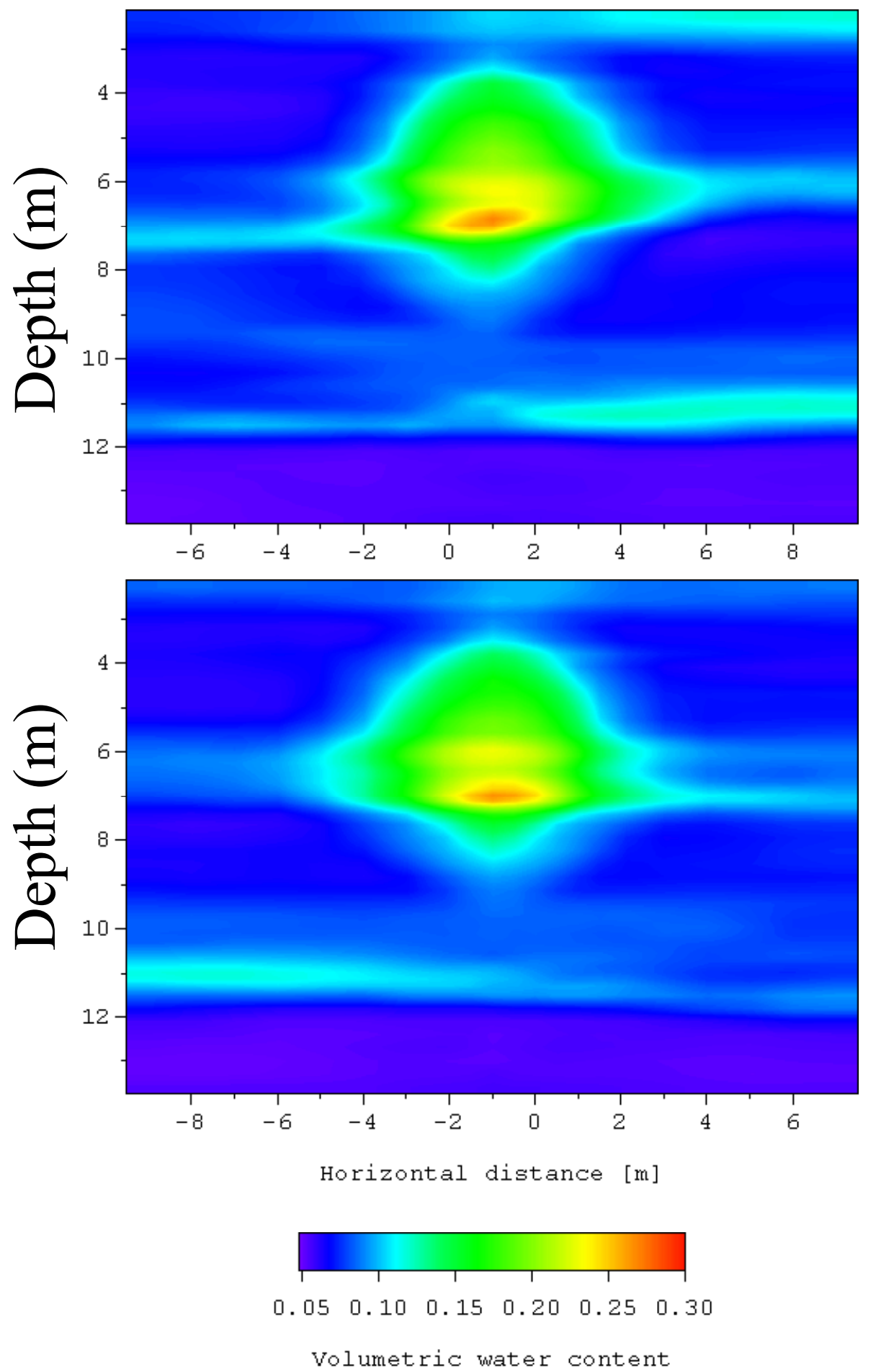

Figure 4.3. Simulated Water Content Distributions on June 16, 2000; 1 Day After Third Injection 

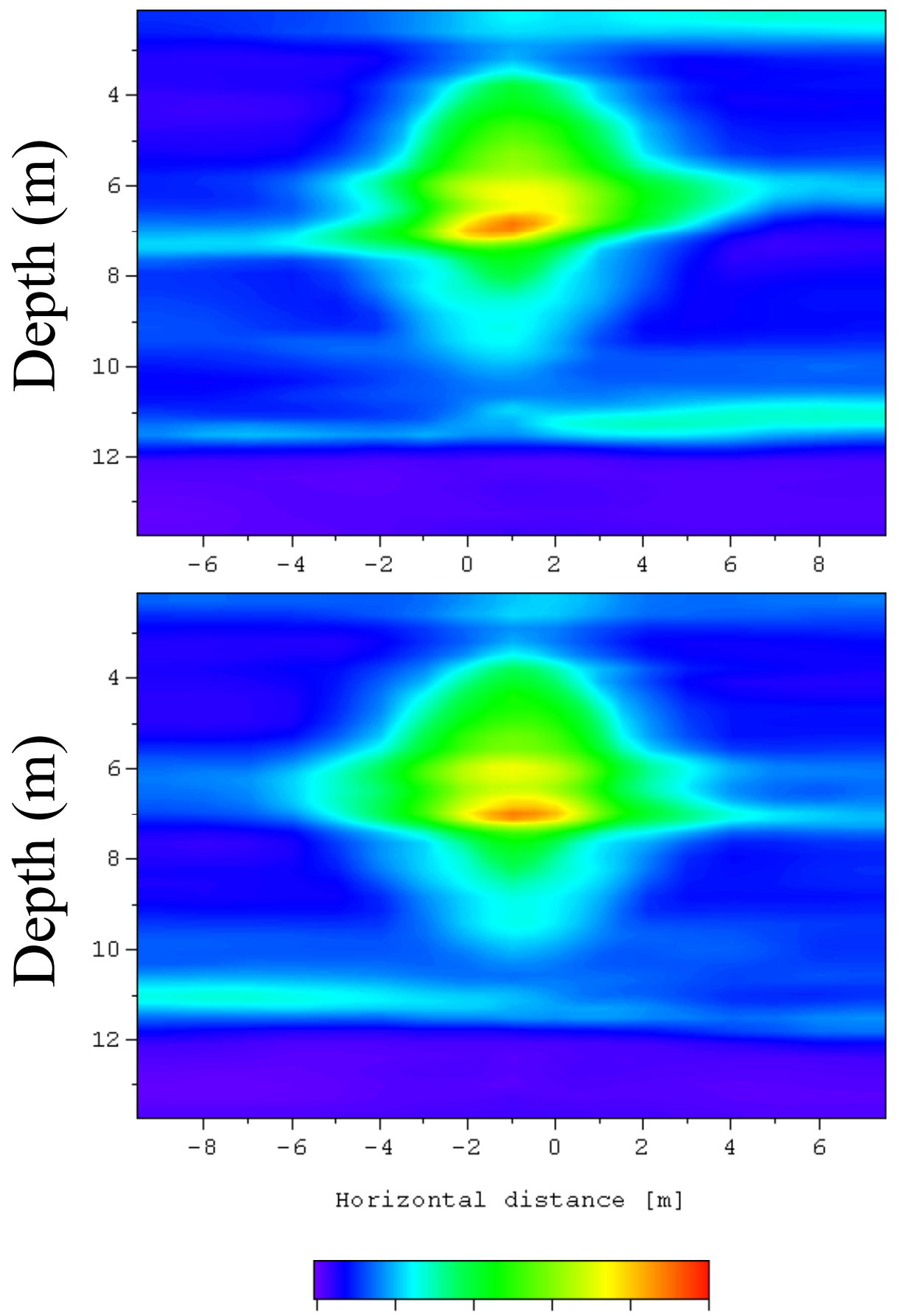

$0.05 \quad 0.10 \quad 0.15 \quad 0.20 \quad 0.25 \quad 0.30$

Volumetric water content

Figure 4.4. Simulated Water Content Distributions on June 23, 2000; 1 Day After Fourth Injection 

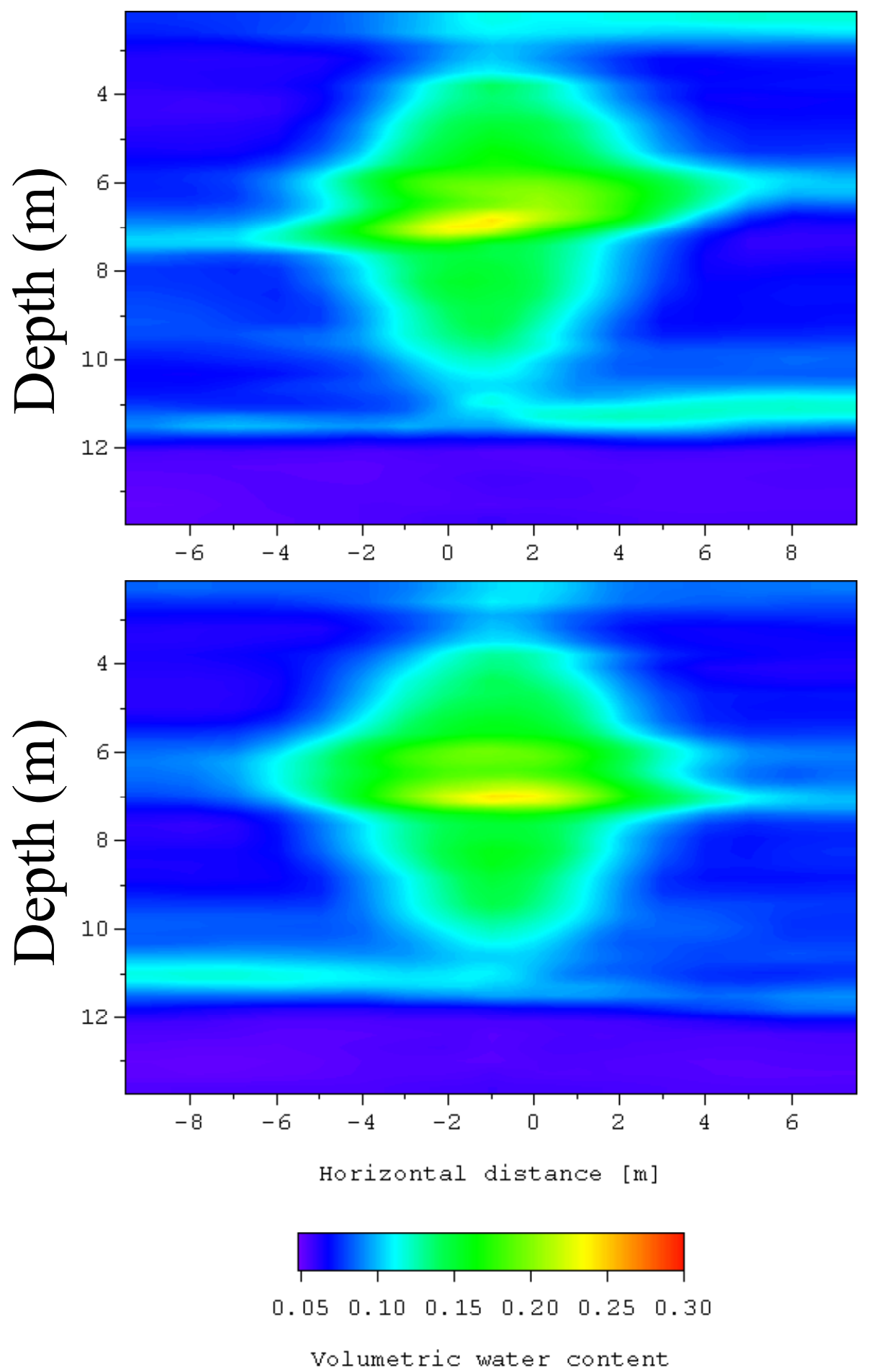

Figure 4.5. Simulated Water Content Distributions on June 29, 2000; 1 Day After Fifth Injection 

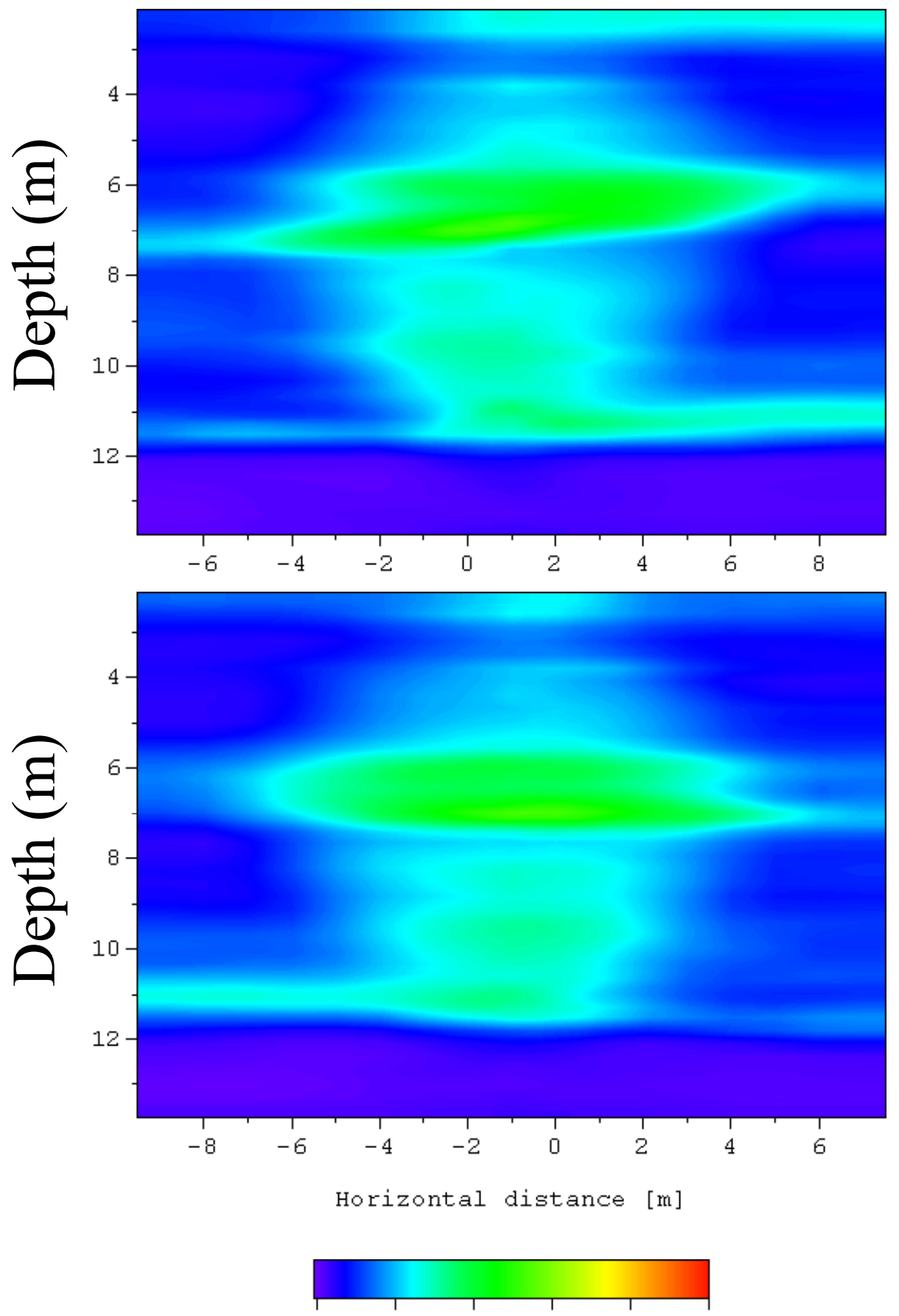

$\begin{array}{lllllll}0.05 & 0.10 & 0.15 & 0.20 & 0.25 & 0.30\end{array}$

Volumetric water content

Figure 4.6. Simulated Water Content Distributions on July 11, 2000, Final Neutron Probe Measurement 
been no attempts to quantify anisotropy ratios for Hanford sediments. Furthermore, the values used in most models are derived from the literature. It is anticipated that the site-specific hydraulic property data collected during the VZTFS FY 2000 and FY 2001 field experiments will improve the quality of the input parameters and provide a better estimate of anisotropy ratios. When coupled with an enhanced conceptual model, these improvements should ultimately lead to better model predictions model simulations, primarily through improved parameter estimates and also through a better understanding and quantification of anisotropic mechanisms. When coupled with an enhanced conceptual model, these improvements should ultimately lead to better model predictions. Efforts to model the field experiments are continuing during FY 2002 and beyond.

\subsection{Moment Analysis}

In the absence of complex state-variable models, a particularly useful method for analyzing spatial data is the method of spatial moments. Spatial moments allow a simple, physically meaningful description of overall plume behavior, and in contrast to the state-variable models, moments can be predicted with less uncertainty. To examine the impact of fluid properties on the overall behavior of the dilute and hypersaline plumes, each plume was characterized by its zeroth, first, and second, moments in the principle direction of flow. In three dimensions, the absolute $n^{\text {th }}$ spatial moment of a distribution $\mathrm{F}(\mathrm{x}, \mathrm{y}, \mathrm{z}, \mathrm{t}), \mathrm{M}_{\mathrm{n}}$, is defined as

$$
M_{n}=\int_{-\infty}^{\infty} \int_{-\infty}^{\infty} \int_{-\infty}^{\infty} x^{p} y^{p} z^{p} F(x, y, z, t) d x d y d z
$$

The normalized $\mathrm{n}^{\text {th }}$ spatial moment about the mean of the distribution $\mathrm{F}(\mathrm{x}, \mathrm{y}, \mathrm{z}, \mathrm{t}), \mathrm{m}_{\mathrm{n}}$, is defined as

$$
\mathrm{m}_{\mathrm{n}}=\frac{\int_{-\infty}^{\infty} \int_{-\infty}^{\infty} \int_{-\infty}^{\infty}(\mathrm{x}-\bar{x})^{\mathrm{n}}(\mathrm{y}-\bar{y})^{\mathrm{n}}(\mathrm{z}-\overline{\mathrm{z}})^{\mathrm{n}} \mathrm{F}(\mathrm{x}, \mathrm{y}, \mathrm{z}, \mathrm{t}) \mathrm{dxdydz}}{\int_{-\infty}^{\infty} \int_{-\infty}^{\infty} \int_{-\infty}^{\infty} \mathrm{F}(\mathrm{x}, \mathrm{y}, \mathrm{z}, \mathrm{t}) \mathrm{dxdydz}}
$$

where the denominator is equivalent to the zeroth moment, $\mathrm{M}_{0}$. The zeroth moment, $\mathrm{M}_{0}$, is unique in that under conditions when it exists, its value is proportional to the total aqueous phase mass contained in the plume. For tracers, it depends only on the amount of mass injected and the volumetric flow rate; it is independent of the duration of the injection. The first moment, $\mathrm{m}_{1}(\mathrm{x}, \mathrm{y}, \mathrm{z}, \mathrm{t})$, measures the mean location of the plume, and the second moment, $\mathrm{m}_{2}(\mathrm{x}, \mathrm{y}, \mathrm{z}, \mathrm{t})$, measures the amount of spreading about its mean position. The third moment, $\mathrm{m}_{3}(\mathrm{x}, \mathrm{y}, \mathrm{z}, \mathrm{t})$, measures the skewness of the distribution. A value of $\mathrm{m}_{3}(\mathrm{x}, \mathrm{y}, \mathrm{z}, \mathrm{t})>0$ suggests a long tail at the leading edge of the plume while $\mathrm{m}_{3}(\mathrm{x}, \mathrm{y}, \mathrm{z}, \mathrm{t})<0$ suggests a long tail at the trailing edge. The fourth moment, $\mathrm{m}_{4}(\mathrm{x}, \mathrm{y}, \mathrm{z}, \mathrm{t})$, measures the kurtosis in the plume. A value of $\mathrm{m}_{4}(\mathrm{x}, \mathrm{y}, \mathrm{z}, \mathrm{t})<3$ suggests a platykurtic distribution; $\mathrm{m}_{4}(\mathrm{x}, \mathrm{y}, \mathrm{z}, \mathrm{t})=3$ describes a mesokurtic plume, while $\mathrm{m}_{4}(\mathrm{x}, \mathrm{y}, \mathrm{z}, \mathrm{t})>3$ suggests a leptokurtic plume. Traditionally, higher order moments $(\mathrm{m}>2)$ are avoided because they are difficult to obtain experimentally and also to interpret. In this study, a method of weighted moments is being developed to aid in interpretation but is not a focus of this report.

Comparison of the spatial moments of the $\theta(x, y, z)$ after injections of similar volumes of dilute sodium thiosulfate solution should provide an indication of the effects of fluid composition and properties on subsurface migration patterns. Differences in the distributions are better visualized in two-dimensional contour plots in Figures 4.7 through 4.10. 
Figure 4.7 compares the change in $\theta(\mathrm{x}, \mathrm{z})$ from the pre-injection condition along the D-H transect after the injection of $4000 \mathrm{~L}$ (1057 gal) of dilute tracer during the FY 2000 field experiment (Figure 4.7a) and 4206 L (1111 gal) of hypersaline water during the FY 2001 field experiment (Figure 4.7b). At this stage, the thiosulfate plume has penetrated almost $1 \mathrm{~m}(3.28 \mathrm{ft})$ deeper than the dilute water plume. There is also a clear difference in the nature of the distribution in the fine-textured layer at around $7 \mathrm{~m}(23 \mathrm{ft})$. The water shows increased spreading above the fine-textured layer and is just beginning to penetrate (Figure 4.7a). On the other hand, the saline plume appears to have penetrated earlier, showing less spreading above the fine layer and more spreading within the fine layer.

The wetting front of the dilute water plume is quite sharp, and lateral spreading was well contained. It is clear that the dilute tracer solution is redistributing laterally, given the relatively low change in $\theta$ in the plume. Water has moved along the upper fine-textured layer, towards the boundary of the monitoring volume, and a discontinuity in $\theta$ is again evident between this layer and the underlying coarse layer. In contrast, the saline plume has remained quite compact.
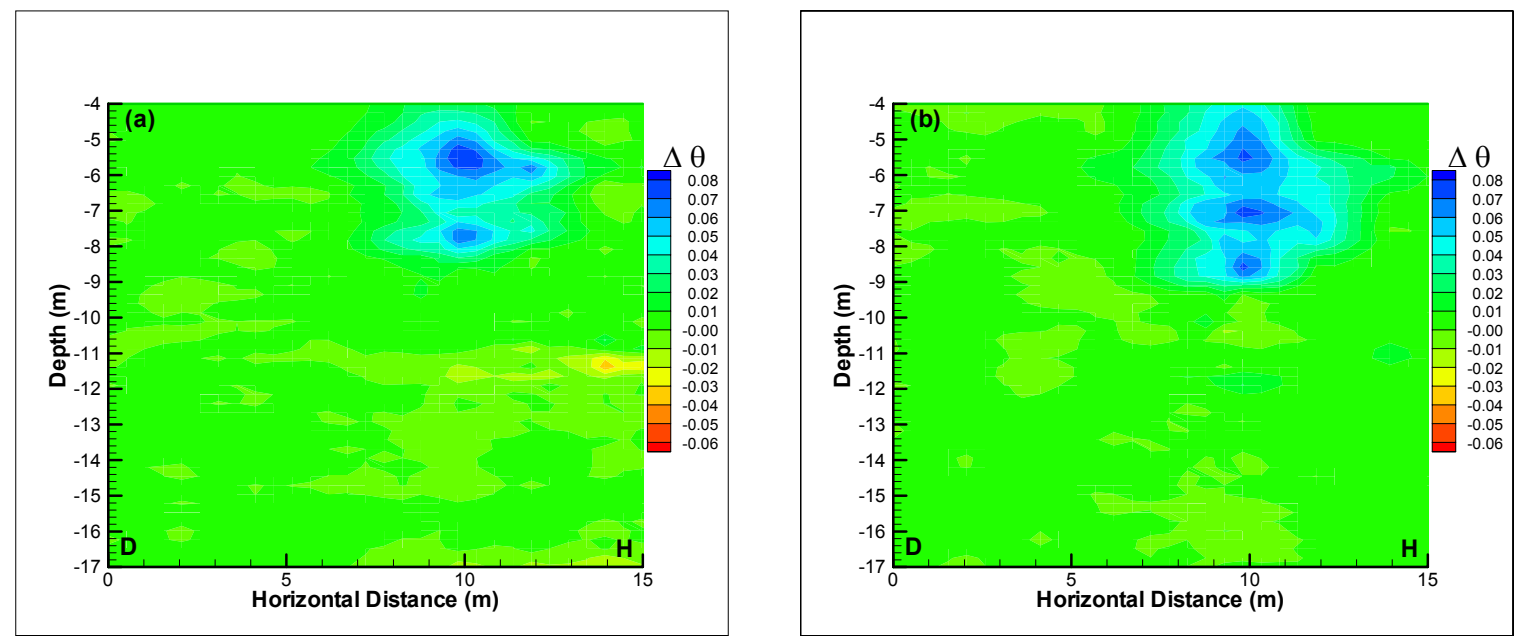

Figure 4.7. Spatial Distribution of Change in Soil Water Content $(\Delta \theta)$ from the Pre-injection Condition Along the D-H Transect after Injection of (a) 4000 L (1057 gal) of Dilute Tracer Solution (FY 2000), and (b) 4216 L (1114) of Sodium Thiosulfate Solution (FY 2001)

Figure 4.8 compares the change in $\theta(\mathrm{x}, \mathrm{z})$, from the pre-injection condition, along the $\mathrm{D}-\mathrm{H}$ transect after the injection of $12,000 \mathrm{~L}$ ( $3170 \mathrm{gal})$ of dilute tracer solution during the FY 2000 field experiment (Figure 4.8a) and 11,400 L (3012 gal) of hypersaline water during the FY 2001 field experiment (Figure 4.8b).

The wetting front is at similar depths for the FY 2000 and FY 2001 field experiments, but the salt plume appears to show some effects of buoyancy, with the plume being detected closer to the surface. It is possible that at the increased moisture content in the soil, the effects of viscosity are beginning to counteract the density effect. 

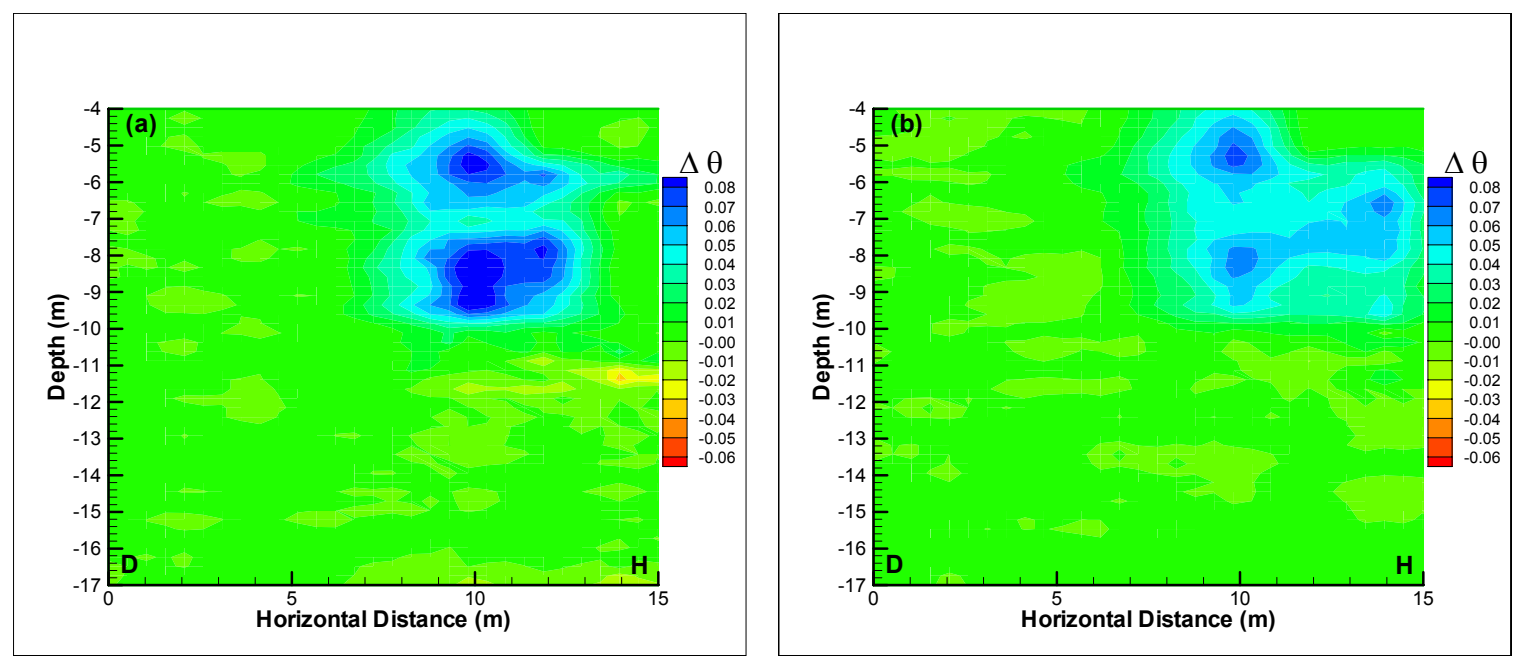

Figure 4.8. Spatial Distribution of Change in Soil Water Content $(\Delta \theta)$ From the Pre-injection Condition Along the D-H Transect after Injection of (a) 12,000 L (3170 gal) of Dilute Tracer Solution During the FY 2000 Field Experiment, and (b) 11,400 L (3012 gal) of Sodium Thiosulfate Solution During the FY 2001 Field Experiment

Figure 4.9 compares the change in $\theta(\mathrm{x}, \mathrm{z})$ between the two experiments, from the pre-injection condition, along the D-H transect after the injection of 20,000 L (5283 gal) of dilute tracer solution during FY 2000 field experiment (Figure 4.9a) and 19,402 L (5125 gal) of hypersaline water during the FY 2001 field experiment (Figure 4.9b). The distribution of $\theta(\mathrm{x}, \mathrm{z})$ observed for the salt plume during FY 2001 resembled the saline plume distributions observed in the laboratory. The wetting front was quite sharp, and lateral spreading was also observed.
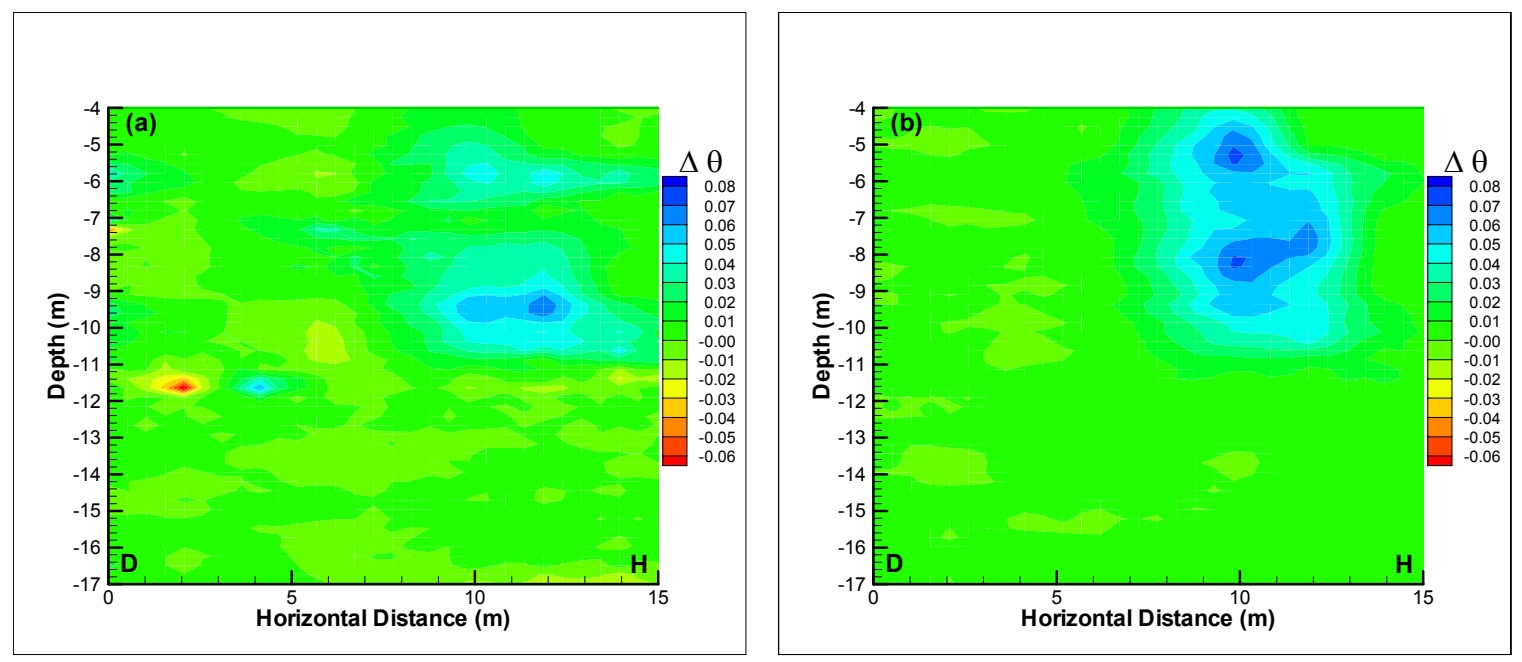

Figure 4.9. Spatial Distribution of Change in Soil Water Content $(\Delta \theta)$ From the Pre-injection Condition Along the D-H Transect after Injection of (a) 20,000 L (5283 gal) of Dilute tracer solution, and (b) 19,402 L (5125 gal) of Sodium Thiosulfate Solution 
It is clear that the dilute tracer solution redistributed laterally during the FY 2000 field experiment, given the relatively low change in $\theta$ in the plume. Water continued to move along the upper fine-textured layer, towards the boundary of the monitoring domain, and a discontinuity in $\theta$ was again evident between this layer and the underlying coarse layer. In contrast, the thiosulfate plume remained quite compact and appeared to have moved very little in the transverse direction. These features may be partly related to the intermittent nature of the injection. Because areas of high permeability are usually coarsetextured, they tend to drain faster than areas of finer texture under normal conditions. Thus, highpermeability zones for saturated flow can become low-permeability zones for unsaturated flow; i.e., the hydraulic structure of the system can change dramatically with saturation.

The final comparison of the two experiments is between the post-injection distributions. Figure 4.10a shows the change in $\theta(x, z) 9$ days after the last injection in the FY 2000 field experiment, while Figure $4.10 \mathrm{~b}$ shows the distribution 8 days after the last injection in the FY 2001 field experiment. There are two major differences between the two distributions. First, the water plume during the FY 2000 experiment has already started to redistribute to the extent that there is very little evidence of the plume. Remnants of the increase in $\theta$ are barely obvious in the upper fine-textured layer and more so at the deeper impeding layer. The plume appears to have moved in a transverse direction, out of the monitoring volume (Figure 4.10a). None of the water injected in FY 2000 appears to have penetrated the lower confining layer at the $12-\mathrm{m}(39.4 \mathrm{ft})$ depth.
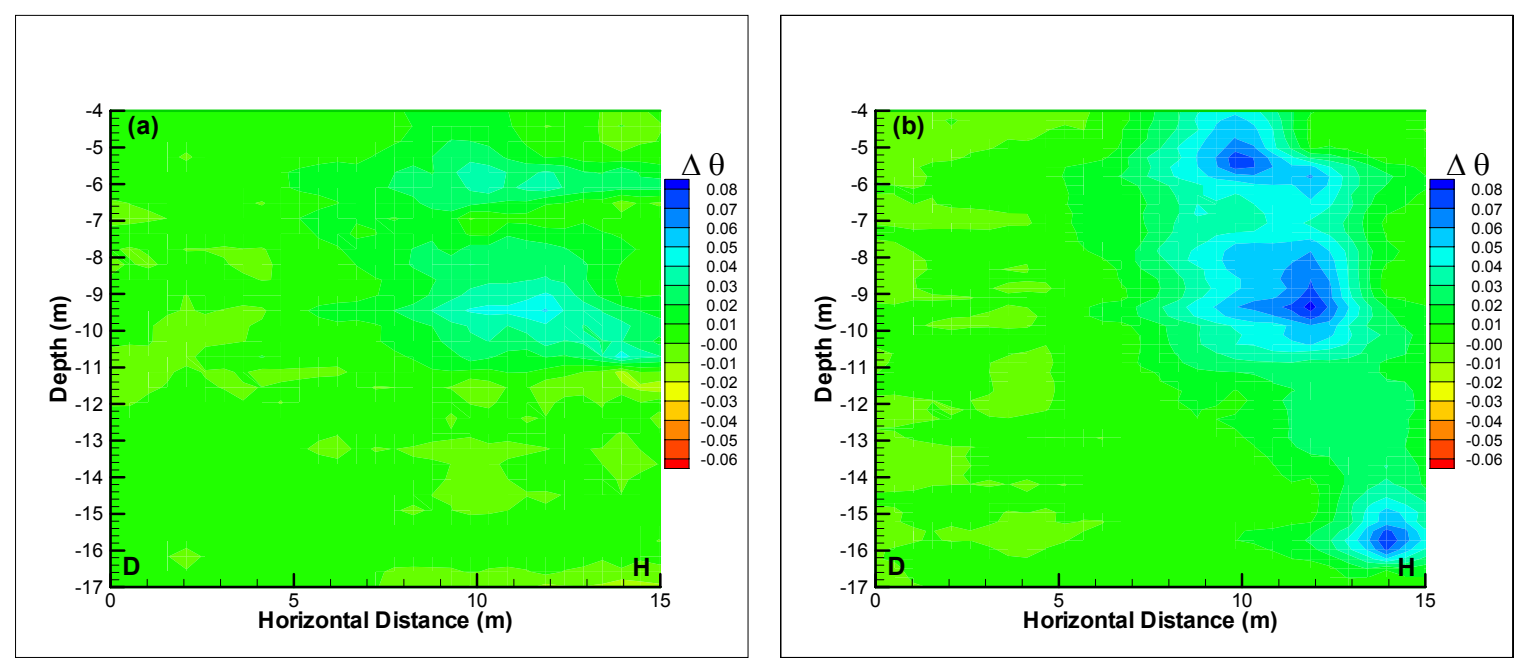

Figure 4.10. Spatial Distribution of Change in Soil Water Content $(\Delta \theta)$ From the Pre-Injection Condition Along the D-H Transect After Injection of (a) 9 Days Post Injection in FY2000 and (b) 8 Days Post Injection in FY 2001

In contrast, the thiosulfate shows little transverse redistribution. Although the interface between the upper fine-textured layer and the underlying coarse layer is beginning to drain, it appears to be a rate much less than the dilute water plume during the FY 2000 field experiment. The main portion of the plume also appears to have moved very little in the intervening period, when compared to Figure 4.10b. However, for the first time, a portion of the plume penetrated the lower confining layer and is apparent at $16 \mathrm{~m}(52.5 \mathrm{ft})$. There is no doubt that is due to preferential flow. 
Preferential flow, the accelerated movement of water through isolated regions of the vadose zone, is recognized as a phenomenon partly responsible for faster transport of contaminants (Hill and Parlange 1972; McCoy et al. 1994). There has also been much speculation about preferential flow being a possible explanation of contaminant distributions observed in Hanford's vadose zone. Preferential flow may occur through "macropores." In the VZTFS field experiment, this would be limited to those caused by structural inhomogeneities or improperly sealed or grouted boreholes. Large channels and cracks that would permit this type of preferential movement would be solution-filled only at pressure potentials above $-0.2 \mathrm{~m}(-0.66 \mathrm{ft})$, so such movement would occur only in near saturated soil. While soil conditions were not close to saturation at the 12-m (39.4-ft) depth, the effect of the fluid properties could have played a role. Although several cores were taken from the site, this is the only region where this pattern was observed.

Wetting-front instability of the saline plume, leading to "fingered flow," could also cause preferential flow. Of the many characteristics that favor fingered flow, two-layered configurations where an upper fine-textured layer restricts flow and the process of redistribution through a lower coarse layer exist at the VZTFS site. Laboratory studies at PNNL have also shown that the properties of hypersaline fluids may influence transport behavior, to the extent of finger formation, through an interaction between fluid and hydraulic properties. Yet, the importance of these mechanisms and the conditions under which they are operable at the field-scale is largely unknown. These issues will be taken into consideration in the planning of field experiments for FY 2002.

The full three-dimensional representations of the data above were analyzed using spatial moments to quantify the differences in the subsurface distribution of the two fluids. The positions of the center of mass and the variance about the center of mass are summarized for FY 2000 in Table 4.1 and for FY 2001 in Table 4.2.

These results show that the locations of the centers of mass for the two plumes were similar in the transverse (x) and lateral (y) directions but were significantly different in the longitudinal (z) direction with the hypersaline plume moving deeper for a given volume. The initial rapid vertical penetration of the hypersaline plume may be due to density-driven fingering (Figure 4.11). As the plume became more dilute, the difference between the two plumes becomes less. As shown in Figure 4.12, the cumulative travel distance of the center of mass for both the dilute and hypersaline water plumes showed a curvilinear increase with time and injected volume, indicative of the highly nonlinear transport process. After 20,000 L (5283 gal), the hypersaline plume had traveled 2.6 times farther than the dilute plume. Most of the discrepancy occurred during the initial stages of the leak with the vertical center of mass of the hypersaline plume traveled twice as deep as that of the dilute plume. Examination of the principal components of the variance over time shows that the hypersaline plume also remained more compact when compared to the dilute plume. The test site shows evidence of macroscopic anisotropy and as a first approximation, we compare the ratio of fluxes in the principal directions for the dilute plume. Mean velocities were $\bar{v}_{x}=6.7 \cdot 10^{-3} \mathrm{~m} \mathrm{~d}^{-1} ; \bar{v}_{y}=6.2 \cdot 10^{-3} \mathrm{~m} \mathrm{~d}^{-1}$; and $\bar{v}_{z}=5.2 \cdot 10^{-3} \mathrm{~m} \mathrm{~d}^{-1}$. The average $\mathrm{v}_{\mathrm{x}} / \mathrm{v}_{\mathrm{y}}$ ratio was 1.079 while the average $\mathrm{v}_{\mathrm{x}} / \mathrm{v}_{\mathrm{z}}$ ratio was 0.128 . 
Table 4.1. Calculated Three-Dimensional Spatial Moments for Distribution of Water Content Changes in FY 2000

\begin{tabular}{|c|c|c|c|c|c|c|c|c|c|c|c|c|}
\hline \multirow[b]{2}{*}{ Date } & \multirow[b]{2}{*}{ Elapsed Time (d) } & \multirow[b]{2}{*}{ Cum Vol (L) } & \multicolumn{3}{|c|}{ Center of Mass } & \multicolumn{2}{|c|}{ Cumulative Travel Distance } & \multicolumn{2}{|c|}{ Path direction } & \multicolumn{3}{|c|}{ Principal Components of Variance } \\
\hline & & & $\bar{x}(\mathbf{m})$ & $\bar{y}(\mathbf{m})$ & $\bar{z} \mathbf{~ ( m ) ~}$ & $\mathbf{x}-\mathbf{y}$ & $x-y-z$ & $\mathbf{x}-\mathbf{y}\left(\Theta_{\mathrm{I}}\right)$ & $\mathbf{x}-\mathbf{y}-\mathbf{y}\left(\Theta_{\mathrm{T}}\right)$ & $s_{x}^{2}\left(\mathbf{m}^{2}\right)$ & $s_{y}^{2}\left(\mathrm{~m}^{2}\right)$ & $s_{y z}^{2}\left(\mathbf{m}^{2}\right)$ \\
\hline $06 / 02 / 00$ & 28 & 4000 & 1.29 & -0.67 & -5.77 & 0.540 & 1.31 & 9.37 & 62.56 & 6.69 & 6.28 & 1.54 \\
\hline 06/09/00 & 35 & 8000 & 1.26 & -0.93 & -6.47 & 0.802 & 2.07 & 6.29 & 53.57 & 5.11 & 6.30 & 1.47 \\
\hline 06/16/00 & 42 & 12000 & 1.32 & -1.22 & -7.29 & 1.10 & 2.93 & 11.94 & 47.23 & 6.83 & 6.72 & 3.46 \\
\hline $06 / 23 / 00$ & 49 & 16000 & 1.40 & -1.24 & -7.48 & 1.17 & 3.13 & 72.46 & 48.10 & 7.47 & 7.46 & 4.15 \\
\hline $07 / 07 / 00$ & 63 & 20000 & 1.67 & -1.76 & \begin{tabular}{|l|}
-7.99 \\
\end{tabular} & 1.76 & 3.91 & 28.56 & 43.46 & 10.12 & 10.08 & 3.87 \\
\hline $07 / 17 / 00$ & 73 & 20000 & 1.75 & -1.54 & -8.14 & 1.99 & 4.19 & 20.26 & 48.65 & 11.47 & 11.72 & 4.50 \\
\hline $07 / 31 / 00$ & 87 & 20000 & 1.55 & -1.37 & -8.26 & 2.25 & 4.48 & 48.97 & 48.61 & 12.98 & 12.17 & 4.23 \\
\hline
\end{tabular}

Table 4.2. Calculated Three-Dimensional Spatial Moments for Distribution of Water Content Changes in FY 2001

\begin{tabular}{|c|c|c|c|c|c|c|c|c|c|c|c|c|}
\hline \multirow[b]{2}{*}{ Date } & \multirow[b]{2}{*}{ Elapsed Time (d) } & \multirow[b]{2}{*}{ Cum Vol (L) } & \multicolumn{3}{|c|}{ Center of Mass ${ }^{(a)}$} & \multicolumn{2}{|c|}{ Cumulative Travel Distance } & \multicolumn{2}{|c|}{ Path direction } & \multicolumn{3}{|c|}{ Principal Components of Variance } \\
\hline & & & $\bar{x}$ (m) & $\bar{y} \mathbf{~ ( m )}$ & $\bar{z}(\mathbf{m})$ & $\mathbf{x}-\mathbf{y}$ & $x-y-z$ & $\mathbf{x}-\mathbf{y}\left(\Theta_{\mathrm{I}}\right)$ & $\mathbf{x}-\mathbf{y}-\mathbf{y}\left(\Theta_{\mathrm{T}}\right)$ & $s_{x}^{2}\left(\mathrm{~m}^{2}\right)$ & $s_{y}^{2}\left(\mathbf{m}^{2}\right)$ & $s_{y z}^{2}\left(\mathbf{m}^{2}\right)$ \\
\hline $03 / 31 / 01$ & 9 & 1935.1 & 1.55 & -0.98 & -7.50 & 0.41 & 5.60 & 57.55 & 57.56 & 69.68 & 31.20 & 14.09 \\
\hline $04 / 05 / 01$ & 14 & 6876.1 & 1.29 & -0.99 & -7.73 & 0.66 & 8.04 & 87.90 & 52.51 & 7.54 & 11.54 & 9.18 \\
\hline $04 / 13 / 01$ & 22 & 11399.8 & 1.97 & -1.06 & -8.18 & 1.35 & 8.86 & 84.18 & 61.74 & 6.42 & 12.42 & 7.98 \\
\hline $04 / 20 / 01$ & 29 & 14196.3 & 1.11 & -1.80 & -7.52 & 2.48 & 10.18 & 49.45 & 31.78 & 4.46 & 6.19 & 4.42 \\
\hline $04 / 27 / 01$ & 36 & 18231.0 & 0.88 & -1.74 & -7.72 & 2.72 & 10.49 & 75.30 & 26.92 & 5.80 & 7.76 & 4.04 \\
\hline $05 / 03 / 01$ & 42 & 25309.9 & 1.63 & -2.32 & -7.85 & 3.66 & 11.45 & 52.13 & 35.09 & 2.07 & 1.28 & 2.75 \\
\hline $05 / 11 / 01$ & 50 & 30398.5 & 2.47 & -2.15 & -9.21 & 4.52 & 13.05 & 78.99 & 48.92 & 3.73 & 6.64 & 9.05 \\
\hline $05 / 18 / 01$ & 57 & 30398.5 & 2.34 & -1.95 & -9.81 & 4.76 & 13.71 & 32.56 & 50.19 & 9.85 & 12.73 & 10.36 \\
\hline $05 / 24 / 01$ & 63 & 30398.5 & 1.14 & -3.74 & -10.54 & 6.92 & 15.98 & 34.01 & 16.90 & 14.11 & 4.81 & 12.22 \\
\hline $06 / 08 / 01$ & 78 & 30398.5 & 3.88 & -3.46 & -10.71 & 9.68 & 18.75 & 84.16 & 48.34 & 0.99 & 5.22 & 11.86 \\
\hline $06 / 22 / 01$ & 92 & 30398.5 & 3.22 & -1.35 & -10.72 & 11.89 & 20.95 & 17.53 & 67.20 & 6.78 & 16.44 & 13.14 \\
\hline $08 / 15 / 01$ & 146 & 30398.5 & 5.46 & -2.48 & -12.50 & 14.39 & 24.03 & 63.39 & 65.61 & 10.75 & 12.00 & 12.98 \\
\hline
\end{tabular}




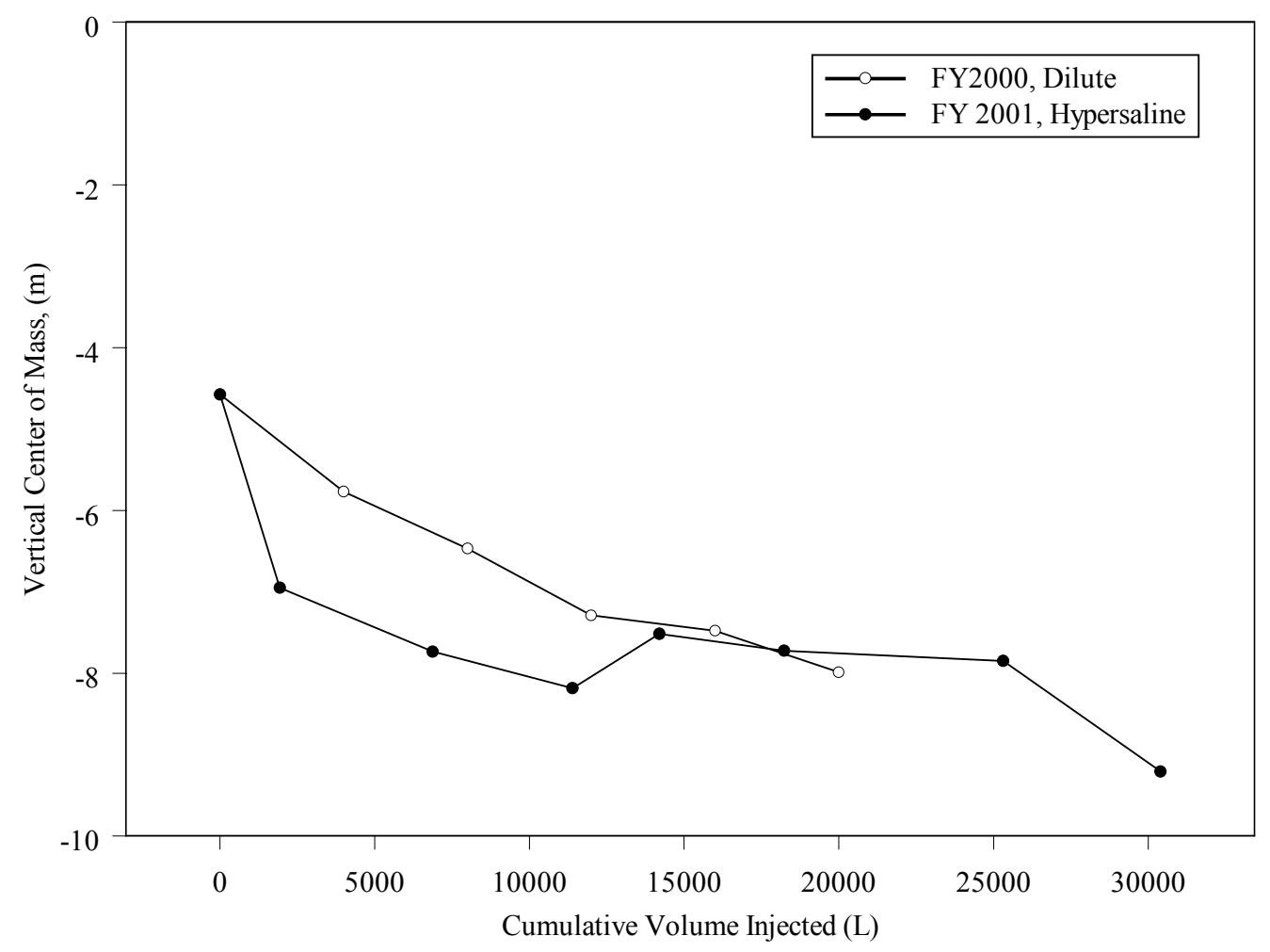

Figure 4.11. Depth of Penetration of the Dilute and Hypersaline Plumes as a Function of Injected Volume

\subsection{Inverse Techniques}

Thus far, simulations have been conducted using hydraulic properties that are similar, but not identical, to those soils found at the VZTFS Site. It is well known that laboratory-determined parameters are usually not directly applicable to the field scale (e.g., Wierenga et al. 1991). Thus, there is a need for techniques capable of estimating hydraulic properties applicable to the field scale. In this work, we introduce the concept of parameter scaling, which when combined with inverse-flow modeling will allow the estimation of field-scale hydraulic parameters for heterogeneous soils. In this new method, the hydraulic parameters of all the soil materials, regardless of their similarity, are scaled to a reference material. The soil variability is described by the scaling factors. Application of parameter scaling will reduce the number of parameters to be estimated with the inverse model. The combination of this technique with an inverse procedure will allow field-scale estimation of the hydraulic parameters of the reference material. The parameter values of each soil material can then be obtained by applying inverse scaling. 


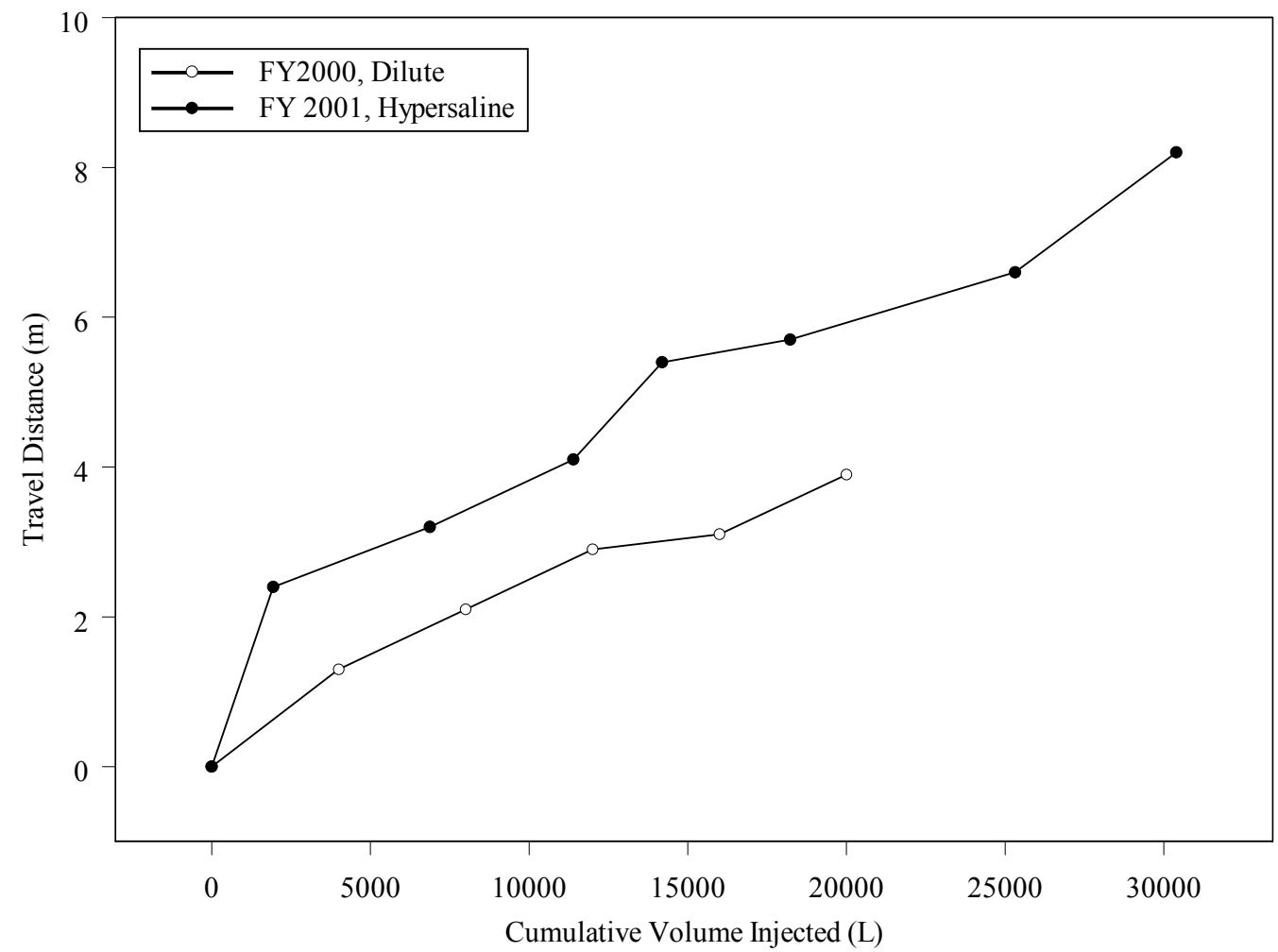

Figure 4.12. Cumulative Distance Traveled by the Centers of Mass of the Dilute and Hypersaline Plumes

Different from the similar media scaling (Miller and Miller 1956), parameter scaling can be done where the media are different. A soil that has $\mathrm{M}$ layers is composed of $\mathrm{N}(\mathrm{N} \leq \mathrm{M})$ different types of materials, each of which is associated with a set of hydraulic parameters. For example, if the van Genuchten (1980) hydraulic functions are used, the hydraulic parameters are $\mathrm{K}_{\mathrm{si}}, \alpha_{\mathrm{i}}, \mathrm{n}_{\mathrm{i}}, \theta_{\mathrm{si}}, \theta_{\mathrm{ri}}$ for $\mathrm{i}=1$ to $\mathrm{N}$, where i denotes a soil material with different hydraulic properties. We artificially select a set of reference values, $\left(\widetilde{K}_{\mathrm{s}}, \widetilde{\alpha}, \widetilde{\mathrm{n}}, \widetilde{\theta}_{\mathrm{s}}, \widetilde{\theta}_{\mathrm{r}}\right)$, which may be the values of one of the $\mathrm{N}$ materials or other values. The linear scaling factors associated with the $\mathrm{N}$ soil materials are defined as

$$
\gamma_{\beta_{i}}=\frac{\beta_{i}}{\widetilde{\beta}}
$$

where $\beta$ is any one of the hydraulic parameters, and $\gamma$ is the scaling factor associated with parameter $\beta$ for soil material $\mathrm{i}=1$ to $\mathrm{N}$. The logarithmic scaling factors may be defined as

$$
\left(\gamma_{\beta_{\mathrm{i}}}\right)_{\mathrm{Ln}}=\frac{\operatorname{Ln}\left(\beta_{\mathrm{i}}\right)}{\operatorname{Ln}(\widetilde{\beta})}
$$


The total number of the scaling factors is the same as the number of soil parameters. Note that the selection of a different reference soil will produce different values of scaling factors. However, the actual parameter values and flow properties will not change. For a 3-layered soil, there would be 15 parameters associated with the three layers. These parameters can be described by 15 scaling factors and one set of reference parameter values. The scaling factors reflect the effects of soil layering, and the reference parameter values reflect the effects of spatial scale.

Parameter scaling has the following characteristics: 1) It does not require the constitutional materials to be similar. As long as the hydraulic properties of the soil materials can be described by a hydraulic function (e.g., Brooks and Corey 1964; van Genuchten 1980), parameter scaling is applicable. 2) Instead of scaling the hydraulic properties [i.e., the $\theta(\psi)$ and $\mathrm{K}(\psi)$ ] relations, the hydraulic parameters (e.g., parameters $K_{\mathrm{s}}, \alpha, n, \theta_{\mathrm{s}}$, and $\theta_{\mathrm{r}}$ for the van Genuchten model) are scaled. As a result, the flow can always be expressed in real time and distance regardless of the soil heterogeneity. This overcomes the difficulty in estimating hydraulic parameters using an inverse procedure by minimizing the differences between the observed and predicted values. 3) After the scaling, the values of the hydraulic parameters of all the soil materials perfectly reduce to the reference values. No scaling error is introduced, and hence the application of an inverse scaling will return the original parameter values. 4) The spatial variability of each hydraulic parameter can be expressed by the scaling factors. Different parameters may have different variability structures.

The inverse modeling program UCODE (Poeter and Hill 1998), developed by the U.S. Geological Survey, was merged with a modified version of the STOMP simulator. The modified version of STOMP allows the input of scaling factors and the reference parameter values to simulate water flow. It also allows the inclusion of a UCODE Control Card and an Observed Data Card in the STOMP input file. By running STOMP, the universal (fn.uni) and the extract (fn.ext) files required by UCODE are constructed. STOMP also produces a new file (fn.sto) that includes the simulated values corresponding to the observations. UCODE was coupled with STOMP to inversely estimate the hydraulic parameters.

The scaling factors determined from local-scale measurements have inherited observation and sampling errors. Consequently, the estimated field-scale parameter values are not accurate. Further optimization of the scaling factors may be needed after the field-scale reference parameters have been inversely estimated. Since the number of scaling factors usually is large for a heterogeneous soil, their simultaneous estimation is difficult to converge. We divide them into $\mathrm{N}_{\mathrm{g}}$ groups, and the scaling factors of the first group are estimated inversely by fixing the values of the rest of the parameters. Then the scaling factors in the second group are estimated. After the scaling factors of the last group are estimated, the estimation goes to the first group again. This process will continue until the convergence criterion is satisfied. This process is called recursive inversion since multiple times of inversion are required.

Three different experimental sites with cases of 1) homogeneous soil, 2) layered soil, and 3) heterogeneous soil were used to test the new technique. Predictive modeling of drainage from a well characterized lysimeter site at Hanford that has both laboratory- and field-measured soil hydraulic properties resulted in an overestimation of soil water content, $\theta$, and an underestimation of pressure heads, $\psi$. However, using field-scale parameter values derived from inverse-flow modeling with the new scaling technique resulted in significantly better model fits for both $\theta$ and $\psi$. The simulation of drainage from a layered soil at a well-instrumented field site near the 300 Area at Hanford also resulted in an overestimation of $\theta$ and $\psi$ when the local-scale parameter values were used. Again, field-scale parameter 
estimates obtained from the inverse scaling method resulted in smaller prediction errors with regression coefficients of 0.956 to 0.997 between the observed and predicted values of $\theta$ and $\psi$, respectively.

Application of the parameter scaling method to the estimated hydraulic parameters from the VZTFS has commenced with a two-dimensional application. The prediction of water-content distributions using laboratory-measured parameter values resulted in very poor model fits $\left(r^{2}=0.28\right)$. However, using inverse scaling improved the goodness of fit with $r^{2}$ increasing to 0.74 (Figure 4.13). Parameters derived from these studies will be compared with those derived from core measurements with the goal of developing adequate upscaling methodology. Such techniques are critical to the development of techniques for long-term, field-scale transport predictions. This type of inverse analysis will be an ongoing effort in FY 2002 and FY 2003.
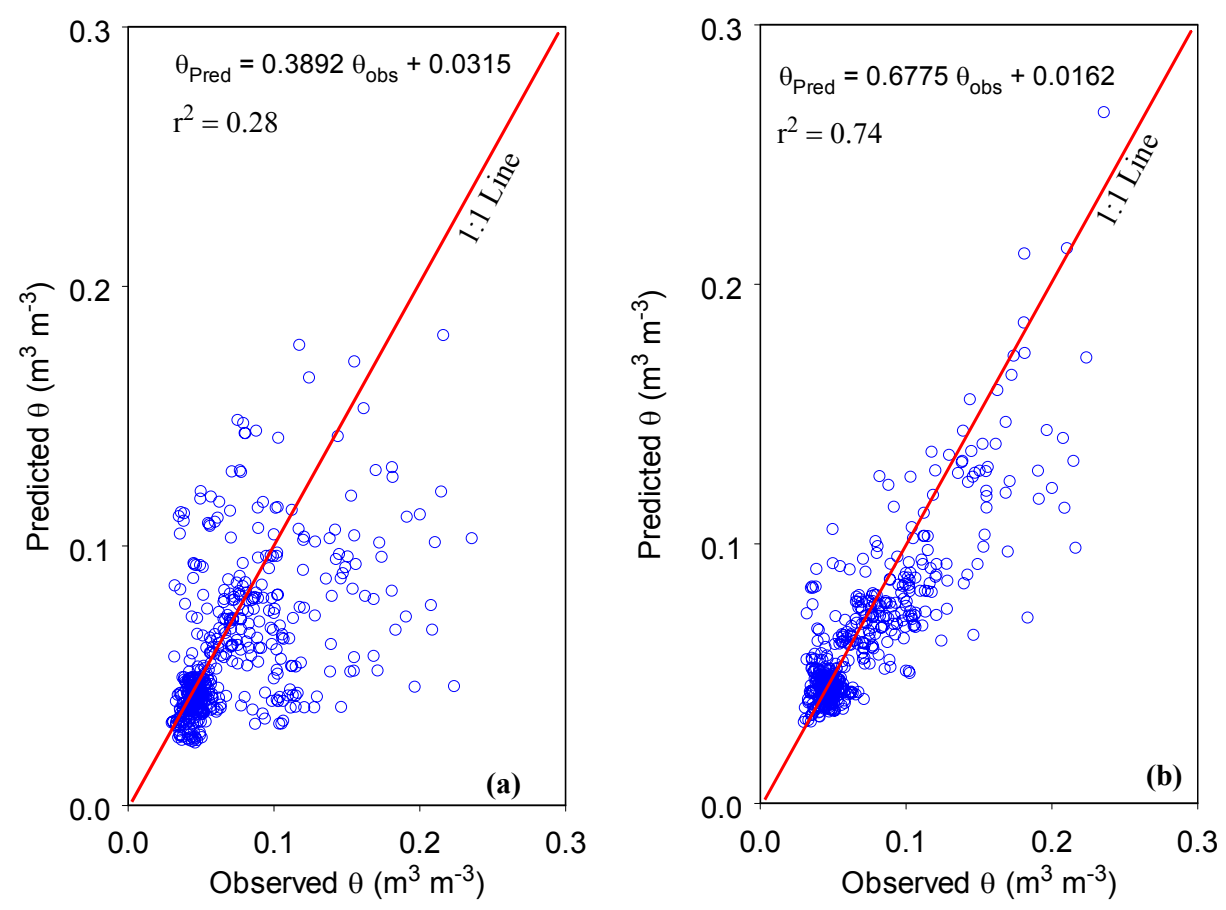

Figure 4.13. Comparison of the Predicted and Observed Soil Water Contents at the H-Section of the Injection Experiment Described in Sisson and Lu (1984). Parameterizations:

(a) lab-scale parameter values, (b) field-scale parameter values after the recursive inversion. Dashed lines: the 1:1 line. Solid lines: linear regression line. 


\subsection{Conclusions}

From the two VZTFS field experiments at the 299-E24-222 (Sisson and Lu) injection site in the 200 East Area of the Hanford Site during FY 2000 and FY 2001, we conclude that the transport of chemicals and isotopic tracers is controlled largely by geologic features and the hydrology of the site. Two distinct horizontal sedimentary layers located at about the 6- and 12-m (19.7- and 39.4-ft) depths appear to control both flow and transport of the vadose zone plume. The slight change in texture from coarse to fine sand appears to have caused significant lateral spreading of the plume.

Laboratory-scale experiments performed to assist with VZTFS design suggest that the properties of hypersaline fluids may influence the transport behavior through an interaction between fluid and hydraulic properties to the extent of finger formation. However, these mechanisms were not directly observed during the FY 2001 field experiment. Water-content distributions were measured in 32 wells $(18 \mathrm{~m}[59 \mathrm{ft}] \mathrm{deep})$ arranged in a concentric pattern over a 16-m $(52.5 \mathrm{ft})$ diameter. Water extracts from soil cores were analyzed for anions including $\mathrm{Cl}^{-}, \mathrm{Br}^{-}, \mathrm{S}_{2} \mathrm{O}_{3}^{-}, \mathrm{NO}_{3}^{-}$, and $\mathrm{SO}_{4}^{2-}$. Differences between wetting-front location and resident concentrations were apparent with the difference being dependent on fluid constitution. Resident concentration profiles were generally asymmetric with a large solute mass occurring at 5 to $7 \mathrm{~m}$ (16.4 to $23 \mathrm{ft})$ and a smaller mass at 9 to $10 \mathrm{~m}(29.5$ to $32.8 \mathrm{ft})$. Multiple peaks were also observed and were coincident with finer-textured lenses embedded in the sand matrix, emphasizing the need to consider local-scale textural discontinuities in conceptual models of field-scale transport at the Hanford Site. Preferential flow of the hyper-saline fluid was evident, as it did penetrate to the greatest monitoring depth ( $18 \mathrm{~m})$ in the FY 2001 test, while results show no evidence of fingering due to fluid properties.

Evaluation of advanced characterization methods for the vadose zone suggests that ERT, HRR, and XBR all have significant promise as diagnostic tools for defining the depth and extent of vadose-zone plumes at Hanford, particularly where monitoring wells can be adapted for use by these instruments. XBR and EMI require PVC casings for monitoring wells, but HRR and ERT can be adapted for use with steel-cased wells, the typical infrastructure that currently exists at the Hanford tank farms. HRR appears to be particularly useful in being able to diagnose the lateral extent of the plume.

The two VZTFS field experiments have confirmed that contaminant transport in the vadose zone at Hanford is a multi-dimensional process. The results of the VZTFS also demonstrate that the importance of the heterogeneous nature of the subsurface sediments is important in determining the shape and extent of vadose-zone plumes. Conceptual models of the vadose zone, which do not include the two- or threedimensional aspects of transport, may not be adequate. An example of the importance of lateral spreading is the impact from lateral movement of meteoric water or water-line leaks that may impact existing tank leaks or other vadose-zone plumes. A complete conceptual model of contaminant transport in the Hanford vadose zone awaits further analysis. The work conducted by the VZTFS reported here will help develop an improved conceptual model of contaminant transport for the Hanford Site, provide a methodology for determining field-scale parameters, establish the relationship between laboratory measurements and field-scale parameters and a methodology for upscaling, and ultimately, provide a basis for predicating transport at uncharacaterized sites. 


\subsection{References}

Brooks, R. H, and A. T. Corey. 1964. "Hydraulic Properties of Porous Media." 1964. Hydrology Paper 3. Colorado State University, Ft. Collins, Colorado.

Cassel, D. K., and A. Klute. 1986. "Water potential: tensiometry,” pp. 540-596. In: A. Klute (ed.) Methods of Soil Analysis, Part 1. Physical and Mineralogical Methods, Agronomy Monograph 9, American Society of Agronomy, Madison, Wisconsin.

Daily, W., A. Ramirez, D. J. LaBrecque, and J. Nitao. 1992. "Electrical resistivity tomography of vadose water movement." Water Resour. Res. 28: 1429-1442.

Engelman, R. E, R. E. Lewis, and D. C. Stromswold. 1995a. Calibration models for density borehole logging-construction report. PNL-10800, Pacific Northwest Laboratory, Richland, Washington.

Engelman, R. E., R. E. Lewis, D. C. Stromswold, and J. R. Hurst. 1995b. Calibration models for measuring moisture in unsaturated formations by neutron logging. PNL-10801, Pacific Northwest Laboratory, Richland, Washington.

Fayer, M. J., J. B. Sisson, W. A. Jordan, A. H. Lu, and P. R. Heller. 1993. Subsurface injection of radioactive tracers: Field experiment for model validation testing, NUREG/CR-5996, U. S. Nuclear Regulatory Commission, Washington, D. C.

Fayer, M. J., R. E. Lewis, R. E. Engleman, A. L. Pearson, C. J. Murray, J. L. Smoot, R. R. Randall, W. H. Wegener, and A. H. Lu. 1995. Re-evaluation of a subsurface injection experiment for testing of flow and transport models, PNL-10860, Pacific Northwest Laboratory, Richland, Washington.

Fayer, M. J., E. M. Murphy, J. L. Downs, F. O. Khan, C. W. Lindenmeier, B. N. Bjornstad. 1999. Recharge data package for the immobilized low-activity waste 2001 performance assessment. PNNL-13033, Pacific Northwest National Laboratory, Richland, Washington.

Fink, J. B. 1980. "Logarithmic Pseudosections for IP and Resistivity." In: 50th Int. Mtg and Exp. Soc. Explor. Geophysics. Houston, Texas.

Fink, J. B. 1990. Induced Polarization, Applications and Case Histories. Investigations in Geophysics Series, Vol 4, Society of Exploration Geophysics (SEG). Tulsa, Oklahoma.

Gee, G. W., A. L. Ward, J. C. Ritter, J. B. Sisson, J. M. Hubbell, and H. Sydnor. 2001. Installation of a Hydrologic Characterization Network for Vadose Zone Monitoring of a Single-Shell Tank Farm at the U. S. Department of Energy Hanford Site, PNNL-13712, Pacific Northwest National Laboratory, Richland, Washington.

Harvey, C. F., and S. M. Gorelick. 1995. "Mapping hydraulic conductivity: Sequential conditioning with measurements of solute arrival time, hydraulic head, and local conductivity." Water Resour Res. 31:

1615-1626. 
Hill, D. E., and J. Y. Parlange. 1972. "Wetting front instability in layered soils." Soil Sci. Soc. Am. Proc. 36: 697-702.

Hubbard, S., Y. Rubin, and E. Majer. 1997. "Ground penetrating radar-assisted saturation and permeability estimation.” Water Resour. Res. 33: 971-990.

Hubble, J. M., and J. B. Sisson. 1996. "Portable tensiometer use in deep boreholes.” Soil Sci. 161:376381.

Hubble, J. M., and J. B. Sisson. 1998. "Advanced tensiometer for shallow or deep soil water potential measurements.” Soil Sci. 140: 271-277.

Khaleel, R., and E. J. Freeman. 1995. Variabilty and scaling of hydraulic properties for 200 Area soils, Hanford Site. WHC-EP-0883, Westinghouse Hanford Company, Richland, Washington.

Khaleel, R., and J. F. Relyea. 1995. "Evaluation of van Genuchten-Mualem relationships to estimate unsaturated hydraulic conductivity at low water contents." Water Resour. Res. 31: 2659-2668.

Krupp, H. K, and D. E. Elrick. 1968. "Density effects in miscible displacement experiments." Soil Sci. 107:372-380.

LaBrecque, D. J., M. Milleto, W. Daily, A. Ramirez, and E. Owen. 1996. "The effects of noise on Occam.s inversion of resistivity tomography data." Geophysics 61: 538-548.

Last, G. V., and T. G. Caldwell. 2001. Core sampling in support of the vadose zone transport field study, PNNL-13454, Pacific Northwest National Laboratory, Richland, Washington.

Last, G. V., T. G. Caldwell, and A. T. Owen. 2001. Sampling of Boreholes WL-3A through -12 in Support of the Vadose Zone Transport Field Study, PNNL-13631, Pacific Northwest National Laboratory, Richland, Washington.

Lu, A., and R. Khaleel. 1993. "Calibration/validation of VAM3D model using injection test data at Hanford” pp 99-111. In: R. Khaleel (ed.) Vadose Zone Modeling Workshop Proceedings, March 29-30, 1993. WC-MR-0420. Westinghouse Hanford Company, Richland, Washington.

Majer, E. L., J. E. Peterson, T. Daley, K. Bruno, L Myer, J. Queen, P. Donfro, and W. Rizer. 1997. Fracture detection using crosswell and single well surveys. Geophysics, Vol 62(2): 495-504, 11997

Mantoglou, A., and L.W. Gelhar. 1987. "Stochastic Modeling of Large-Scale Unsaturated Flow Systems." Water Resour. Res., 23 (1) 37-46.

McCoy, E. L., C. W. Boast, R. C. Stehouwer, and E. J. Kaldivko. 1994. "Macropore hydraulics: Taking a sledgehammer to classical theory." Advances in Soil Science. Soil Processes and Water Quality (R. Lal and B. A. Stewart, eds.), pp. 303-348. Lewis Publishers, Boca Raton, Florida.

McKinley, J. P., C. J. Zeissler, J. M. Zachara, R. J. Serne, R. M. Lindstrom, H. T. Schaef, and R. D. Orr. 2001. "Distribution and retention of ${ }^{137} \mathrm{Cs}$ in sediments at the Hanford site, Washington." Environ. Sci. Technol., 35, 3433-3441. 
Miller, E. E, and R. D. Miller. 1956. "Physical theory for capillary phenomena," J. Appl. Phys. 27: 324332.

McCord, J. T., D. B. Stevens, and J. L. Wilson. 1991. "Hysteresis and state-dependent anisotropy in modeling unsaturated hillslope hydrologic processes." Water Resour. Res. 27: 1501-1518.

Newmark, R. L., S. Boyd, W. Daily, R. Goldman, R. Hunter, D. Kayes, K. Kenneally, and A. Ramirez. 1994. In: Proceedings of the Symposium on the Application of Geophysics to Engineering and Environmental Problems (SAGEEP) 94. Boston, Massachusetts, March 27-31, pp. 195-211.

Poeter, E. P., and M. C. Hill. 1998. Documentation of UCODE, a computer code for universal inverse modeling. U.S. Geological survey, water-resources investigations report 98-4080.

Polmann, D. J., D. McLaughlin, S. Luis, L. W. Gelhar and R. Ababou. 1991. "Stochastic Modeling of Large-Scale Flow in Heterogeneous Unsaturated Soils," Water Resour. Res., 27 (7): 1447-1458

Pruess, K. 1996. "A Fickian Diffusion Model for the Spreading of Liquid Plumes Infiltrating in Heterogeneous Media." Transport in Porous Media, 24 (1) 1-33.

Ramirez, A., W. Daily, D. J. LaBrecque, E. Owen, and D. Chestnut. 1993. "Monitoring an underground steam injection process using electrical resistance tomography." Water Resour.Res. 29: 73-87.

Ramirez, A., W. Daily, and R. Newmark. 1995. "Electrical resistance tomography for steam injection and process control.” JEEG 0(1): 39-51.

Ramirez, A., W. Daily, A. Binley, D. LaBrecque and D. Roelant. 1996. "Detection of leaks in underground storage tanks using electrical resistance methods." J. Environ. and Engr. Geophysics. 1(3): 189-203.

Rockhold, M. L., C. J. Murray, and M. J. Fayer. 1999. "Conditional simulation and upscaling of soil properties." In: Proceedings of the International Workshop on Characterization and Measurement of the Hydraulic Properties of Unsaturated Porous Media, pp. 1391-1401. M. Th. Van Genuchten, F. J. Leij and $\mathrm{L}$. Wu (eds.). University of California, Riverside.

Sisson, J. B., and A. H. Lu. 1984. Field Calibration of Computer Models for Application to Buried Liquid Discharges: A Status Report, RHO-ST-46P, Rockwell Hanford Operations, Richland, Washington.

Smoot, J. L., and A. H. Lu. 1994. "Interpretation and modeling of a subsurface injection test, 200 east area, Hanford Washington." In: G. W. Gee and N. R. Wing (eds.) Thirty-third Hanford Symposium on Health and the Environment. In-situ Remediation: Scientific Basis for Current and Future Technologies, Nov-7-11, 1994, Richland, Washington, Battelle Press.

Smoot, J. L. and R. E. Williams. 1996. A geostatistical methodology to assess the accuracy of unsaturated flow models. NUREG/CR-6411, U. S. Nuclear Regulatory Commission, Washington, D. C.

Stephens, D. B., and S. E. Heermann. 1988. "Dependency of anisotropy on saturation in a stratified sand." Water Resour. Res. 24: 770-778. 
Tschapek, M., C. O. Scoppa, and C. Wasowski. 1978. "The surface tension of soil water.” J. Soil Sci. 29, 17-21.

Tyler, S. W. 1988. "Neutron moisture meter calibration in large diameter boreholes." Soil Sci. Soc. Am. J. 53: 890-893.

U.S. Department of Energy (DOE). 1999. 200-BP-1 prototype barrier treatability test report. DOE/RL99-11, Richland, Washington.

van Genuchten, M.Th. 1980. "A closed form equation for predicting the hydraulic conductivity of unsaturated soils.” Soil Sci. Soc. Am. J. 44: 892-898.

Ward, A. L., and G. W. Gee. 1997. "Performance evaluation of a field-scale surface barrier." $J$. Environ. Qual. 26:694-705.

Ward, A. L., G. W. Gee, and M. D. White. 1997. A Comprehensive Analysis of Contaminant Transport in the Vadose Zone Beneath Tank SX-109. PNNL-11440, Pacific Northwest National Laboratory, Richland, Washington.

Ward, A. L., and G. W. Gee. 2000. Vadose Zone Transport Field Study: Detailed Test Plan for Simulated Leak Tests, PNNL-13263, Pacific Northwest National Laboratory, Richland, Washington.

Ward, A. L. and G. W. Gee. 2001. Vadose Zone Transport Field Study: FY2001 Test Plan, PNNL-13451, Rev. 1, Pacific Northwest National Laboratory, Richland, Washington.

Washburn, E.W. 1921. "The dynamics of capillary flow.” Phys. Rev. 2nd Ser. 12(3), 273.

Weast, R. C. 1986. CRC Handbook of Chemistry and Physics. 67th Edition. CRC Press, Boca Raton, Florida.

Wierenga, P. J., R. G. Hills, and D. B. Hudson. 1991. "The Las Cruces trench site: Characterization, experimental results, and one-dimensional flow predictions," Water Resour. Res. 27:2695-2705.

Yeh, T.-C.J., L. W. Gelhar, and A. L. Gutjahr. 1985a "Stochastic Analysis of Unsaturated Flow in Heterogeneous Soils, 2, Statistically Anisotropic Media with Variable $\alpha$. . Water Resour. Res. 21 (4) 457-464.

Yeh, T.-C. J., L. W. Gelhar, and A. L. Gutjahr. 1985b. "Stochastic analysis of unsaturated flow in heterogeneous soils 1. Statistically isotropic media." Water Resour. Res. 21: 447-456. 
PNNL-13679

\section{Distribution}

No. of

\section{Copies}

OFFSITE

1 Carl I. Steefel

Lawrence Livermore National Laboratory L-204

P.O. Box 808

Livermore, California 94551

2 Lawrence Livermore National Laboratory L-130

Livermore, California 94550

Attn: William D. Daily Abe Ramirez

4 Lawrence Berkeley National Laboratory 1 Cyclotron Road

MS 90-1116

Berkeley, California 94720-4767

Attn: Donald J. DePaolo

Michael Hoversten

Ernest L. Majer

Karsten Preuss

1 Mark Conrad

Lawrence Berkeley National Laboratory

1 Cyclotron Road

MS 70A-4418

Berkeley, California 94720

1 Peter C. Lichtner

Los Alamos National Laboratory

Environmental Sciences Division (EES-5)

MS F-649

Los Alamos, New Mexico 87545
No. of

Copies

OFFSITE

2 Los Alamos National Laboratory Environmental Science Group MS J-497

Los Alamos, New Mexico 87545

Attn: Everett P. Springer

Brent Neuman

3 Idaho National Engineering and Environmental Laboratory

P.O. Box 1625

2251 N. Boulevard

Idaho Falls, Idaho 83415-2107

Attn: Earl D. Mattson

J. B. Sisson

J. M. Hubbell

1 Gregory A. Newman

Sandia National Laboratories

P.O. Box 5800

MS-0750

Albuquerque, New Mexico 87185-0750

1 James B. Fink

HydroGEOPHYSICS, Inc.

5865 South Old Spanish Trail

Tucson, Arizona 85747

1 P.J. Wierenga

Soil, Water, and Environmental Science

University of Arizona

Tucson, Arizona 85721

1 T. C. Jim Yeh

University of Arizona

Department of Hydrology and Water Resources

The University of Arizona, Bldg. 11

Tucson, Arizona 85721

Distr. 1 
No. of

Copies

\section{OFFSITE}

1 Rosemary J. Knight

University of British Columbia

2219 Main Mall

Vancouver, BC

Canada V6T 1 Z4

1 Wesley L. Bratton

Vista Engr. Tech. L.L.C.

8203 W. Quinalt

Bldg. C., Suite 200

Kennewick, Washington 99336

1 Wade Riggsbee

Yakima Nation

1933 Jadwin

Richland, Washington 99352

1 Ivana Witt

Yakima Nation

1933 Jadwin

Richland, Washington 99352

1 Gordon J. Rogers

1108 N. Rd. 36

Pasco, Washington 99301

\section{ONSITE}

2 DOE Office of River Protection

C. A. Babel

R. M. Yasek

H6-60

H6-60

6 DOE Richland Operations Office

B. L. Foley

$\mathrm{P} 7-62$

J. P. Hanson

R. D. Hildebrand

R. W. Lober

J. G. Moore

K. M. Thompson
No. of

Copies

\section{ONSITE}

9 BHI

R. L. Biggerstaff $\quad \mathrm{H} 0-02$

L. R. Curry H0-19

A. G. Dada H0-02

R. J. Fabre X5-50

K. R. Fecht H0-02

B. H. Ford H0-21

G. B. Mitchem H0-19

M. J. Graham H0-09

R. L. Jackson H0-19

4 CHG

J. W. Cammann R2-39
A. J. Knepp
$\mathrm{H} 0-22$
F. M. Mann
H0-22
D. A. Myers
$\mathrm{H} 0-22$

3 CHI

V. J. Rohay H0-19

C. D. Wittreich H9-03

1 FFS

R. Khaleel B4-43

2 MACTER-ERS

J. F. Bertxch B2-62

R. G. McCain B2-62

3 Duratek

M. G. Gardner H1-11

J. E. Meisner H1-11

R. K. Price H1-11

5 Washington Department of Ecology

F. W. Bond

B5-18

J. Caggiano B5-18

D. Goswami B5-18

S. Leja B5-18

N. H. Uziemblo B5-18 
No. of

Copies

\section{ONSITE}

2 U.S. Environmental Protection Agency

D. A. Faulk

B5-01

D. R. Sherwood

B5-01

60 Pacific Northwest National Laboratory

B. Barnett

K6-81

W. F. Bonner

K9-14

M. J. Fayer

K3-33

M. D. Freshley (2)

$\mathrm{H} 0-21$

G. W. Gee (20)

K9-33

T. J. Gilmore

K6-81

D. G. Horton

K6-81

G. V. Last

K6-81

P. E. Long

K9-33

W. J. Martin

K6-81

G. W. McNair (2)

H0-21

P. D. Meyer

BPO

C. J. Murray

K6-81

S. M. Narbutovskih

K6-96

S. P. Reidel

K6-81

J. C. Ritter

K9-33

M. L. Rockhold

K9-33

R. J. Serne

K6-81

M. D. Sweeney

K6-81

M. J. Truex

K6-96

A. L. Ward (10)

K9-33

K. Waters-Hustad

K9-36

M. D. White

K9-36

B. A. Williams

K6-81

M. D. Williams

K9-36

S. B. Yabusaki

K9-36

J. M. Zachara

K8-96

F. Zhang

K9-33

Information Release Office (2)

Distr. 3 